\title{
FEATURE
}

\section{Biopharmaceutical benchmarks 2018}

\author{
Gary Walsh
}

Monoclonal antibodies (mAbs) continue to reign supreme, although cellular and gene therapies are slowly starting to gather momentum. Burgeoning growth in biosimilars may threaten future brand monopolies for mAbs and other biologics.

Antibodies continue to dominate biopharAmaceutical approvals, but new nucleic acid modalities and cellular therapies are also slowly launching on the market. This article provides an update on three previous surveys of biopharmaceutical approvals ${ }^{1-3}$. The current survey period (January 2014 to July 2018) witnessed the approval of 155 biopharmaceutical products (see Table 1 for definition) in the United States and/or European Union, when counted by product trade name. Some products contain identical active ingredients or are sold under different trade names in the two regions. Taking this into account, 129 distinct biopharmaceutical active ingredients entered the market.

With these new approvals, the number of individual biopharmaceutical products having gained a license in these regions now totals 374, containing 285 distinct active biopharmaceutical ingredients. However, over the years, 58 products have been withdrawn from the market following approval in one or both regions, almost always for commercial reasons. When withdrawals are taken into account, the number of individual biopharmaceutical products with current active licenses stands at 316 (Table 1).

Annual approval numbers over the current survey period ranged from a low of 14 in Europe in 2014 to a high of 36, also in Europe, in 2017 (Fig. 1a). Products approved over the four and a half years include $68 \mathrm{mAbs}, 23$ hormones, 16 clotting factors, 9 enzymes, 7 vaccines, 5 nucleic acid-based products and 4 engineered cell-based products. As this study period was coming to a close, the first RNA interference (RNAi) drug was approved in the United States.

Gary Walsh is in the Industrial Biochemistry Program, Department of Chemical Sciences and Bernal Institute, University of Limerick, Ireland. e-mail:gary.walsh@ul.ie
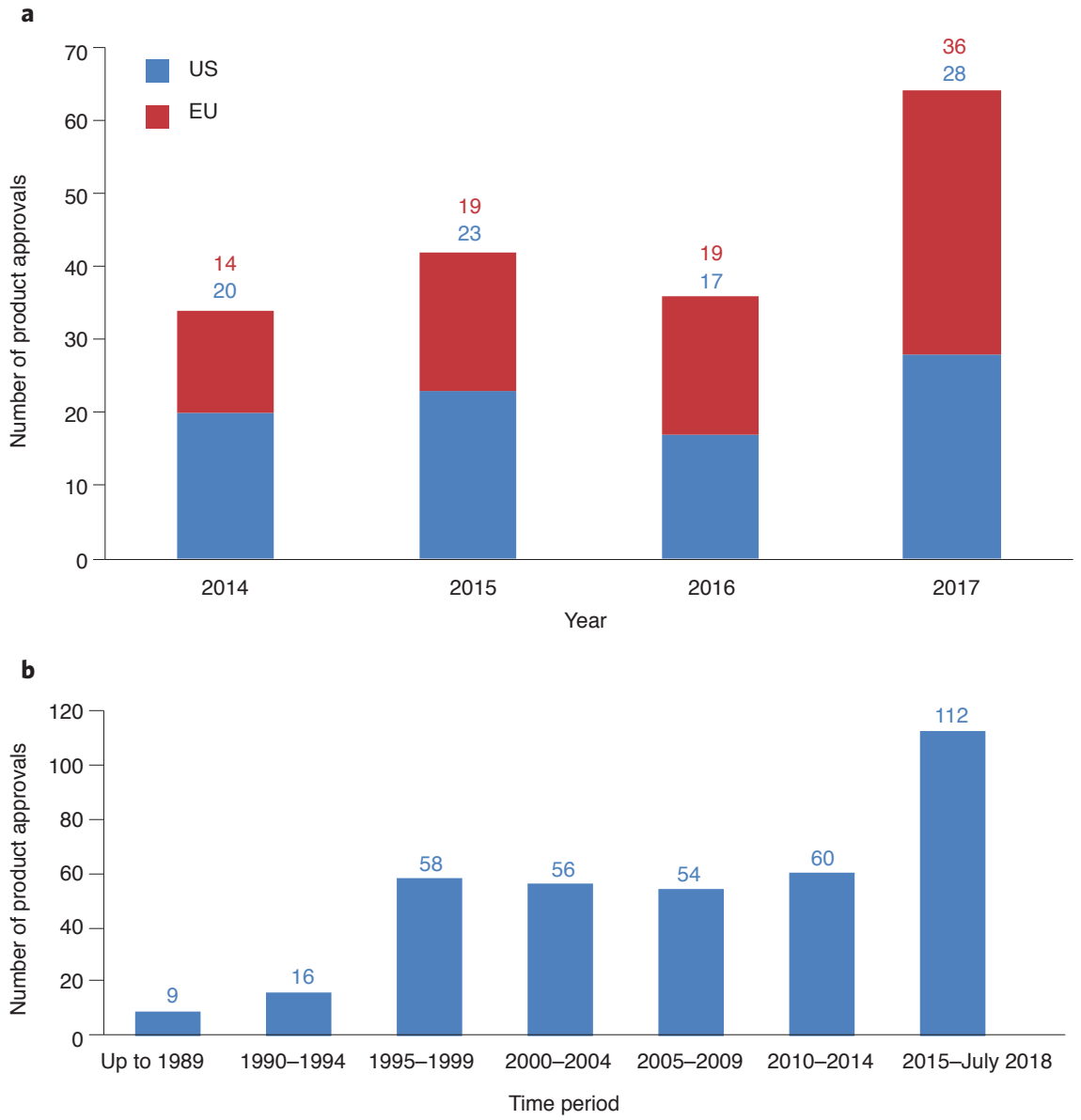

Figure 1 Product approvals profile. (a) Annual product approval numbers (by product trade name) by individual region. (b) Number of product approvals in one or both regions over the indicated periods.

Here I list all recombinant biologics approved during the past four and a half years (from January 2014 to July 2018), examining the types of biopharmaceutical drugs that have reached the US and EU markets as well as the indications for which they are registered. As in previous articles ${ }^{1-3}$, I have not included tissue-engineering products, which the US Food and Drug Administration (FDA) classifies as pure medical devices.

\section{In a snapshot}

Overall, new approvals followed relatively predictable lines, with cancer representing the single most common indication (33 products). Other common indications included various 
inflammation-related conditions (24 products), hemophilia (16 products) and diabetes (15 products). Approvals for other indications, less commonly targeted by biopharmaceuticals, included asthma, migraine, HIV and inhalational anthrax.

Of the 155 individual biopharmaceutical products approved, 81 (52\%) were genuinely new to the market, with the remaining products representing biosimilars, me-too products, and products previously approved elsewhere. Those 81 new products (by trade name) contained a total of 71 distinct active biopharmaceutical ingredients (Table 2). Looking at each region independently, 97 products were licensed in the United States in the survey timeframe while 109 products gained marketing authorization in the European Union.

In the same period, US regulators approved a grand total of 207 products containing novel molecular (chemical or biological) entities, indicating that $47 \%$ of all genuinely new drug approvals in the US were biopharmaceuticals. This represents a substantial increase over values reported in our previous surveys in 2010 and $2014(21 \% \text { and } 26 \% \text {, respectively })^{1,2}$, but tallies well with data presented in our 2006 survey $^{3}$, which estimated that some $44 \%$ of all drugs in the then developmental pipeline were biotech-based. Ambiguity in EU data reporting structures precludes calculation of an analogous figure for Europe.

\section{Overall trends}

Comparing approvals over the current survey period with those in earlier periods, or with cumulative approvals, reveals interesting, if not somewhat predictable, trends. Approval numbers in each five-year period from 1995 until 2014 have remained remarkably constant (54-60 approvals; Fig. 1b). However, approvals have accelerated markedly since that time. The past three and a half years alone (January 2015 to July 2018) have seen 112 (Fig. 1b) product approvals-essentially double the typical five-yearly historical approval pace. Although a wave of biosimilar approvals contributed to this trend, the number of genuinely novel approved products hasn't lagged far behind: such drugs represented $52 \%$ of approvals in the past four and a half years compared with $59 \%$ in the period 2010 to 2014 (ref. 1).

\section{The era of the antibody is upon us}

The data also show an increasing dominance of mAbs within the universe of biopharmaceutical approvals. Although they represented just over a quarter $(27 \%)$ of all first-time approvals from 2010 to 2014 , they comprise over half (53\%) of first time approvals from 2015 to July 2018 (Fig. 2a).

Table 2 Biopharmaceuticals approved in the US and/or EU January 2014-July 2018 by category

Category Products (by trade name)

Genuinely new biopharmaceuticals

Adynovi/Adynovate, Vonvendi, Obizur, Elocta/Eloctate, Andexxa, Rebinyn/ Refixia, Alprolix, Idelvion, Suliqua/Soliqua, Xultophy, Myalepta/Myalept, Ozempic, Eperzan/Tanzeum, Trulicity, Oxervate, Plegridy, Shingrix, Trumenba, pandemic influenza vaccine H5N1, Mosquirix, Aimovig, Crysvita, Fasenra, Hemlibra, Ilumya, Trogarzo, Bavencio, Besponsa, dinutuximab beta Apeiron/ Qarziba, Dupixent, Imfinzi, Kevzara, Kyntheum/Siliq, Rituxan Hycela, Tecentriq, Tremfya, Zinplava, Anthim, Cinqair/Cinqaero, Darzalex, Empliciti, Lartruvo, Taltz, Blincyto, Cosentyx, Keytruda, Nivolumab BMSa/Opdivo, Nucala, Praluent,

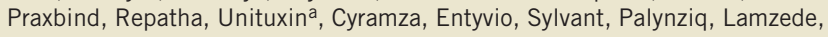
Brineura, Mepsevii, Kanuma, Strensiq, Vimizim, Tegsedi, Luxturna, Spinraza, Exondys 51, Imlygic, Alofisel, Kymriah, Yescarta, Strimvelis, Zalmoxis

Biosimilars Semglee, insulin lispro Sanofi, Lusduna, Abasaglar/Basaglar, Bemfola, Movymia/ Terrosa, Retacrit ${ }^{\mathrm{b}}$, Fulphila, Nivestym/Nivestim ${ }^{\mathrm{b}}$, Zarxio ${ }^{\mathrm{b}}$, Accofil, Halimatoz/ Hefiya/Hyrimoz, Herzuma, Kanjinti, Mvasi, Trazimera, Zessly, Amgevita/ Amjevita/Solymbic, Blitzima/Truxima/Ritemvia/Rituzena, Cyltezo, Imraldi, Ixifi, Ogivri, Ontruzant, Renflexis/Flixabi, Rixathon/Riximyo, Inflectra/Remsimab, Erelzi, Benepali

Reformulated, me-too, Afstyla, Vihuma/Nuwiq, Iblias/Kovaltry, Ixinity, Admelog, Fiasp, Toujeo, Afrezza, different indication, Rekovelle, Natpara, Natpar, Saxenda, Ristempaa, Heplisav-b, Gardasil 9, and related Ocrevus, Portrazza, Zinbryta ${ }^{a}$, Oncaspar, Lifmior, Spectrila

Previously approved Rixubis, Ruconest, Ryzodeg 70-30/Ryzodeg, Tresiba, Bexsero, Mylotarg, Gazyva/ elsewhere Gazyvaro

aProducts were both approved and subsequently withdrawn from one or both regions within the survey timeframe.

biosimilars approved in one region since 2014, but which were approved in the other region before 2014.

The relative importance of $\mathrm{mAbs}$ in terms of the percentage of overall biopharmaceutical product sales also continues to grow steadily (Fig. 2b), although not so dramatically as product approval numbers might imply. However, antibody sales, both in terms of absolute value and as a percentage of overall biopharmaceutical sales, will likely continue to increase, particularly as revenues derived from the recent glut of $\mathrm{mAb}$ approvals grow toward maximum market value.

Notably, approvals of gene- and other nucleic acid-based products (antisense oligonucleotides (ASOs) and gene therapies, including gene-engineered cells) increased as well during this period. The number of nucleic acid and cell-based products approved in the period totaled nine, five nucleic acid and four engineered cells (Table $\mathbf{1}$ ).

The period of this study also witnessed a pickup in approvals of some traditional product classes as compared with previous study periods, notably clotting factors (Box 1) and some hormones, although approvals of most traditional product classes continued to drop off. For example, no recombinant thrombolytic agent, anticoagulant, interleukin or human growth hormone has been approved since 2014, and only one interferon and one erythropoietin were approved. This continued trend likely reflects market saturation relative to demand for these products.

Another continuing trend is the increased prominence of mammalian over nonmammalian expression systems used for producing approved products (Fig. 3). In fact, the trend toward mammalian cell lines has accelerated dramatically in the past three to four years. Sixty-two of the 71 genuinely new biopharmaceutical active ingredients that have come on the market in the survey period (Table 2) are recombinant proteins. Of those, 52 (84\%) are expressed in mammalian cell lines, one (Kanuma, sebelipase alfa) is expressed in a mammalian transgenic system, and the remaining nine are produced using Escherichia coli (five products) or yeast (four products), all in S. cerevisiae. The surge in mammalian-based production is unsurprising, given the many recent $\mathrm{mAb}$ and clotting factor product approvals, with both product classes bearing post-translational modifications and thus requiring mammalian expression systems.

Chinese hamster ovary $(\mathrm{CHO})$ cell-based systems remain by far the most common mammalian cell line in use; $84 \%$ (57 of the 68 $\mathrm{mAb}$ products approved in the current survey period) are produced in $\mathrm{CHO}$ systems, with the remaining antibodies approved produced in either NS0 cells (nine products) or Sp2/0 cells (two products). Overall, recent approvals (Tables $\mathbf{1}$ and 2) also confirm that there is little industrial enthusiasm for exploring new expression systems.

The current survey period has also been characterized by a continual rise in the market value of biopharmaceuticals. Data from various La Merie financial reports indicate that cumulative sales over 2014-2017 reached \$651 billion, whereas total sales for 2017 alone reached $\$ 188$ billion (http://www.lamerie.com) ${ }^{4}$. 
a
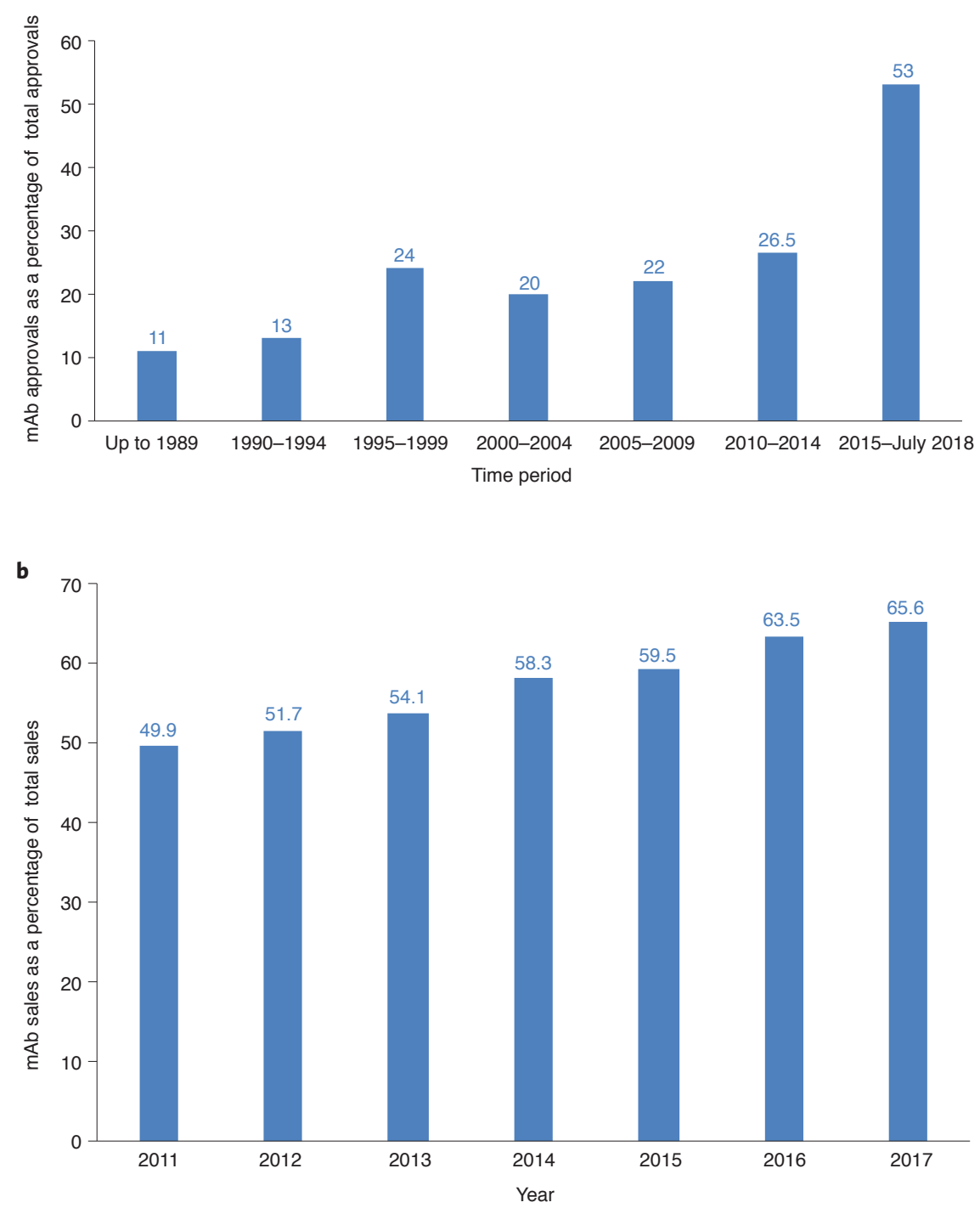

Figure 2 Overview of mAb approvals. (a) mAbs approved for the first time in the indicated periods, expressed as a percentage of total biopharmaceuticals approved for the first time in the same time period. (b) mAbs global annual sales value expressed as a percentage of total biopharmaceutical global sales for the indicated years. Financial data from La Merie Business Intelligence.

The mAb Humira (adalimumab) has been by far the single most lucrative product each year during the survey period, having generated global sales just short of $\$ 19$ billion in 2017 and $\$ 62.6$ billion cumulatively between 2014 and 2017 (Table 3). The top ten selling biopharmaceuticals together generated sales of $\$ 80.2$ billion in 2017 , representing almost $44 \%$ of total biopharmaceutical product revenues. Forty-five individual biopharmaceutical products recorded 'blockbuster' status sales (>\$1 billion) last year.

mAbs continue to represent the most lucrative single product class. Total mAb sales (including Fc fusion protein-based antibodylike traps) reached $\$ 123$ billion last year ( $\$ 103.4$ billion if fusion products are excluded).
Moreover, mAbs represented eight of the top ten products by sales in 2017 (six of the top ten if the fusion traps are excluded). In terms of target indications, the vast majority of antibody or antibody-like trap fusion products target inflammatory, autoimmune conditions (cumulative 2017 sales of $\$ 64.6$ billion, with products targeting tumor necrosis factor (TNF)- $\alpha$ alone generating \$39.8 billion) and cancer (2017 cumulative sales of $\$ 43.1$ billion). In terms of non-antibody-based products, insulins are the next most lucrative product class, collectively generating sales of $\$ 22$ billion in 2017.

\section{Biosimilars blossom}

The survey period witnessed a surge in biosimilar approvals, signaling that this class of product is maturing. When considered by product trade name, 52 biosimilars have gained approval in the European Union and/ or the United States since 2006 (Table 4), although 3 were subsequently withdrawn for commercial reasons.

By product category, the majority of biosimilar product approvals were antibody based ( 27 of 52), with 10 approvals of granulocyte colony stimulating factor (G-CSF) biosimilars and single-digit approvals of all others. The 52 licensed biosimilar products are actually based on 34 distinct active ingredients (Table 4). For example, the four rituximab-based biosimilars approved in Europe in 2017 (under the trade names Blitzima, Truxima, Ritemvia and Rituzena) all contain the same active substance: Celltrion's biosimilar rituximab, developed as CT-P10.

By region, 48 biosimilar products have received marketing authorization in the European Union, with 31 of these (65\%) having gained authorization in the current survey period. In the United States, far fewer (13) biosimilars gained a license, the first being Zarzio (filgrastim-sndz) in March 2015, with the first biosimilar mAb (Inflectra; infliximab-dyyb) gaining approval in April 2016. This geographical discrepancy is unsurprising, given that the EU biosimilar regulatory framework (including the underpinning legislation and follow-on regulatory guidelines) pre-dates the US regulatory framework by almost a decade.

Of the 52 biosimilars approved thus far, two-thirds (35) are first-time approvals since 2014. This period witnessed few approvals of 'traditional' biosimilars, unlike earlier periods, in which most biosimilars approved were human growth hormone, erythropoietin or G-CSF products. Since 2014, approvals of these biosimilars have invariably been approvals in the United States of products previously approved in the EU. In recent years, the focus of approvals has shifted toward engineered insulins (4 approvals) and mAbs (25 product approvals; Table 4). Drivers here are market value, coupled with patent expiry and the availability of analytical methodology capable of demonstrating structural similarity in the context of proteins as large and complex as mAbs (Box 2). The survey period has therefore witnessed the approval of a raft of products demonstrating biosimilarity to the top-selling drugs, with biosimilar versions having come on-stream for eight of the top ten global-selling originator products (Table 3 ).

Biosimilars have achieved a widespread degree of acceptance in the European Union, where several such products have been on the market for over a decade. In that time, 


\section{Box 1 Clotting factors}

Genetic defects characterized by lowered expression (or altered amino acid sequence) of any clotting factor can compromise the blood clotting process, leading to congenital hemophilia. Characterized by spontaneous and prolonged hemorrhage, hemophilia is due in over $80 \%$ of cases to a deficiency in factor VIII activity (hemophilia A), while in most of the remainder it is due to a deficiency in factor IX (hemophilia B). Global incidence of hemophilia is estimated at between 200,000 and 400,000 , with hemophilia A having an average incidence of $\sim 2$ people per 10,000. Disease severity is linked to the percentage of residual active factor produced by the patient, and the disease is treated via intravenous administration of the missing clotting factor. Before the introduction of clotting factor concentrates in the 1960s, the life expectancy was of the order of 15-25 years. In the early 1980s, before the advent of screening tests of HIV in donated blood, large numbers of hemophiliacs contracted AIDS from clotting factors purified from human plasma. The introduction of recombinant clotting factors beginning in the early 1990s drastically reduced dependence on plasma-derived products, and the 2017 global market value for such recombinant products stood at $\$ 8.5$ billion. Treatment costs typically vary from $\$ 30,000$ to several hundred thousand dollars annually, depending on condition severity and the development of inhibitory antibodies (which 20-30\% of hemophilia A patients can develop).

The current survey period witnessed a surge in clotting factor approvals, with ten factor VIII and six factor IX products coming on-stream, although several share the same active ingredient (Table 1 ). In the main, the products approved either are characterized by manufacturing process improvements over earlier-generation products or are engineered to increase serum half-life. For example, Bayer's Kovaltry/lblias is essentially an updated Kogenate, a recombinant factor VIII. Unlike Kogenate, Kovaltry/lblias is produced in a baby hamster kidney (BHK) cell line that also expresses heat shock protein 70, with resulting improvement in recombinant productivity. Moreover, all animaland human-derived additives have been eliminated from the cell culture and purification processes, and a virus filtration step has been introduced for improved nonenveloped viral clearance robustness.

Clotting factor products are usually administered therapeutically (to control active bleeding) or prophylactically (to reduce frequency of future bleeding events). Administration for therapeutic purposes is tailored to individual circumstance while prophylactic administration of unmodified (first-generation) factors typically occurs three times weekly. Engineering to increase serum half-life has relied on PEGylation (Adynovi/Adynovate and Rebinyn/Refixia), Fc fusion (Elocta/Eloctate and Alprolix) or albumin fusion (Idelvion). Engineering had typically reduced prophylactic administration to twice weekly, and such products would be described by some as biobetter clotting factors.

The current survey period also witnessed the approval of a novel mAb-based product indicated for the prophylaxis of hemophilia $A$ in patients who produce anti-factor VIII antibodies, which neutralize any exogenously administered factor VIII). Hemlibra (emicizumab) is a bispecific IgG, one arm of which binds factor IXa while the other binds factor X, effectively triggering factor VIII-independent clot formation. Market analysts predict Hemlibra may attain blockbuster status (sales above $\$ 1$ billion) by 2019 , reaching $\$ 4$ billion by 2022 (https://clarivate.com/blog/life-sciences-connect/green-light-market-hemlibra-hemophilia-inhibitors-us/).

EU-monitoring systems for safety concerns have not identified any relevant difference in the nature, severity or frequency of adverse effects between biosimilars and their reference medicines, and a decade of clinical experience accrued with these products shows that the approved biosimilars can be used as safely and effectively in all their approved indications as other biological medicines ${ }^{5}$. Acceptance in the United States is not as strong, which is unsurprising given the shorter window of experience with biosimilars.

A 2016 report from consultants IMS Health on the impact of biosimilar competition in the European economic area ${ }^{6}$ identifies EU-wide average price reductions from $8 \%$ in the case of anti-TNF biosimilar products to $33-34 \%$ savings in the context of erythropoietin and G-CSF biosimilars, relative to reference product pricing the year before biosimilar entrance. Moreover, the report found that biosimilar entry affected not only the price of the relevant reference product, but of the whole product class. Globally, 2017 sales generated cumulatively by all biosimilar reference products reached $\$ 73.3$ billion. An interesting although hypothetical calculation suggests savings of up to $\$ 22$ billion to global healthcare systems if biosimilar entry drove a $30 \%$ savings across the board in relation to all these products.

The development of so-called 'biobetters' represents a potential threat to biosimilar development. A biobetter describes an already approved biopharmaceutical entity altered in some way (e.g., a structural modification or an altered finished product combination or formulation) to improve some aspect of its

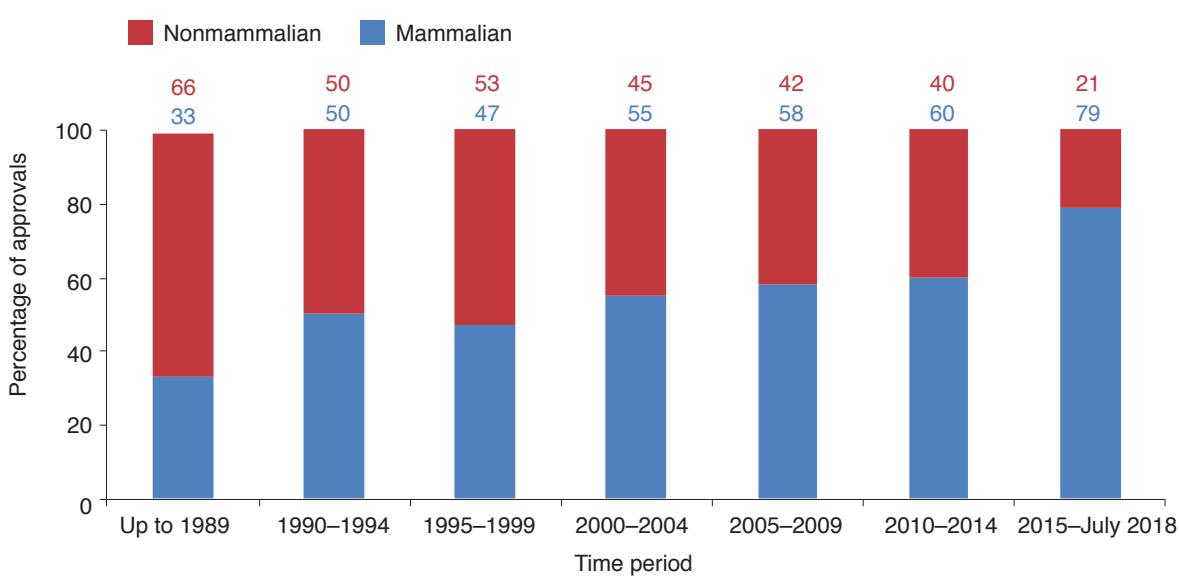

Figure 3 Relative use of mammalian- versus nonmammalian-based production cell lines in the manufacture of biopharmaceuticals approved over the indicated periods. Each dataset is expressed as a percentage of total biopharmaceutical product approvals for the period in question. 
Table 3 The 20 top-selling biopharmaceutical products in 2017

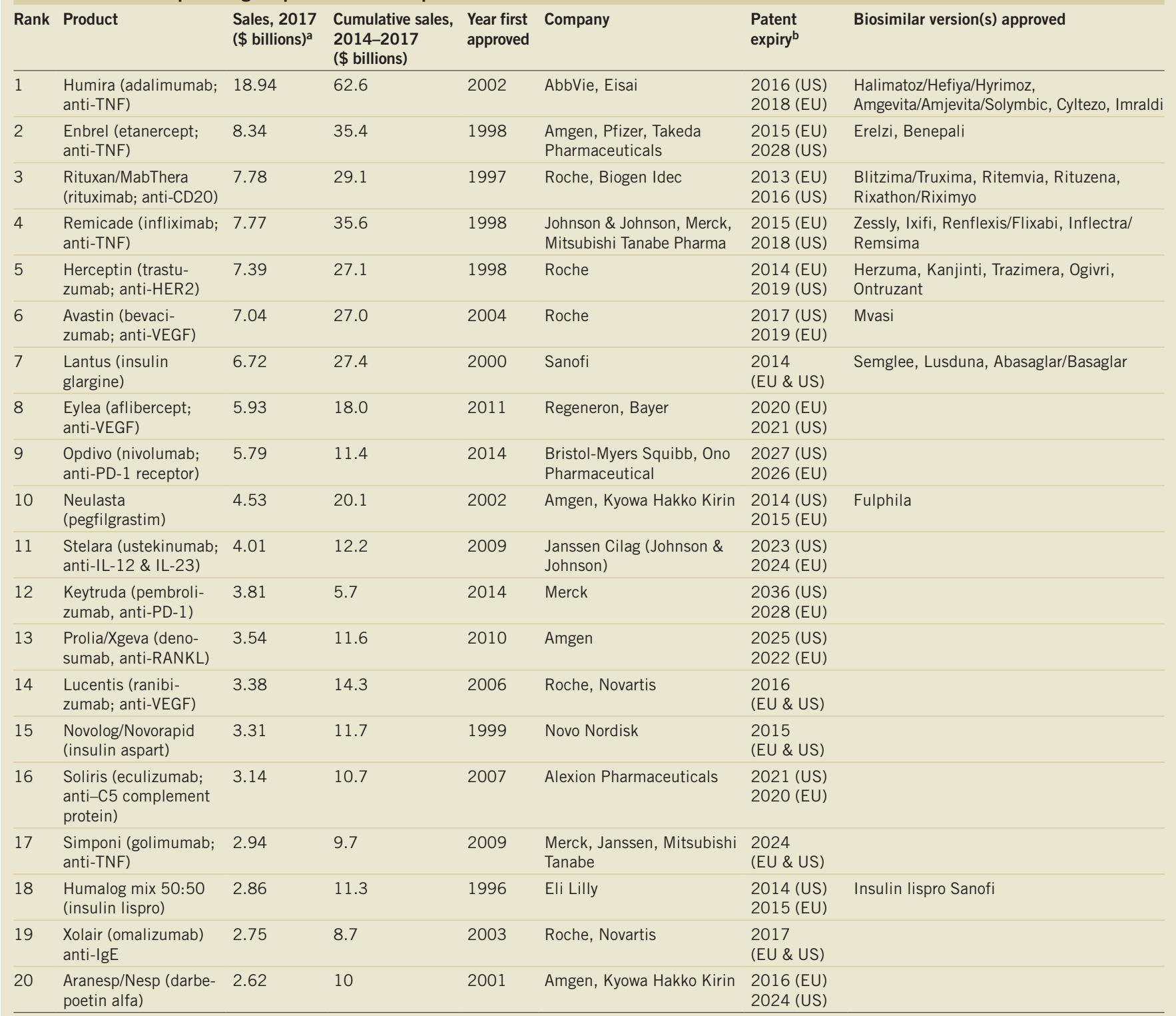

aFinancial data from La Merie Business intelligence. bPatent data from various sources, including http://www.gabionline.net/Biosimilars/General/Biologicals-patent-expiries.

HER2, human epidermal growth factor receptor 2; IgE, immunoglobulin E; IL, interleukin; PD-1, programmed cell death receptor 1; RANKL, receptor activator of nuclear factor- $\mathrm{B}$ ligand; VEGF, vascular endothelial growth factor.

\section{mAb approvals}

The data in our survey underscore the current and increasing dominance of mAbs in the biopharma sector, in terms of overall product approvals, biosimilar approvals and market value. Whereas cancer remains the most common target indication, during the period several products aimed at nontraditional $\mathrm{mAb}$ target conditions were approved. These include Aimovig (erenumab), indicated for migraine; Fasenra (benralizumab) and Cinqair/Cinqaero (reslizumab) for asthma; Trogarzo (ibalizumab) for HIV infection; and Anthim (obiltoxaximab) for inhalation anthrax. Also notable was the approval of several anti-interleukin mAbs to treat psoriasis, as opposed to the more traditional anti-TNF products for this indication. The new products include Cosentyx (secukinumab), Ilumya (tildrakizumab-asmn), Kyntheum/Siliq (brodalumab), Tremfya (guselkumab) and Taltz (ixekizumab). Taltz is also unusual in that it is a humanized immunoglobulin G4 (IgG4). It was consequently engineered to contain a serineto-proline substitution (S228P), which reduces the frequency of half-antibody formation or other heterologous antibody combinations sometimes observed with IgG4 antibodies.

It is also notable that all the mAbs approved in the survey period were engineered in some way: virtually all novel antibodies approved are either humanized or fully human. One new antibody-drug conjugate (Besponsa, inotuzumab ozogamicin) made it to market, along with two new bispecific products (Hemlibra, emicizumab/emicizumab-kxwh; Blincyto, blinatumomab; Boxes 1 and 3). Tecenetriq (atezolizumab), a mAb against programmed cell death receptor ligand 1 (PD-L1), is unusual in that it contains an amino acid substitution (asparagine to alanine) at position 298, in the $\mathrm{CH} 2$ domain of each heavy chain. This substitution prevents antibody glycosylation and thus blocks glycan-dependent Fc-effector functions, which is in turn important in the context 


\begin{tabular}{|c|c|c|c|c|}
\hline Product type & Biosimilar (trade name) & Year (and region) approved & Reference product & Drug (active ingredient) manufacturer \\
\hline \multicolumn{5}{|l|}{ Somatropin-based } \\
\hline \multirow{2}{*}{$\begin{array}{l}\text { Human growth } \\
\text { hormone-based }\end{array}$} & Omnitrope & 2006 (EU) & Genotropin & Sandoz (Kundl, Austria) \\
\hline & Valtropin & $\begin{array}{l}2006 \text { (EU) } \\
\text { Withdrawn } 2012\end{array}$ & Humatrope & LG Life Sciences (Jeonbuk-do, Republic of Korea) \\
\hline \multicolumn{5}{|l|}{ Epoetin-based } \\
\hline \multirow[t]{6}{*}{ Epoetin-based } & Binocrit & 2007 (EU) & Eprex/Erypo & Rentschler (Laupheim, Germany) \& Lek (Menges, Slovenia) \\
\hline & Epoetin alfa hexal & 2007 (EU) & Eprex/Erypo & Rentschler \& Lek \\
\hline & Abseamed & 2007 (EU) & Eprex/Erypo & Rentschler \& Lek \\
\hline & Retacrit & 2018 (US) & Eprex/Erypo (EU) & Norbitec (Uetersen, Germany) \\
\hline & & 2007 (EU) & Epogen/Procrit (US) & Norbitec (Uetersen, Germany) \\
\hline & Silapo & 2007 (EU) & Eprex/Erypo & Norbitec \\
\hline \multicolumn{5}{|l|}{ Filgrastim-based } \\
\hline \multirow[t]{9}{*}{ G-CSF-based } & Ratiograstim & $2008(E U)$ & Neupogen & Sicor (Vilnius, Lithuania) \\
\hline & Filgrastim ratiopharm & $\begin{array}{l}2008 \text { (EU) } \\
\text { Withdrawn } 2011\end{array}$ & Neupogen & Sicor \\
\hline & Biograstim & $\begin{array}{l}2008 \text { (EU) } \\
\text { Withdrawn } 2015\end{array}$ & Neupogen & Sicor \\
\hline & Tevagrastim & 2008 (EU) & Neupogen & Sicor \\
\hline & $\begin{array}{l}\text { Zarxio (US) } \\
\text { Zarzio (EU) }\end{array}$ & $\begin{array}{l}2015 \text { (US) } \\
2009 \text { (EU) }\end{array}$ & Neupogen & Sandoz (Kundl, Austria) \\
\hline & Filgrastim hexal & 2009 (EU) & Neupogen & Sandoz (Kundl, Austria) \\
\hline & $\begin{array}{l}\text { Nivestym (US) } \\
\text { Nivestim (EU) }\end{array}$ & $\begin{array}{l}2018 \text { (US) } \\
2010 \text { (EU) }\end{array}$ & Neupogen & Hospira (Pfizer) (Zagreb, Croatia) \\
\hline & Grastofil & $2013(E U)$ & Neupogen & Intas Biopharmaceuticals (Gujarat, India) \\
\hline & Accofil & 2014 (EU) & Neupogen & Intas Biopharmaceuticals \\
\hline Pegfilgrastim-based & Fulphila & 2018 (US) & Neulasta & Mylan (Zurich) \\
\hline \multicolumn{5}{|c|}{ Follicle-stimulating hormone-based } \\
\hline \multirow{2}{*}{$\begin{array}{l}\text { Follicle-stimulating } \\
\text { hormone-based }\end{array}$} & Ovaleap & 2013 (EU) & Gonal F & Merckle Biotec (UIm, Germany) \\
\hline & Bemfola & 2014 (EU) & Gonal F & $\begin{array}{l}\text { Polymun Scientific Immunbiologische Forschung } \\
\text { (Klosterneuburg, Austria) }\end{array}$ \\
\hline \multicolumn{5}{|l|}{ Insulin-based } \\
\hline \multirow[t]{3}{*}{ Insulin glargine-based } & Abasaglar & $2014(E U)$ & Lantus & $\begin{array}{l}\text { Lilly del Caribe (Carolina, Puerto Rico, USA) } \\
\text { Eli Lilly (Indianapolis) }\end{array}$ \\
\hline & Lusduna & $\begin{array}{l}2017 \text { (EU) } \\
2017 \text { (US), tentative }\end{array}$ & Lantus & Merck Sharp \& Dohme (Elkton, VA, USA) \\
\hline & Semglee & 2018 (EU) & Lantus & Biocon Nusajaya (Johor, Malaysia) \\
\hline Insulin lispro-based & Insulin lispro Sanofi & 2017 (EU) & Humalog & Sanofi-Aventis (Frankfurt) \\
\hline \multicolumn{5}{|l|}{ mAb-based and related } \\
\hline \multirow[t]{6}{*}{ Infliximab-based } & Inflectra & $\begin{array}{l}2016 \text { (US) } \\
2013 \text { (EU) }\end{array}$ & Remicade & Celltrion (Incheon, Republic of Korea) \\
\hline & Remsima & 2013 (EU) & Remicade & Celltrion \\
\hline & Flixabi & 2016 (EU) & Remicade & $\begin{array}{l}\text { Biogen (Hillerod, Denmark) } \\
\text { Samsung Bioepis (Incheon, Republic of Korea) }\end{array}$ \\
\hline & Renflexis & 2017 (US) & Remicade & $\begin{array}{l}\text { Biogen (Hillerod, Denmark) } \\
\text { Samsung Bioepis }\end{array}$ \\
\hline & Ixifi & 2017 (US) & Remicade & Pfizer \\
\hline & Zessly & 2018 (EU) & Remicade & Boehringer Ingelheim (Biberach an der Riss, Germany) \\
\hline \multirow[t]{7}{*}{ Adalimumab-based } & $\begin{array}{l}\text { Amgevita (EU) } \\
\text { Amjevita (US) }\end{array}$ & $\begin{array}{l}2017 \text { (EU) } \\
2016 \text { (US) }\end{array}$ & Humira & Amgen (Thousand Oaks, CA, USA) \\
\hline & Solymbic & 2017 (EU) & Humira & Amgen \\
\hline & Cyltezo & 2017 (EU \& US) & Humira & Boehringer Ingelheim (Fremont, CA, USA) \\
\hline & Halimatoz & 2018 (EU) & Humira & $\begin{array}{l}\text { Cook Pharmica (Bloomington IN, USA) } \\
\text { Sandoz (Langkampfen, Austria) }\end{array}$ \\
\hline & Hefiya & 2018 (EU) & Humira & $\begin{array}{l}\text { Cook Pharmica (Bloomington IN, USA) } \\
\text { Sandoz (Langkampfen, Austria) }\end{array}$ \\
\hline & Hyrimoz & 2018 (EU) & Humira & $\begin{array}{l}\text { Cook Pharmica (Bloomington IN, USA) } \\
\text { Sandoz (Langkampfen, Austria) }\end{array}$ \\
\hline & Imraldi & 2017 (EU) & Humira & $\begin{array}{l}\text { Biogen (Research Triangle Park, NC, USA) } \\
\text { Biogen (Hillerød, Denmark) }\end{array}$ \\
\hline
\end{tabular}




\begin{tabular}{|c|c|c|c|c|}
\hline Product type & Biosimilar (trade name) & Year (and region) approved & Reference product & Drug (active ingredient) manufacturer \\
\hline \multirow[t]{6}{*}{ Rituximab-based } & Blitzima & 2017 (EU) & MabThera & Celltrion \\
\hline & Truxima & 2017 (EU) & MabThera & Celltrion \\
\hline & Ritemvia & 2017 (EU) & MabThera & Celltrion \\
\hline & Rituzena & 2017 (EU) & MabThera & Celltrion \\
\hline & Rixathon & 2017 (EU) & MabThera & Sandoz (Langkampfen, Austria) \\
\hline & Riximyo & 2017 (EU) & MabThera & Sandoz (Langkampfen, Austria) \\
\hline \multirow[t]{5}{*}{ Trastuzumab-based } & Ontruzant & 2017 (EU) & Herceptin & Biogen (Hillerød, Denmark) \\
\hline & Ogivri & 2017 (US) & Herceptin & Mylan \\
\hline & Herzuma & 2018 (EU) & Herceptin & Celltrion \\
\hline & Kanjinti & 2018 (EU) & Herceptin & Patheon Biologics (Groningen, the Netherlands) \\
\hline & Trazimera & 2018 (EU) & Herceptin & Boehringer Ingelheim (Biberach an der Riss, Germany) \\
\hline Bevacizumab-based & Mvasi & $\begin{array}{l}2018 \text { (EU) } \\
2017 \text { (US) }\end{array}$ & Avastin & Amgen \\
\hline \multirow[t]{2}{*}{ Etanercept-based } & Benepali & 2016 (EU) & Enbrel & Biogen (Hillerød, Denmark) \\
\hline & Erelzi & $\begin{array}{l}2017 \text { (EU) } \\
2016 \text { (US) }\end{array}$ & Enbrel & $\begin{array}{l}\text { Sandoz (Novartis) (Langkampfen, Austria) (EU) } \\
\text { Novartis Pharma (Stein, Switzerland) (US) }\end{array}$ \\
\hline \multicolumn{5}{|l|}{ Teriparatide-based } \\
\hline \multirow[t]{2}{*}{ Teriparatide-based } & Movymia & 2017 (EU) & Forsteo & Richter-Helm BioLogics (Bovenau, Germany) \\
\hline & Terrosa & 2017 (EU) & Forsteo & Richter-Helm BioLogics \\
\hline
\end{tabular}

of the product's mode of action and safety profile. Fasenra, by contrast, is engineered such that its glycocomponent is afucosylated (like that of Gazyva/Gazyvaro (obinutuzumab), approved initially in 2013), which increases the antibody-dependent cell-mediated cytotoxicity activity important for its mode of action. The period also witnessed the approval of one Fab antibody fragment (Praxbind; idarucizumab), designed to bind and thus neutralize the anticoagulant drug dabigatran.

Although technically outside the timeframe of this survey, the approval of Cablivi (caplacizumab) in Europe at the end of August represents a major milestone in $\mathrm{mAb}$ therapeutics, as it is the first nanobody to gain regulatory approval. It is indicated to treat acquired thrombotic thrombocytopenic purpura, which is a rare, life-threatening, autoimmune blood clotting disorder. Cablivi is a humanized, 259 amino acid, $2.78 \mathrm{kDa}$ bivalent nanobody produced in E. coli that binds to von Willebrand factor, a key protein in hemostasis. This in turn inhibits the interaction of von Willebrand factor with blood platelets, preventing platelet adhesion and hence the clotting characteristic of the condition.

Although often considered the poster child of biopharma, antibody-based products are just as susceptible to commercial influence and pharmacovigilance as any other therapeutic product. Three mAbs approved in the current survey period have been withdrawn within this period. European marketing authorizations for Unituxin (dinutuximab, approved for neuroblastoma) from United Therapeutics and nivolumab BMS (nivolumab, approved for non-small-cell lung cancer) from Bristol-Myers Squibb were withdrawn, due to drug supply difficulties in the case of Unituxin and for commercial reasons in the case of nivolumab BMS. Biogen and AbbVie's Zinbryta (daclizumab), which was approved in 2016 for multiple sclerosis, was withdrawn globally in 2018 after serious adverse events, such as liver damage and immune reactions, became apparent.

\section{Recombinant enzymes and transgenic production}

The survey period also witnessed the approval of nine recombinant enzymes for the treatment of various genetic conditions. From a technological perspective, Alexion Pharmaceuticals' Kanuma (sebelipase alfa; recombinant human lysosomal acid lipase) is interesting in that it is produced in the eggs of transgenic chickens, with enzyme purification directly from transgenic egg white. The transgenic chicken line was developed via injection of a retroviral vector carrying the human coding sequence into chick embryos.

However, transgenic-based platforms for biopharmaceutical production have failed to gain widespread use in the biopharmaceutical sector. Technical challenges arising from random integration of transgenes into host chromosomes and the difficulty of controlling transgene copy number in production animals has limited the appetite for commercial investment in transgenic animal platforms capable of generating economically viable levels of recombinant proteins. It will be interesting to follow whether recent developments in
CRISPR-based gene editing, which overcome some of these technical difficulties ${ }^{7}$, change the industry outlook. Ovalbumin, for example, is expressed at two grams per hen egg, with one hen capable of laying more than 300 eggs a year. CRISPR-targeted insertion of a therapeutic-protein-encoding sequence into the ovalbumin gene could therefore afford high-level protein production ${ }^{8}$.

\section{Nucleic acid-based approvals}

Nucleic acid-based products (gene therapies, DNA or RNA vaccines, ASOs, small interfering RNAs (siRNA), aptamers and modified RNA molecules) have yet to exert a profound influence on the biopharma product landscape, although the period witnessed the approval of five such products (three ASOs and two gene therapies). This brings the total tally of approvals in this category to nine, although the gene therapy Glybera (alipogene tiparvovec) was withdrawn from the market last year.

Glybera was approved as a single-administration gene therapy for adults suffering from familial lipoprotein lipase deficiency with a treatment price tag on the order of $\$ 1$ million. The developer and manufacturer opted not to renew its European marketing authorization in 2017 due to lack of demand for the product. Luxturna (voretigene neparvovec-rzyl), approved last year in the United States, appears set to be almost as costly; the one-time treatment will cost $\$ 850,000$. Luxturna contains a live, nonreplicating adeno-associated virus serotype 2 genetically modified to express the human retinal pigment epithelium-specific $65-\mathrm{kDa}(R P E 65)$ gene. Delivered directly via 
subretinal injection, it is indicated for patients with inherited retinal disease due to mutations in both copies of this gene. The headline costs of either of these products likely reflect the rarity of the target conditions and thus potential market size, as opposed to a fundamental cost basis for gene therapy products per se. The third gene therapy approval, Imlygic (talimogene laherparepvec), for example, is projected to cost an average of $\$ 65,000$ per patient. Indicated for the treatment of melanoma recurrent after initial surgery, Imlygic is a live, attenuated herpes simplex virus type 1 carrying the human GM-CSF coding sequence. Viral replication subsequent to injection directly into the tumor is believed to trigger cell lysis, and it is believed that the release of tumor-derived antigens along with the GM-CSF may also promote an antitumor effect.

Three approved ASO products hold orphan status for the treatment of rare conditions with limited therapeutic options. It is notable that one of these ASO products, Ionis Pharmaceuticals' Spinraza (nusinersen) for spinal muscular atrophy, was the main source of sales growth for Biogen in 2017, generating $\$ 188$ million in sales in the first quarter of 2018. Spinraza targets splicing defects that lead to this disorder, and rare conditions arising due to mRNA mis-splicing are likely to be an increasing area of focus for this modality.

In terms of downregulation of misregulated mRNA expression, ASOs now have to compete with siRNAs. Although technically outside the timeframe of this current survey, the recent approval of Alnylam's Onpattro (patisiran) represents the most notable recent approval of an oligonucleotide-based therapeutic. Approved in both US and EU in August 2018, Onpattro is the first RNAibased gene expression silencing product to gain approval in either region.

\section{Traditional biotech product approvals}

The current survey period also witnessed the approval of 46 traditional biotech products classified as new by regulatory authorities in terms of active substance-just one more than recorded in our previous survey. Traditional products refer to those produced naturally or via nonrecombinant means in or by a biological source.

The profile of approvals (Supplementary Table 1) by and large mirrors product types approved in previous surveys and include a range of blood-derived products (for example, plasma-purified human albumin, clotting factors and immunoglobulins), as well as traditional (nonrecombinant) vaccines and nonengineered cells.

\section{Box 2 Analytical approaches to validating biosimilar mAb quality}

Biosimilar guidelines require the generation of comparative data between a proposed new biosimilar product and the reference product to which it claims similarity, at the levels of both the active substance and finished product. The marketing application, relative to a standard product application, must contain a full quality module, incorporating comparative quality analysis, as well as reduced comparative clinical and nonclinical data modules. Comparative quality studies largely rely on analytical techniques and instrumentation, now capable of fully characterizing biopharmaceuticals as large and complex as mAbs, with mass spectrometry (MS)-based techniques coming to the fore. Any comparative differences identified (for example, differences in glycocomposition) are then considered in terms of effect on biosimilarity, with further investigation via biological assay or preclinical or clinical evaluation, as appropriate.

An analysis of the comparative quality information presented in the European public assessment reports of approved biosimilar mAbs provide insight into the broad range of state-of-the-art analytical techniques used in practice (similar techniques are used as appropriate in the context of other protein-based biosimilars). The commonly applied analytical approaches discernible in these documents include the following:

- Determination of intact molecular mass by electrospray MS. Other size analysis modalities cited included size exclusion high performance liquid chromatography (SEHPLC) and capillary electrophoresis in the presence of sodium dodecyl sulfate.

- Primary structural analysis by methods including classic $\mathrm{C}$ - and $\mathrm{N}$-terminal sequencing (partial sequence determination), with full sequence determination invariably relying on initial protein fragmentation, peptide mapping and MS techniques such as matrix-assisted laser desorption/ionization time-of-flight (MALDI-TOF) MS or liquid chromatography/tandem MS (LC-MS/MS). This includes the detection of C-terminal lysine variability (common in IgGs, but without anticipated clinical impact as C-terminal lysines are rapidly removed in serum).

- Sulfhydryl analysis via ultraviolet (UV)/visible light spectrophotometry and SE-HPLC, with disulfide linkage assignment via LC-MS-based peptide mapping under reducing and nonreducing conditions.

- Higher order structural analysis: secondary structural analysis via far-UV circular dichroism spectroscopy and/or Fourier transform infrared spectroscopy; tertiary analysis via near-UV circular dichroism spectroscopy or intrinsic fluorescence spectroscopy; thermal stability of higher order structure via differential scanning calorimetry; X-ray crystallography of the Fc domain.

- Glycosylation analysis: composition or structural determination, including levels of fucosylation and terminal galactosylation (which can influence antibody effector functions), by exoglucanase digestion and hydrophobic interaction chromatography analysis, high-performance anion-exchange chromatography with pulsed amperometric detection (HPAE-PAD).

- Analysis of additional modifications (for example, site specific deamidation, oxidation) by MS-based methods, peptide mapping with LC-MS).

- Charge heterogeneity profile by ion exchange-based HPLC, isoelectric focusing.

- Purity analysis: HPLC-based separation modalities based on size, charge and hydrophobicity, capillary gel electrophoresis, western blot analysis.

\section{Engineered cell-based approvals}

Traditional cell-based therapeutics containing cells extracted from human tissue or blood continue to come on the market. Examples include hematopoietic progenitor cells derived from cord blood, as well as autologous cultured chondrocytes used to treat cartilage defects (Supplementary Table 1).

A notable recent milestone in cell-based therapeutics is the approval of genetically engineered cell-based therapies, four of which have been approved since 2016: Kymriah (tisagenlecleucel), Yescarta (axicabtagene ciloleucel), Zalmoxis and Strimvelis. These products may be viewed as both cell and gene therapies, given that the cells carry a therapeutic gene into the patient's body. All four products have orphan status or target niche conditions and either are under additional monitoring or require further postauthorization safety studies. Three of the four (Kymriah, Yescarta and Strimvelis) use autologous cells, whereas the fourth (Zalmoxis) uses allogeneic cells as a starting point. One is a hematopoietic stem cell therapy (Strimvelis) and the other 


\section{Box 3 BiTE technology}

Pioneered by Micromet, a biotechnology company acquired by Amgen, the first bispecific T-cell engager (BiTE) product, Blincyto (blinatumomab), gained approval in the United States and European Union for the treatment of B-cell precursor acute lymphoblastic leukemia during the current survey period. The BiTE platform consists of a bispecific antigen-binding antibody fragment, one arm of which is designed to bind the CD3 cell surface receptor complex, invariably found on cytotoxic T cells, while the other arm is designed to bind a surface tumor antigen associated with a target cancer cell type 17,18. The BiTE construct therefore acts as a bridge, bringing cytotoxic T cells into close proximity to the target cancer cells and triggering lysis of the latter by the former.

The Blincyto construct consists of two single-chain variable fragments (scFv domains) joined by a short, flexible linker sequence consisting of glycine and serine residues. The $55 \mathrm{kDa}, 504$ amino acid construct includes a C-terminal hexahistidine sequence, which facilitates purification using zinc-immobilized metal affinity chromatography. One scFv domain targets the T-cell CD3 receptor, while the other binds the pan-B-cell antigen CD19, facilitating T-cell-mediated lysis of B cells. Because of its relatively low molecular mass, the construct has a short serum half-life ( $2-3 \mathrm{~h}$ ). This requires continuous infusion over a four-week period, representing a limitation in terms of patient convenience. Approaches to the development of next-generation constructs with extended serum halflives include fusion to human albumin and Fc-based constructs, with an aim of facilitating a once-weekly dosage schedule.

The Amgen pipeline contains several more BiTE constructs undergoing phase 1 clinical trials for the treatment of various cancers, including multiple myeloma and acute myeloid leukemia. BiTE constructs targeting solid tumors have thus far yielded limited success. Limitations may include the degree of tumor penetration (by the construct and T cells), as well as the relatively broad expression of target antigen, which may limit dose escalation.

three are T-cell therapies. In all cases, genetic modification is undertaken ex vivo using a viral vector to achieve transduction, followed by infusion of the genetically modified cells into the patient.

Two of the products (Kymriah and Yescarta) fall into the new wave of cellular immunotherapies for oncology. They are notable in that they are the first chimeric antigen receptor (CAR)-T cell-based products ${ }^{9,10}$ to gain regulatory approval, effectively validating this technology from a regulatory standpoint. In addition to US approval in 2017 , both gained marketing authorization in Europe in August 2018. In the case of both approved products, the CAR-T cells target the CD19 antigen, found on the surface of B lymphocytes, facilitating efficient T-cell-mediated destruction of B cells-thus their indication for the treatment of B-cellbased cancers, against which they have shown striking clinical results.

\section{Future directions}

Although published estimates vary somewhat, some $40 \%$ of the 6,000 or more products currently in clinical development globally are biopharmaceuticals. This suggests that the substantial increase in the proportion of approved pharmaceutical products that are biopharmaceuticals seen in this survey period is not a blip, but will be sustained into the future.
The profile of products in advanced-stage clinical trials suggests that biopharmaceutical approvals over the next few years will continue to be predominantly protein-based (rather than nucleic acid- or cell-based), that they will be produced largely using conventional mammalian cell expression systems, that mAbbased products will continue to dominate the approvals, that a steady stream of biosimilars will continue to gain approval (particularly in indications with large, lucrative markets), and that cancer will remain the primary target indication.

Fifty-four genuinely new mAbs in late-stage clinical trials are under regulatory review in the United States and European Union ${ }^{11}$, framing nearer-term putative approvals in these regions. Of these, 28 (52\%) target cancer, 7 for liquid malignancies and 21 for solid tumors. Most are fully human or humanized IgGs, along with a smaller number (5) of antibody fragment (Fab or single-chain variable fragment ( $\mathrm{scFv})$ ) products. Of the 28 anticancer products, 9 are conjugated to an effector molecule (radiolabel, chemical or toxin).

The antibody market, although highly successful, is also becoming very crowded. In some cases, multiple mAbs target the same therapeutic target (for example, CD20, TNF and vascular endothelial growth factor) and have overlapping indications. The mainstreaming of biosimilar mAbs and, potentially, the development of competing product types, such as CAR-T cell immunotherapies, further increases the competitive pressure and incentive to innovate. Not surprisingly, a greater diversity of modalities and targets is seen further back in the developmental pipeline, reflected in various antibody formats engineered to enhance functionality in some way, the pursuit of novel disease targets and the assessment of mAbs in combination with a second therapeutic agent.

Indeed, such competitive pressures have driven, and continue to drive, innovation among categories other than mAbs. For example, incentive to innovate is illustrated by the recent approval of several clotting factors engineered to increase serum half-life and an increasing number of trials assessing both previously approved and experimental biopharmaceuticals in combination with other drugs to treat various cancers.

Biosimilars will continue to feature with increasing prominence in the global biopharmaceutical landscape, but their greatest impact will continue to be in regions outside the more developed markets, such as the United States and European Union. Thus far, an estimated 260 biosimilar products have been approved in at least one global market-of which only a relatively small minority (52) have been approved in the European Union and/or the US. That being said, many of the additional products approved would likely find it challenging to meet EU and US regulatory expectations in the context of biosimilarity.

Globally, some 188 biosimilars are in development, 61 of which are in phase 3 trials ${ }^{12}$. Specifically within Europe and the United States there are an estimated 50 biosimilars in development (https://www2.deloitte.com/ content/dam/Deloitte/us/Documents/lifesciences-health-care/us-lshc-biosimilarswhitepaper-final.pdf). Despite recent headline approvals, penetration in the US market in particular is likely to occur relatively slowly, underscored by regulatory and legal uncertainties, complex pricing and contracting mechanisms and, of course, patient and clinician acceptance. Overall, however, biosimilar market growth is anticipated to be strong, with market reports (e.g., https://www.marketsandmarkets.com/Market-Reports/biosimilars-40. html) typically forecasting a \$23 billion global market value within the next five to six years, up substantially from an estimated 2017 value of the order of $\$ 4.5$ billion.

The predominance of protein-based approved biopharmaceuticals is likely to remain an industry reality for the foreseeable future. Nucleic acid-based products have yet 
to make a substantial and sustained impact on the list of biopharmaceutical products that are registered in Europe and the United States. A study ${ }^{13}$ from the Journal of Gene Medicine estimates that 2,597 gene therapy-based clinical trials have been approved globally since 1989 . Despite this large body of data, gene-therapybased approvals in Europe and the United States remain in the single digits. Advances in adenoassociated virus (AAV) and lentiviral gene therapy modalities (particularly in ex vivo cellular therapy contexts) - together with increasing interest in CRISPR endonuclease-based gene editing, with several companies now poised to take such approaches into human testing-are likely to provide further impetus to the development of nucleic acid-based treatments.

The rapid advances and clinical adoption of T-cell-based adoptive therapies (including CAR-T cells) is a particularly notable development in the period of this study. The success of this cellular gene therapy is built on the exceptional responses obtained in some trials for some cancers, particularly liquid malignancies. However, scientific, technological and manufacturing hurdles may all complicate its more widespread adoption, certainly in the nearer term ${ }^{14-16}$.

Overall, the past four and a half years have witnessed continued and accelerated growth in the biopharma sector. Antibodies continue to reign supreme and look to dominate for several years to come. Elsewhere, two developments in biopharmaceutical products have been particularly notable over the past five years. First, the massive proliferative capacity of cellular therapy has been effectively harnessed in the form of immunotherapy for late-stage cancers. It is this ability to identify, expand, attack and destroy malignant cells that has made CAR-T cell therapies so successful and overshadowed the longer term goal of cellular therapy: regeneration. Regenerative cell therapy was for many years seen as the main opportunity for modalities based on living cells and, in particular, stem cells; that is no longer the case. Second, increasing evidence of safety and growing familiarity of physicians and insurers with biosimilars means the economic advantages of these products are no longer being ignored. It seems likely that the rapid growth of biosimilar products will continue over the years to come.

Note: Any Supplementary Information and Source Data files are available in the online version of the paper (doi:10.1038/nbt.4305).

1. Walsh, G. Biopharmaceutical benchmarks 2014. Nat. Biotechnol. 32, 992-1000 (2014).

2. Walsh, G. Biopharmaceutical benchmarks 2010. Nat. Biotechnol. 28, 917-924 (2010).

3. Walsh, G. Biopharmaceutical benchmarks 2006. Nat Biotechnol. 24, 769-776 (2006).

4. La Merie Business Intelligence. http://www.lamerie.com (2018).

5. Biosimilars in the EU report: information guide for health professionals. https://www.ema.europa.eu/ documents/leaflet/biosimilars-eu-information-guidehealthcare-professionals en.pdf (2017).
6. The impact of biosimilar competition on price, volume and market share, June 2016. http://ec.europa.eu/ growth/content/impact-biosimilar-competition-pricevolume-and-market-share-updated-version-2016-0_en (2016).

7. Bertolini, L.R. et al. The transgenic animal platform for biopharmaceutical production. Transgenic Res. 25 329-343 (2016).

8. Park, T.S. et al. Deposition of bioactive human epidermal growth factor in the egg white of transgenic hens using an oviduct-specific minisynthetic promoter. FASEB J. 29, 2386-2396 (2015).

9. Miliotou, A.N. \& Papadopoulou, L.C. CAR T-cell therapy: a new era in cancer immunotherapy. Curr. Pharm. Biotechnol. 19, 5-18 (2018).

10. June, C.H., O'Connor, R.S., Kawalekar, O.U., Ghassemi, S. \& Milone, M.C. CAR T cell immunotherapy for human cancer. Science 359, 1361-1365 (2018).

11. Kaplon, H. \& Reichert, J.M. Antibodies to watch in 2018. MAbs 10, 183-203 (2018).

12. FirstWord. Charting the Global Biosimilar Pipeline (FirstWord Publishing, 2018).

13. Ginn, S.L., Amaya, A.K., Alexander, I.E., Edelstein, M. \& Abedi, M.R. Gene therapy clinical trials worldwide to 2017: an update. J. Gene Med. 20, e3015 (2018).

14. Zheng, P.P., Kros, J.M. \& Li, J. Approved CAR-T cell therapies: ice bucket challenges on glaring safety risks and long-term impacts. Drug Discov. Today 231175 1182 (2018).

15. Labanieh, L., Majzner, R.G. \& Mackall, C.L. Programming CAR-T cells to kill cancer. Nat. Biomed. Eng. 2, 377-391 (2018).

16. Köhl, U., Arsenieva, S., Holzinger, A. \& Abken, H. CAR $T$ cells in trials: recent achievements and challenges that remain in the production of modified T cells fo clinical applications. Hum. Gene Ther. 29, 559-568 (2018).

17. Klinger, M., Benjamin, J., Kischel, R., Stienen, S. \& Zugmaier, G. Harnessing $T$ cells to fight cancer with BiTE $®$ antibody constructs - past developments and future directions. Immunol. Rev. 270, 193-208 (2016).

18. Trivedi, A. et al. Clinical pharmacology and translational aspects of bispecific antibodies. Clin. Transl. Sci. 10 147-162 (2017). 


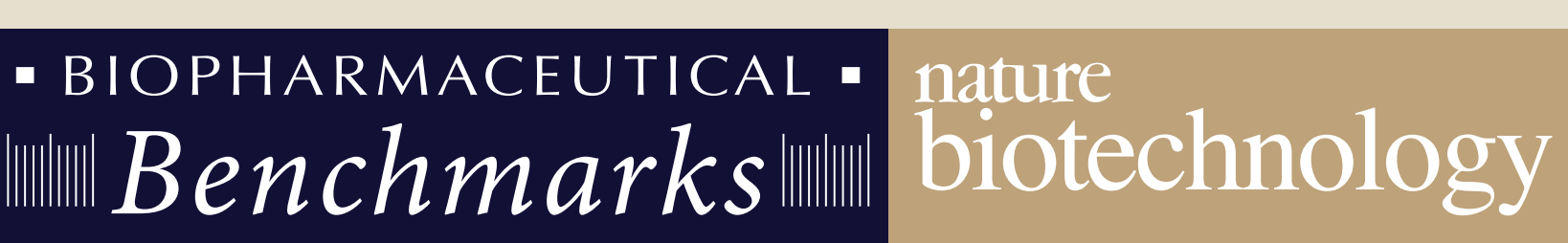

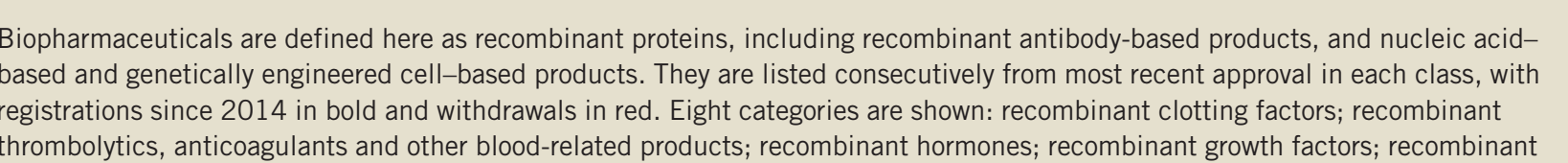

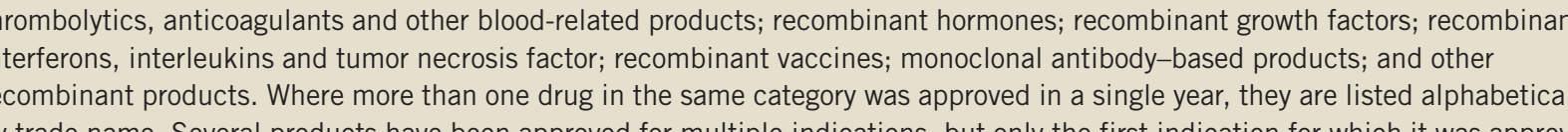

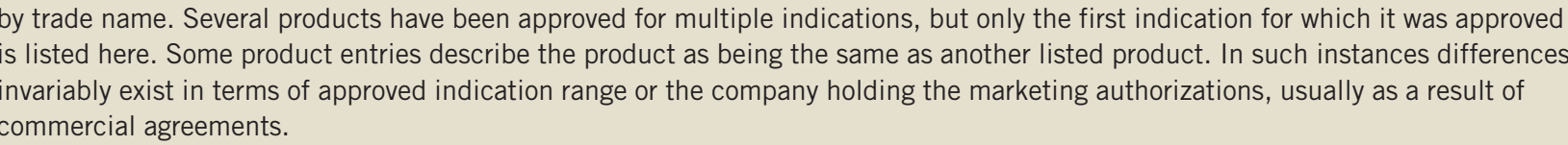

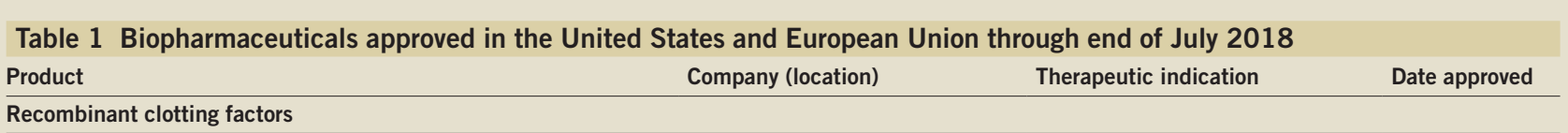

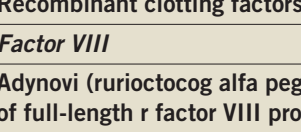

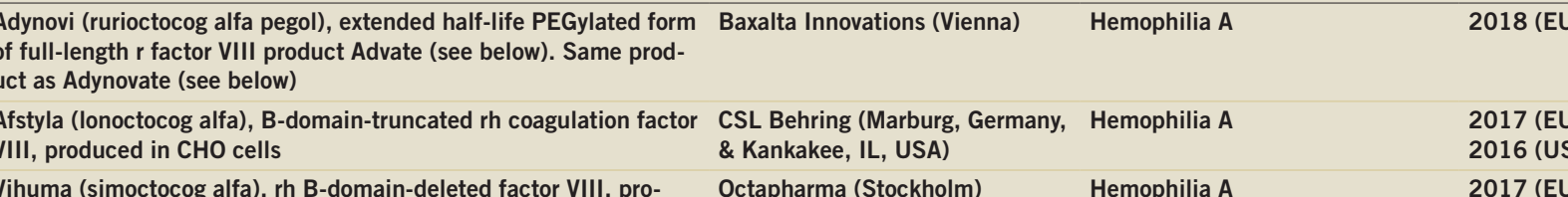

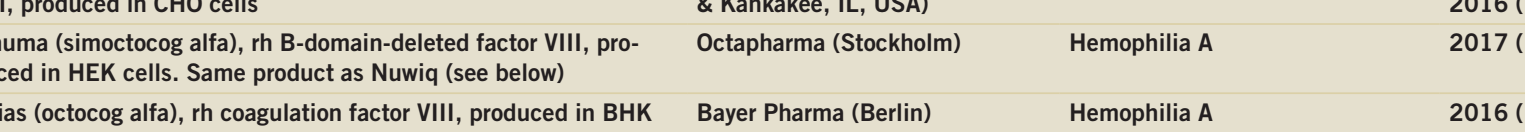

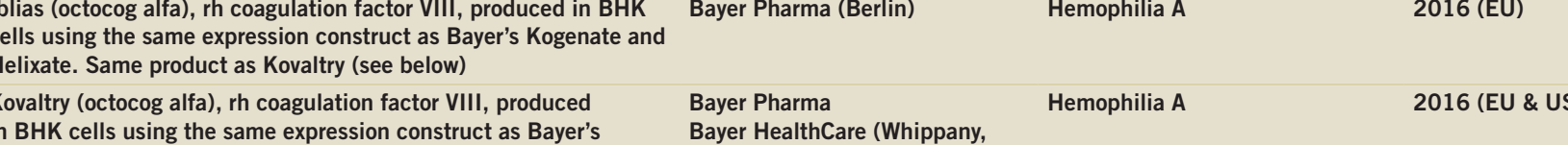

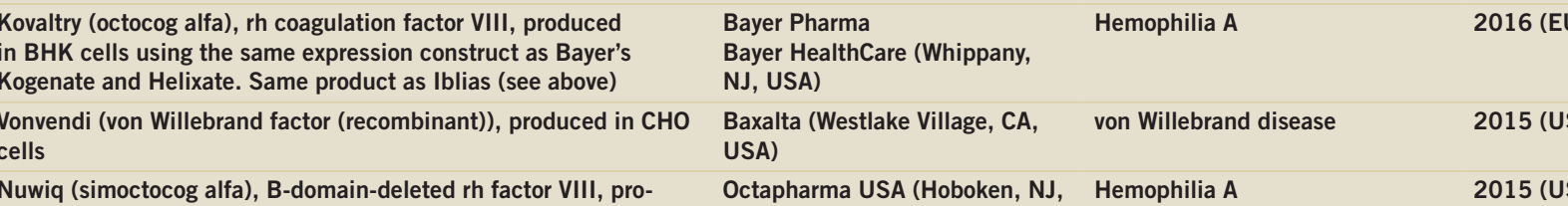

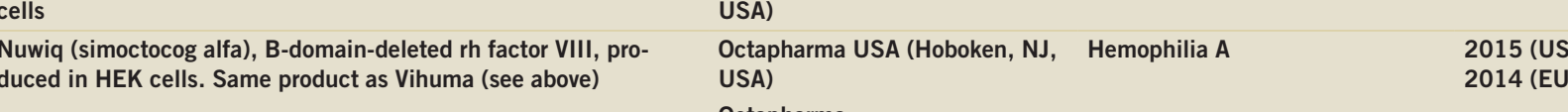

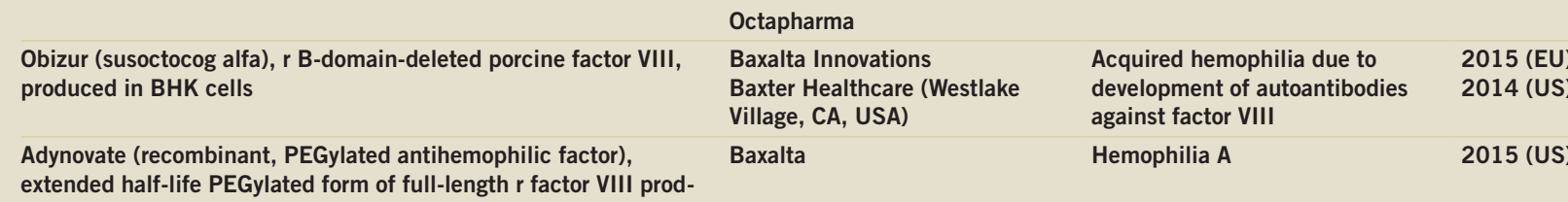

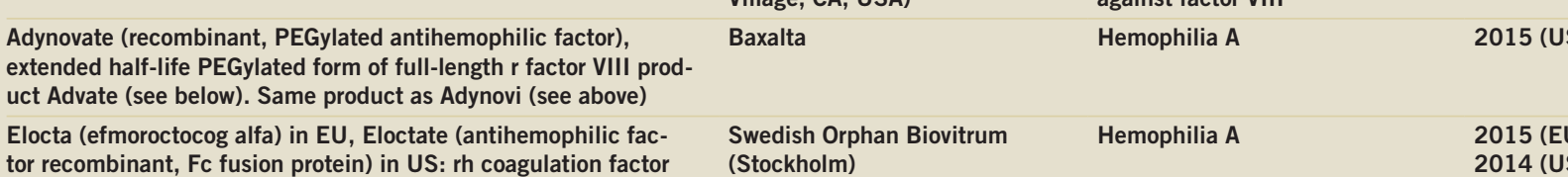

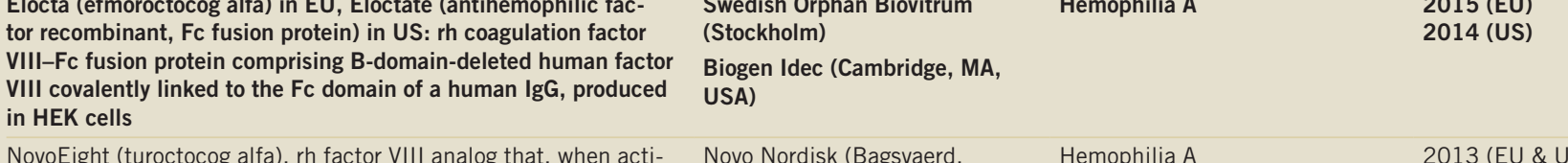

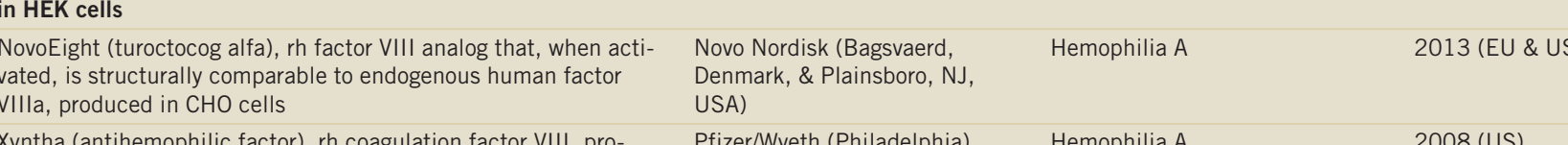

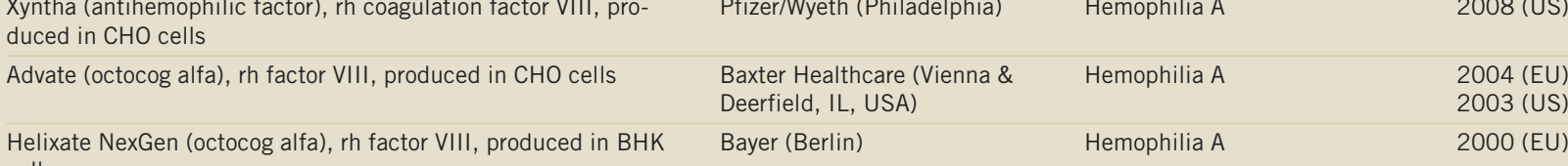

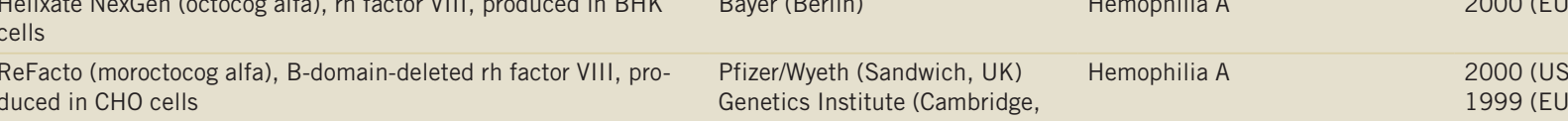

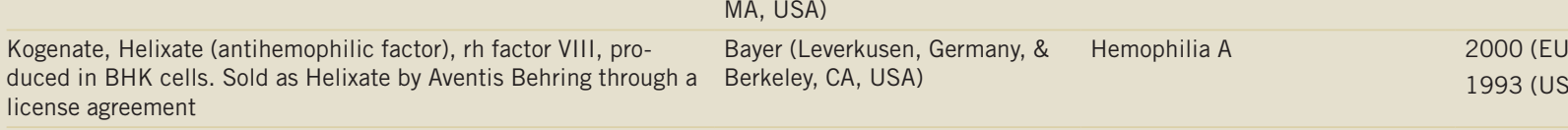

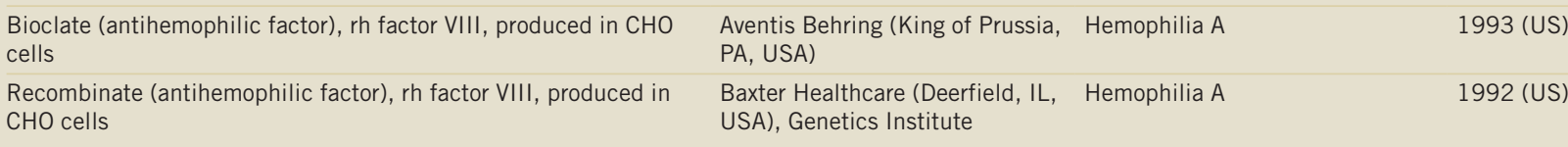

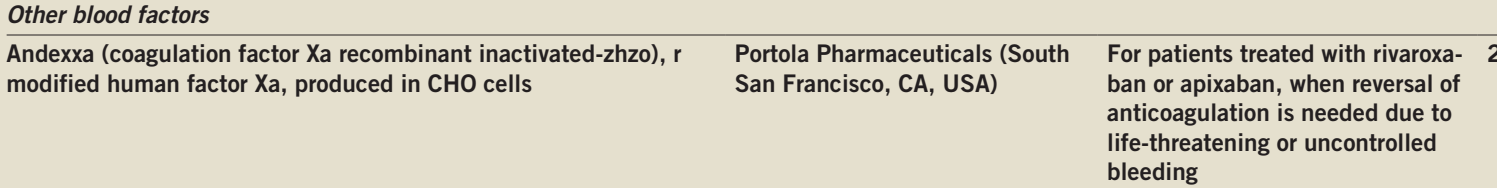

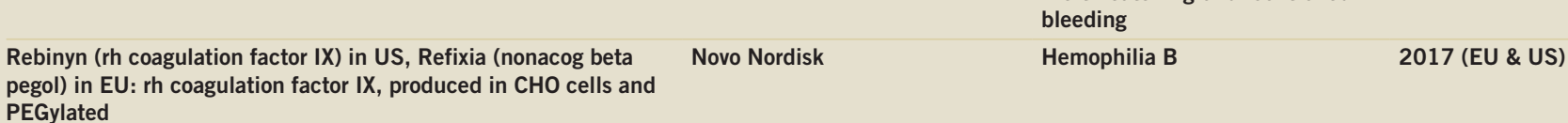

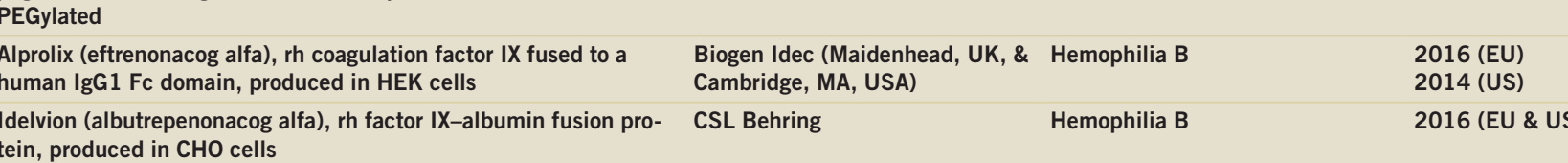

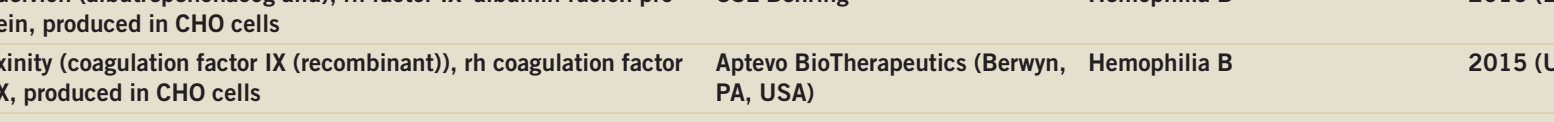

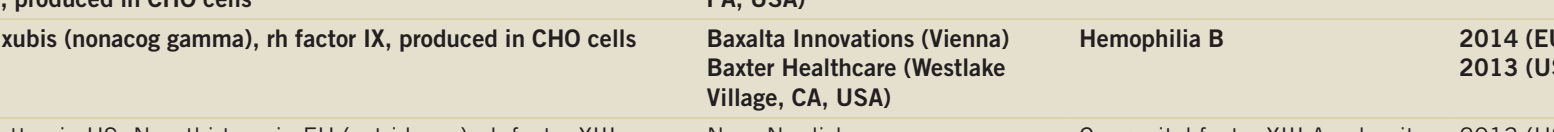

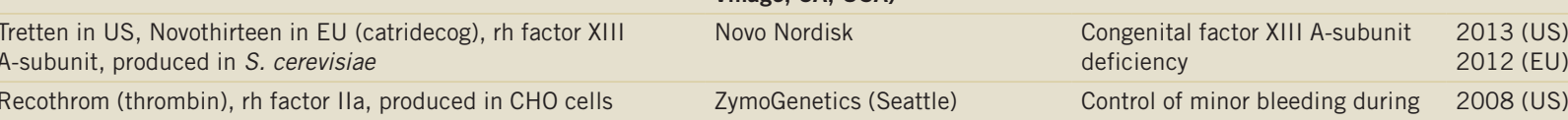

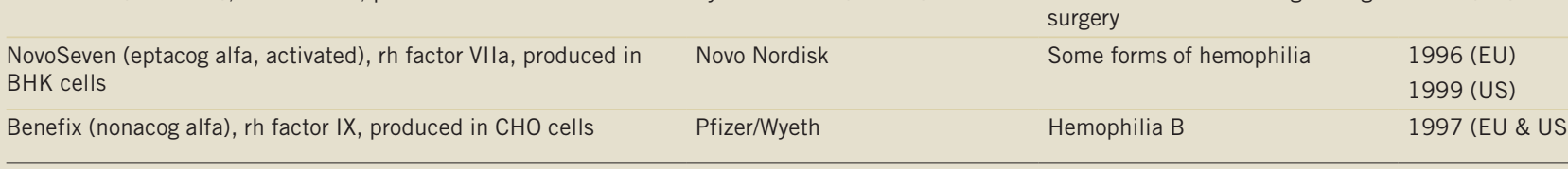

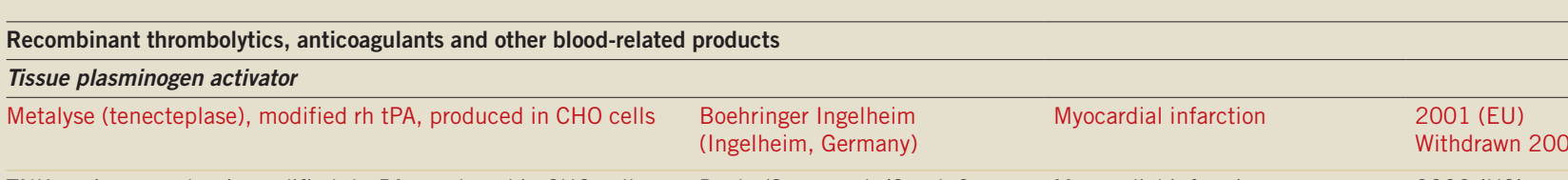

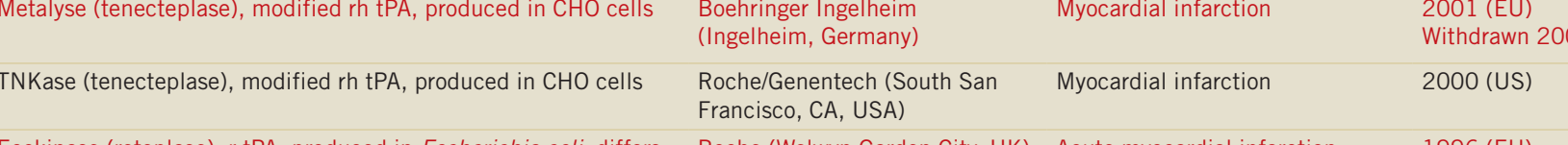

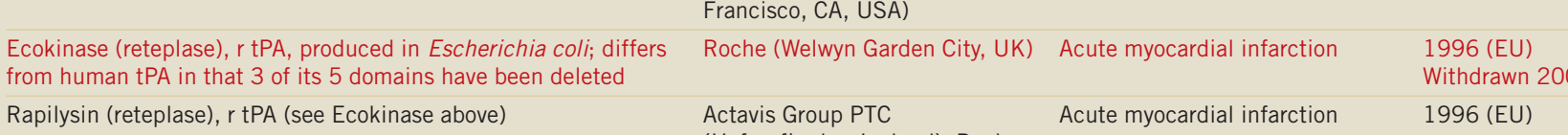

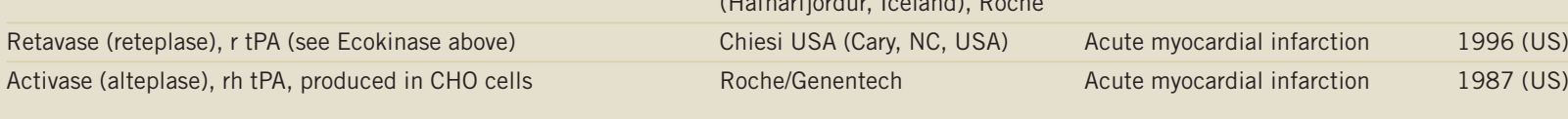

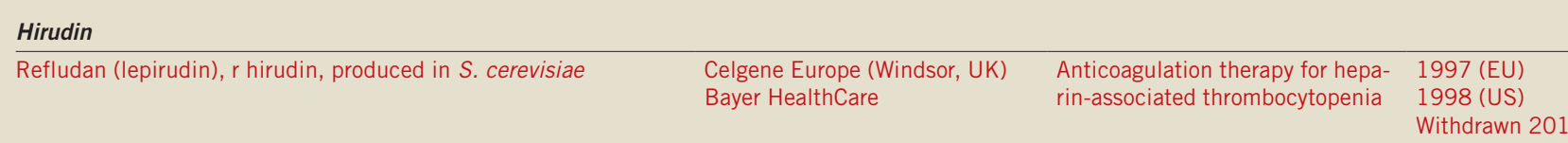

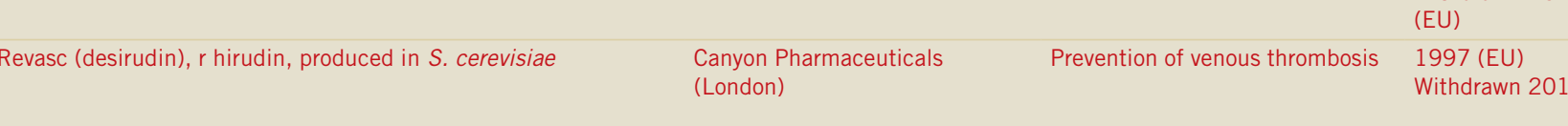

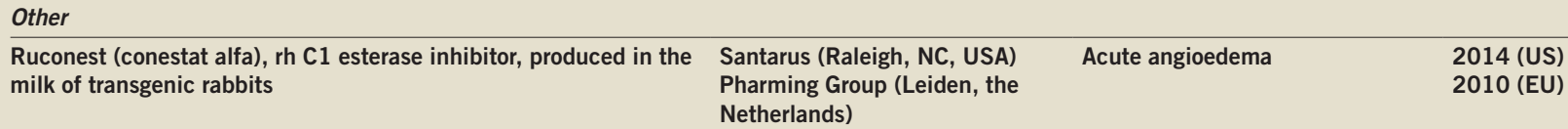

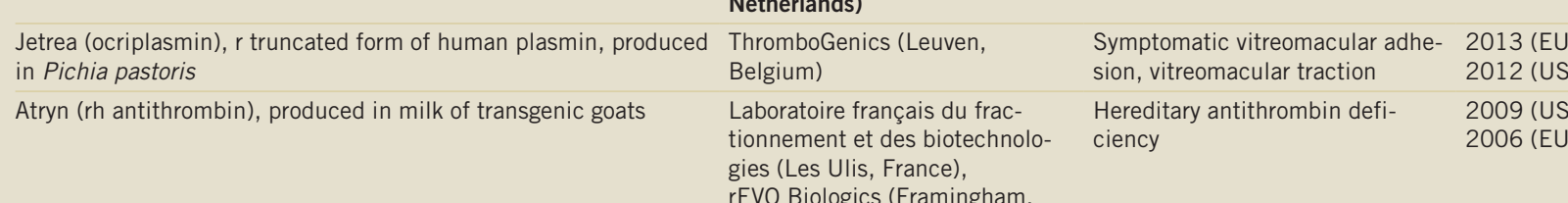

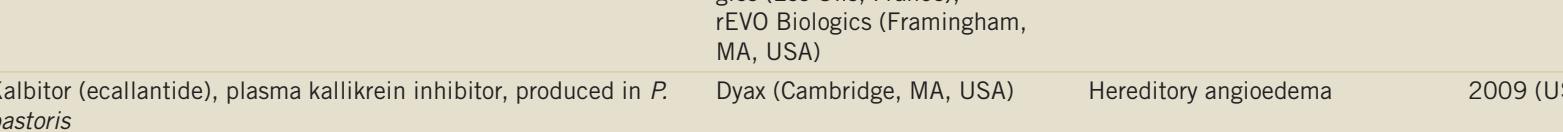

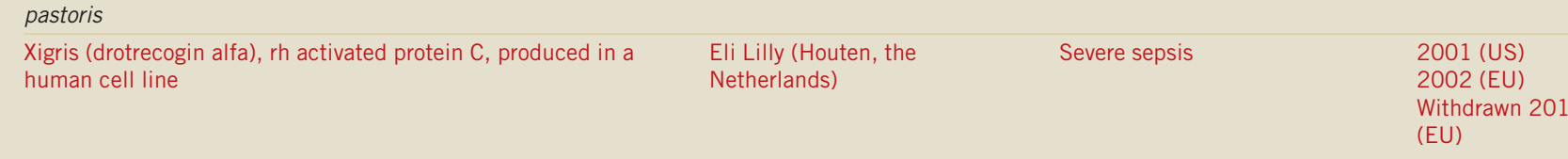

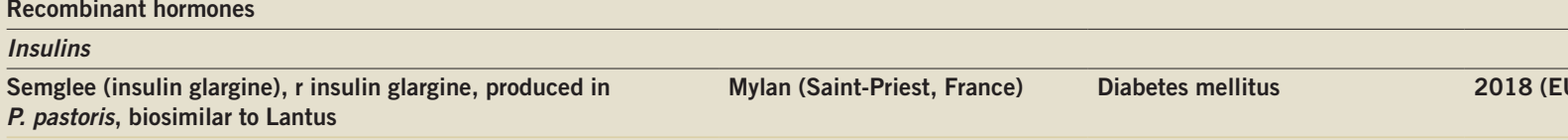

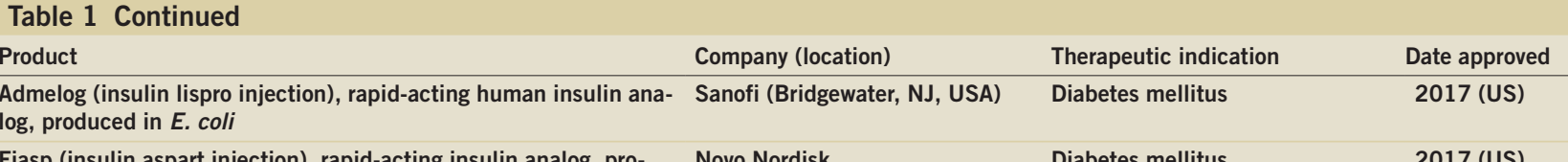

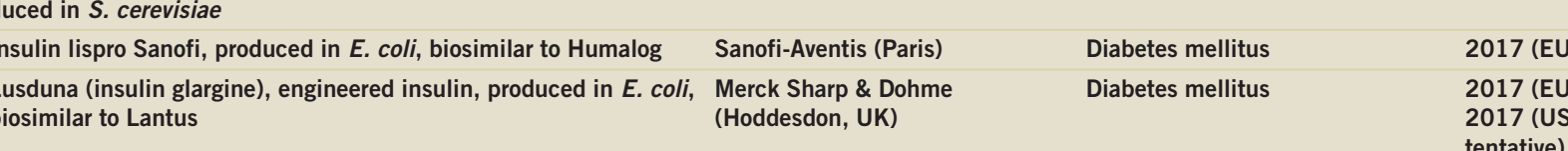

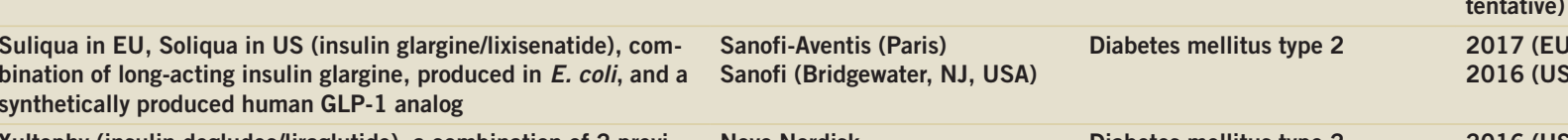

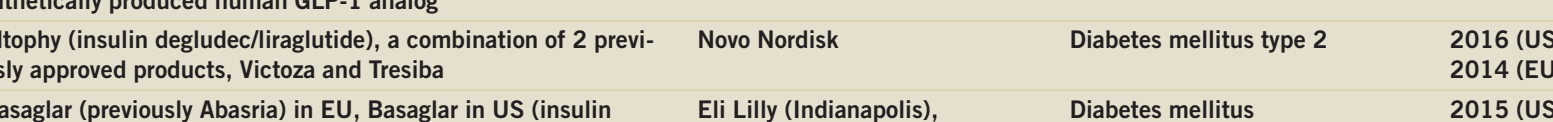

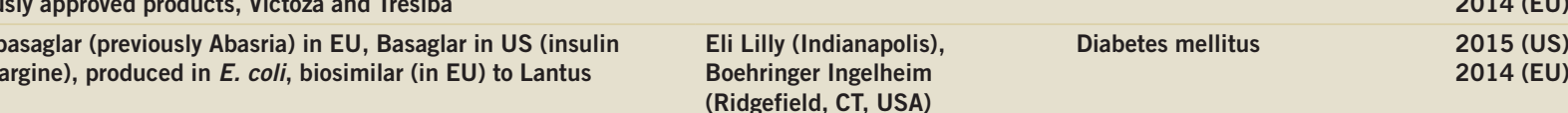

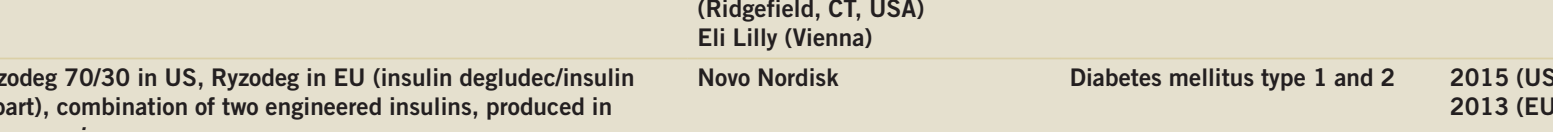

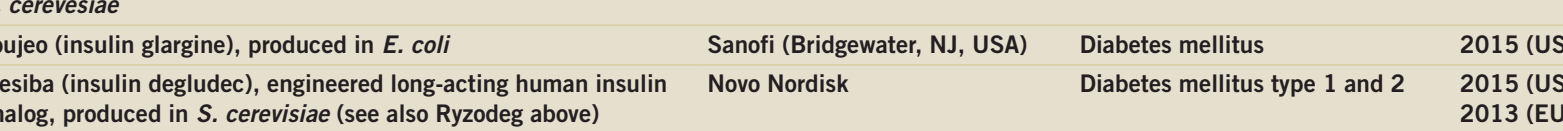

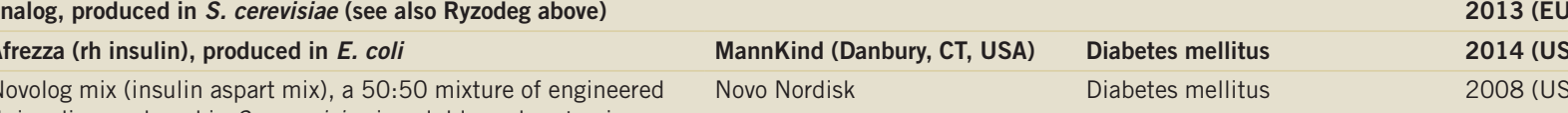

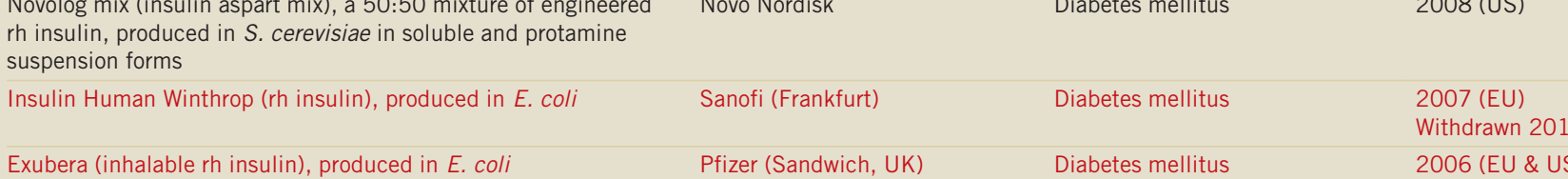

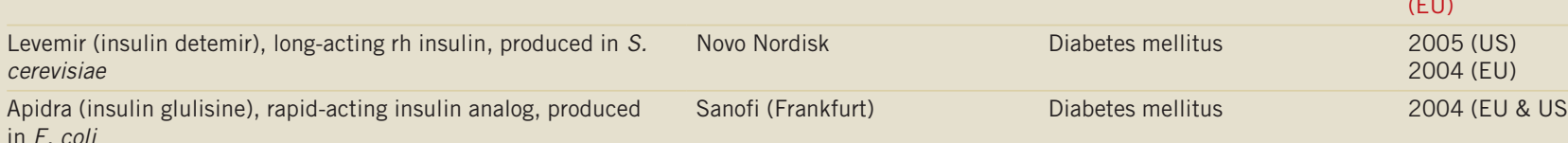

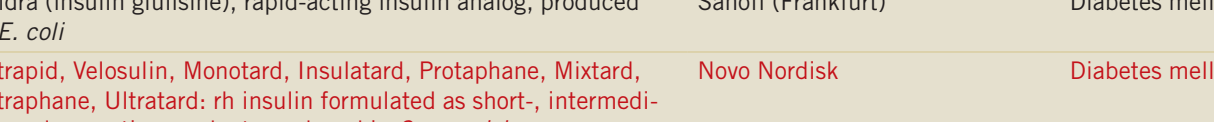

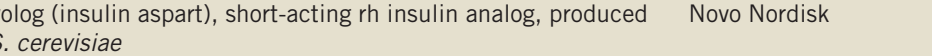

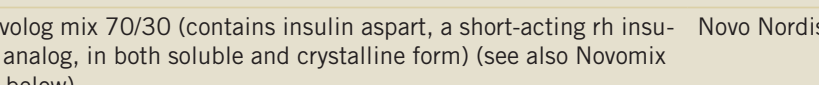

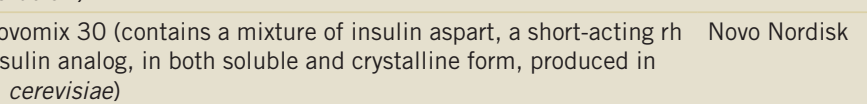

and

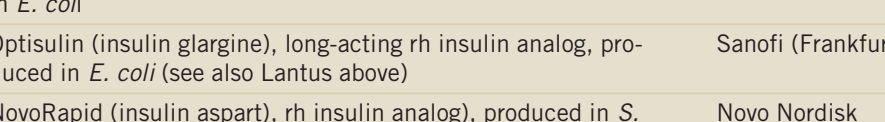

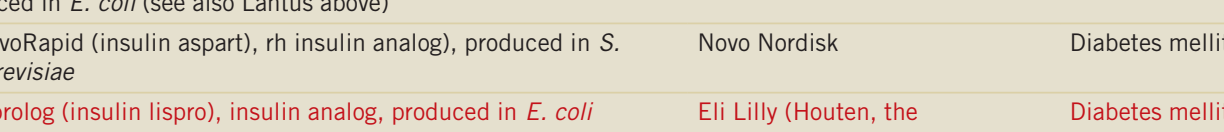

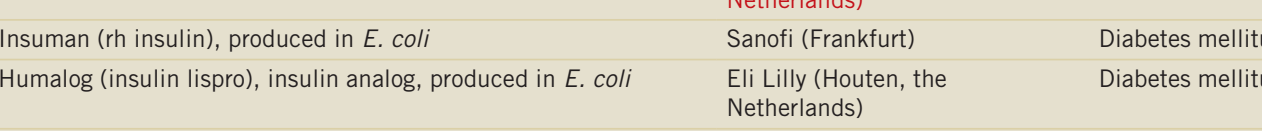

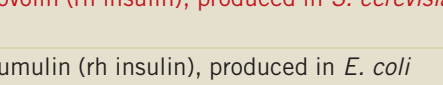

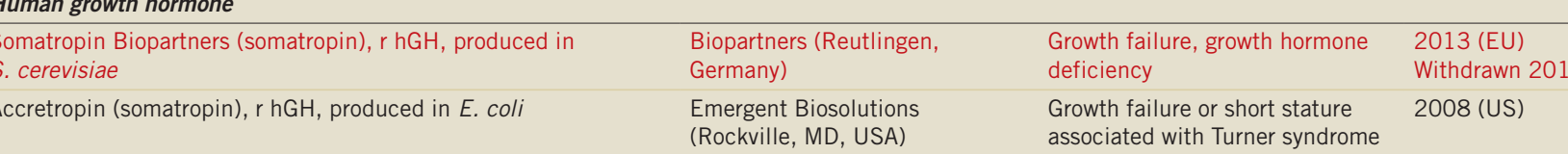

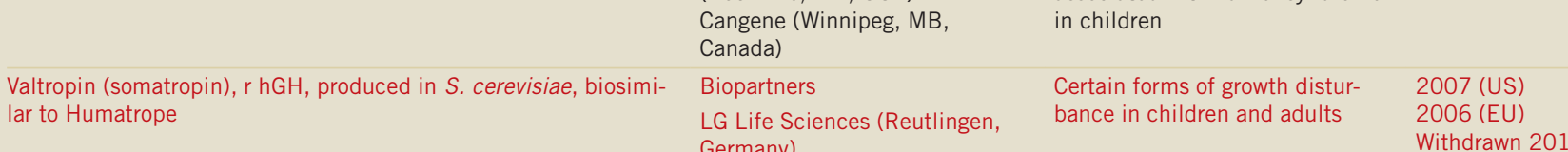

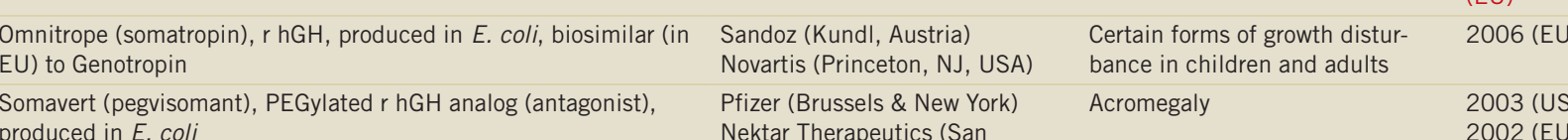

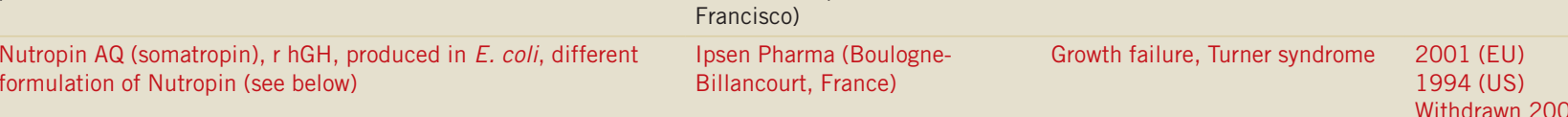

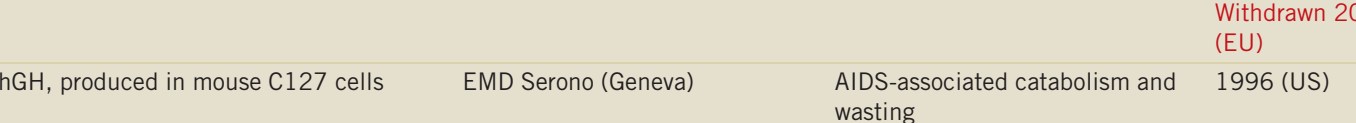

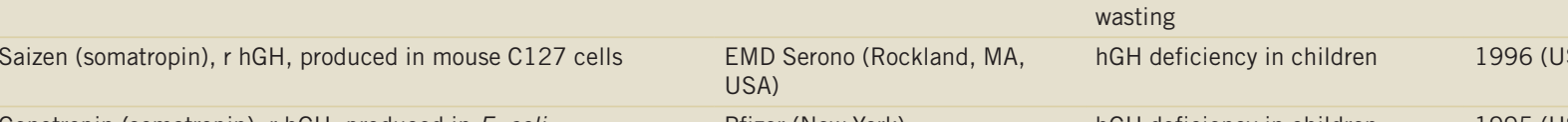

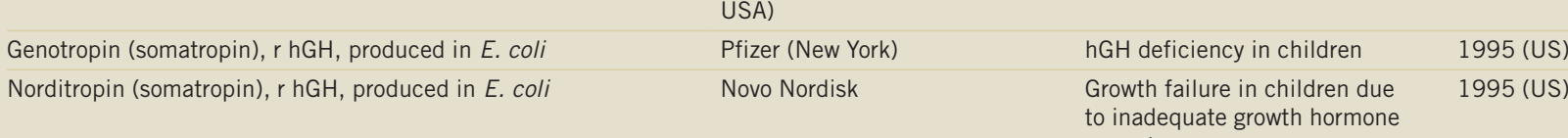

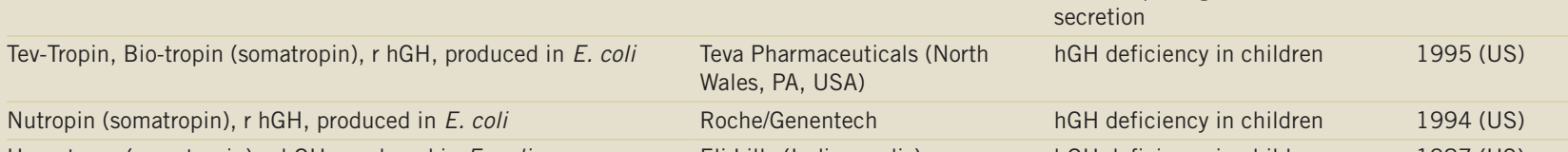

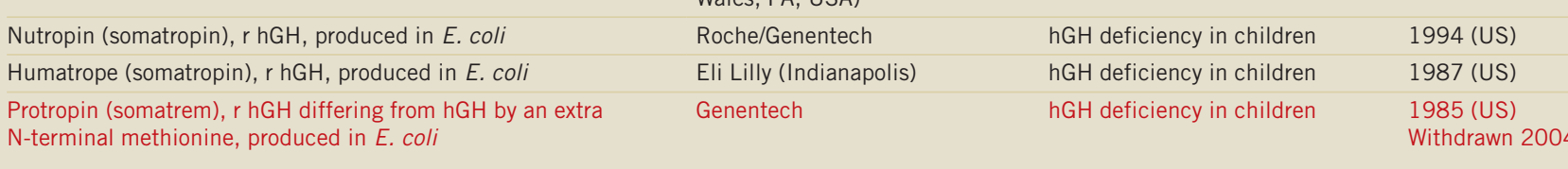

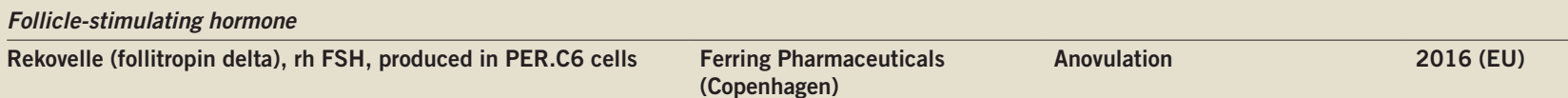

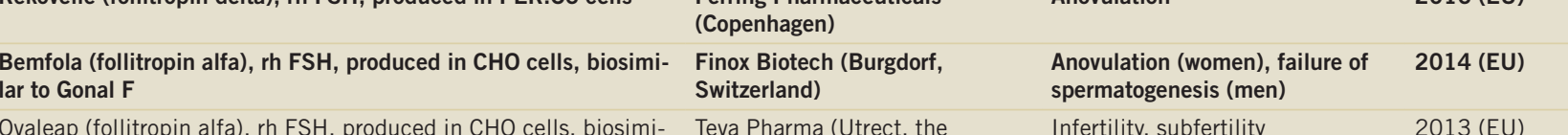

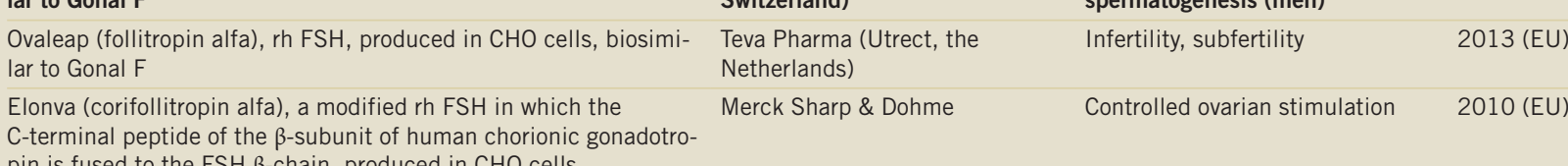

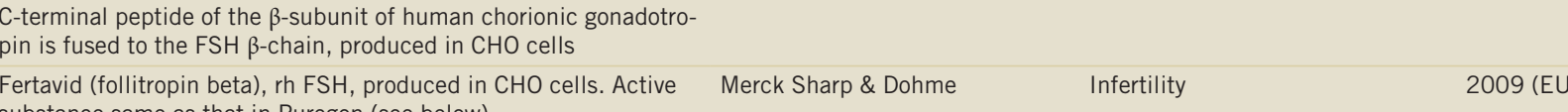

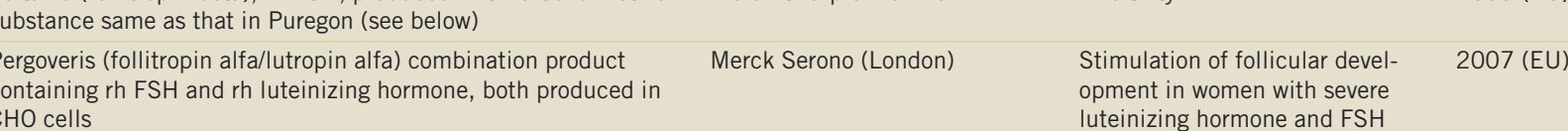

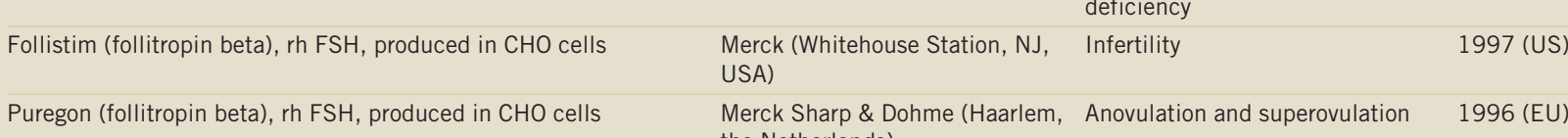

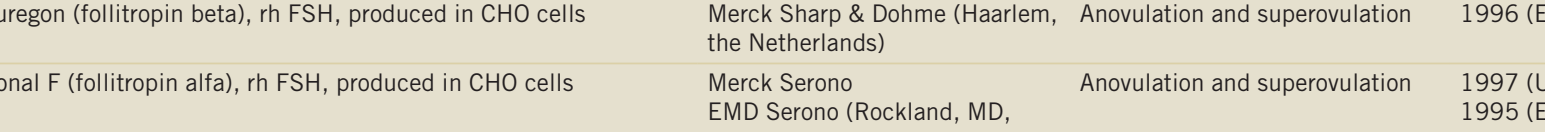

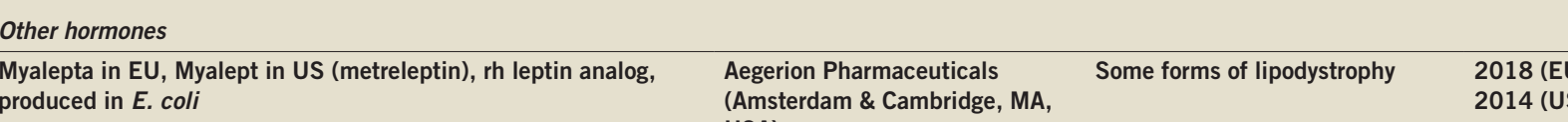

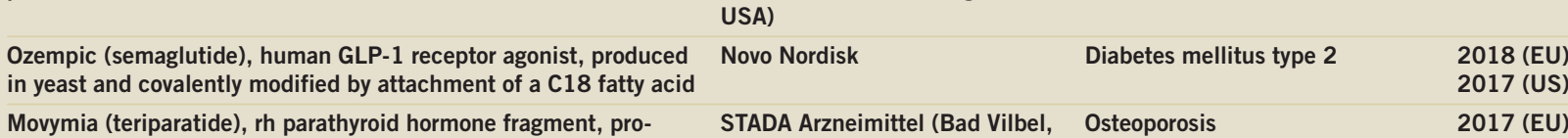

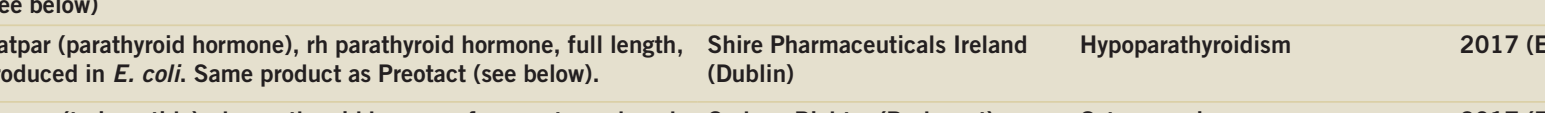

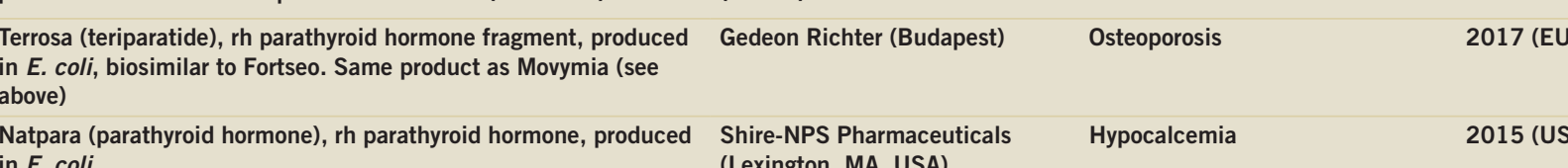

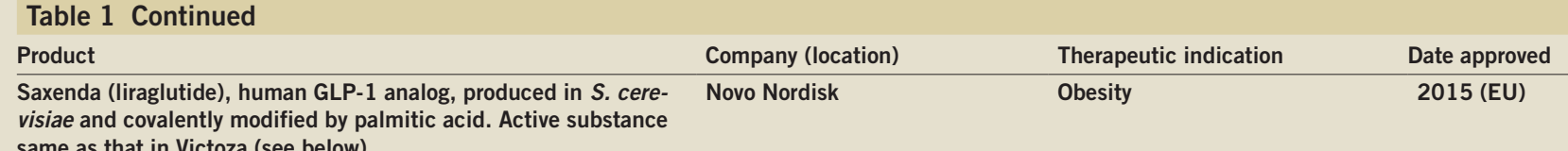

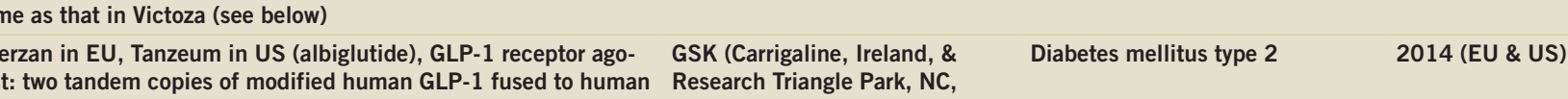

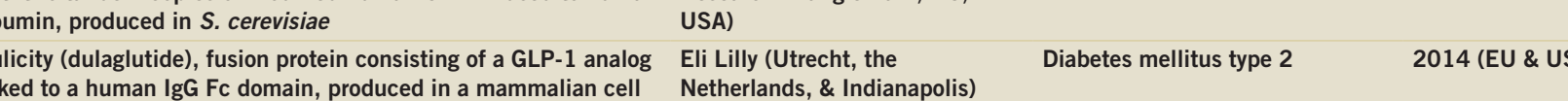

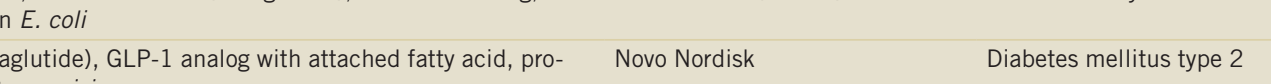

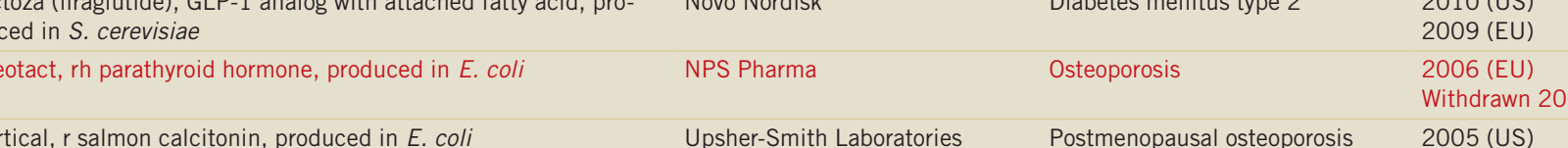

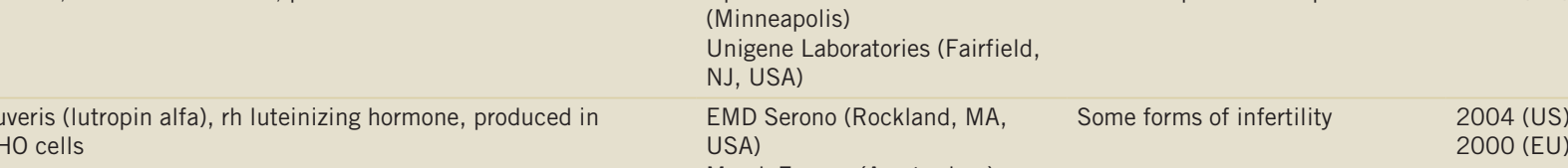

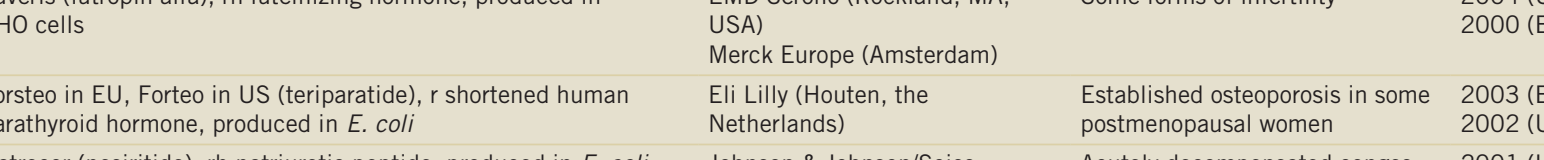

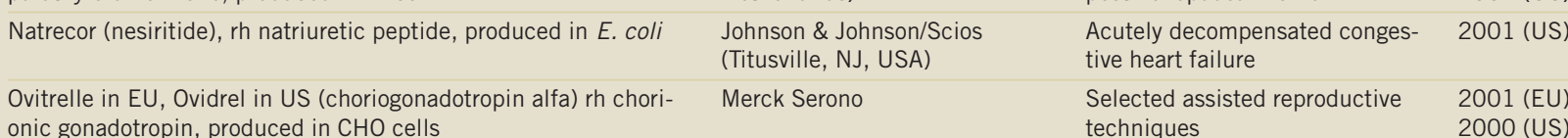

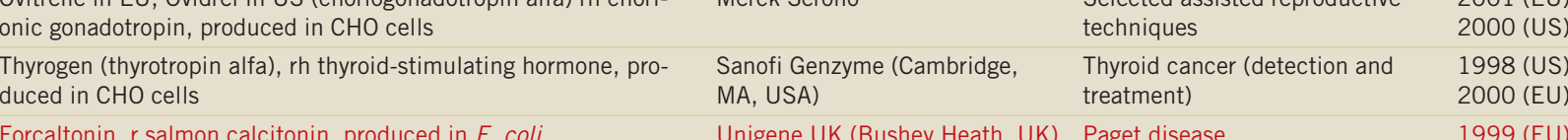

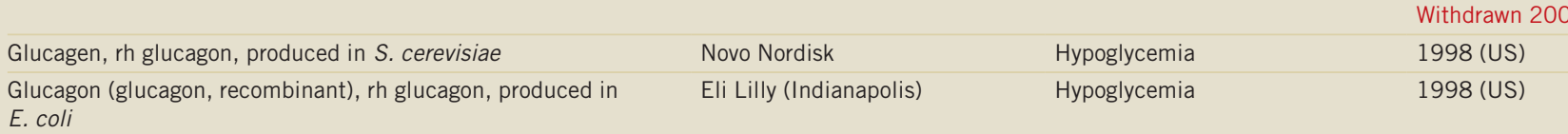

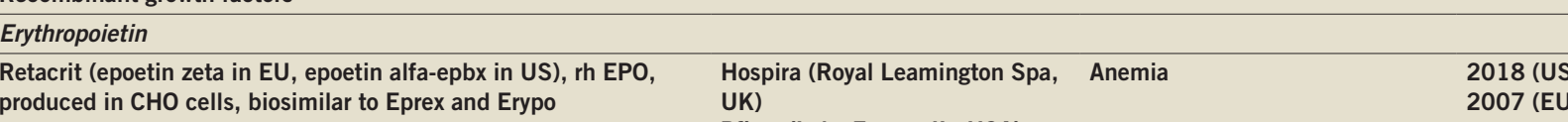

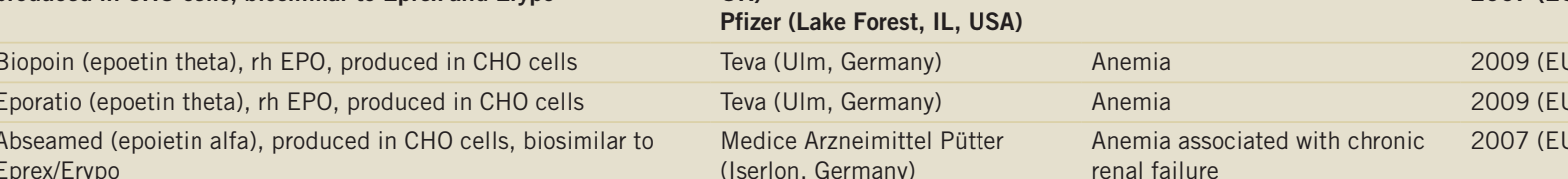

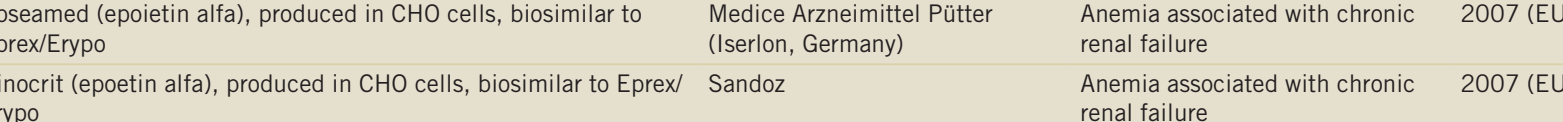

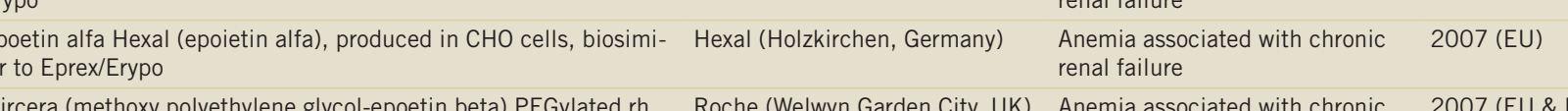

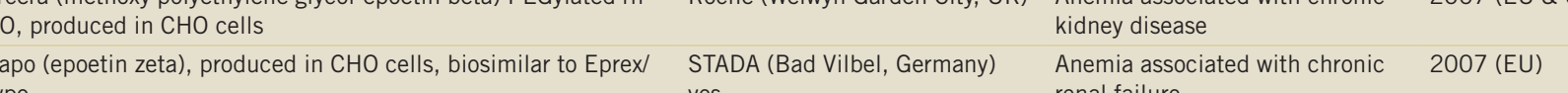

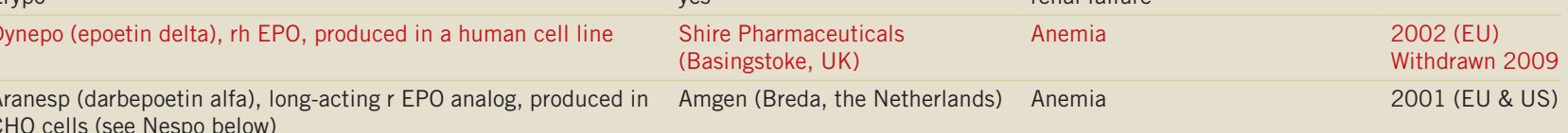

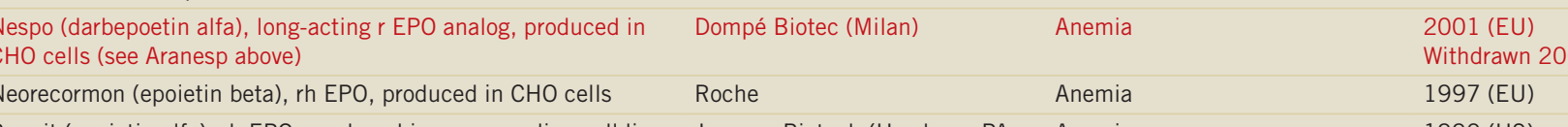

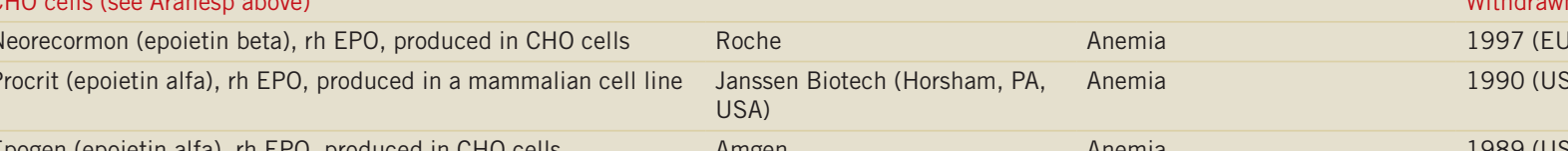

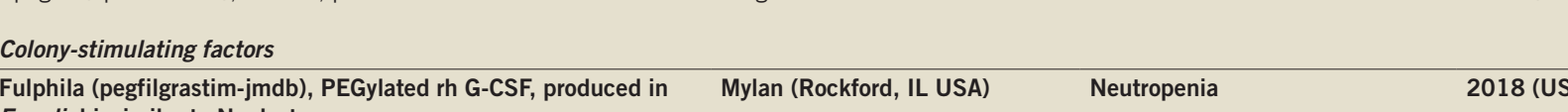

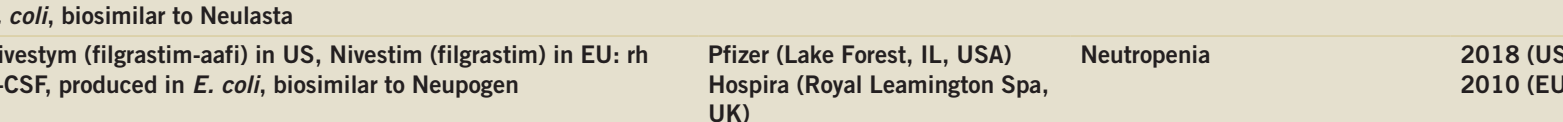

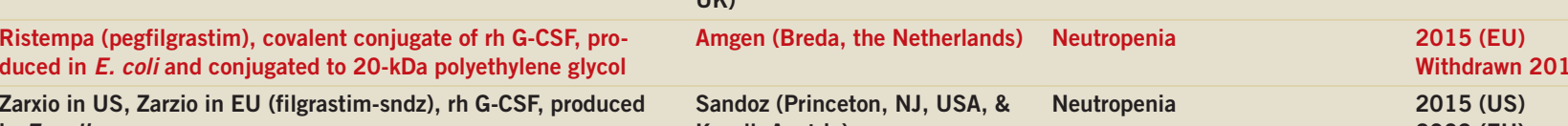

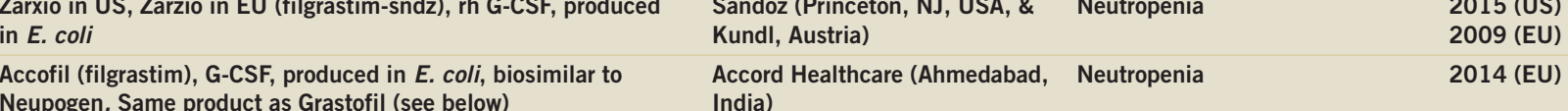

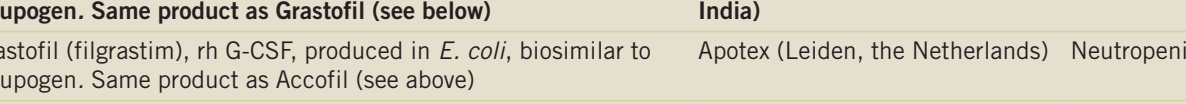

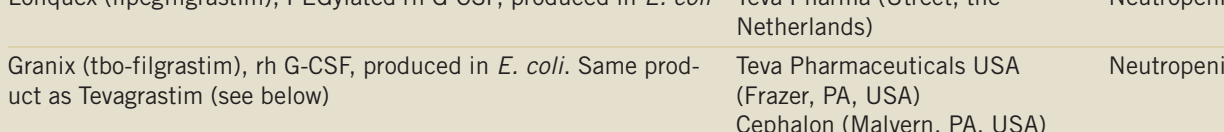

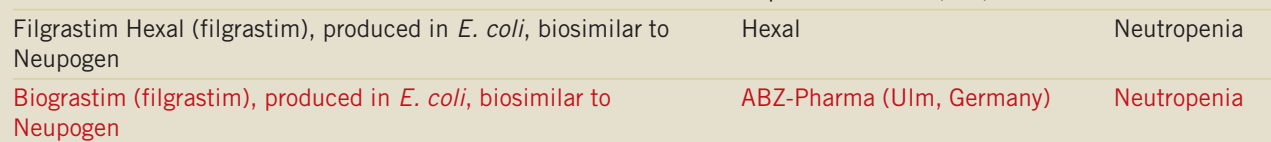

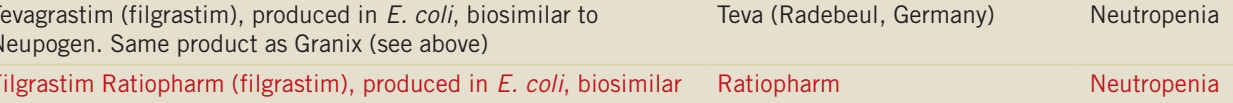

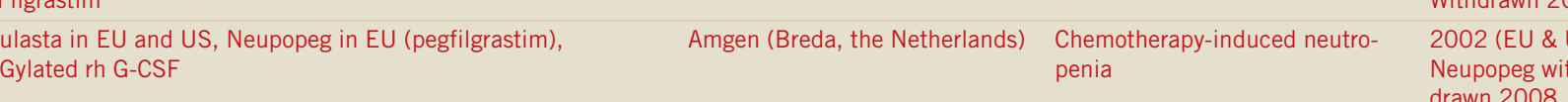

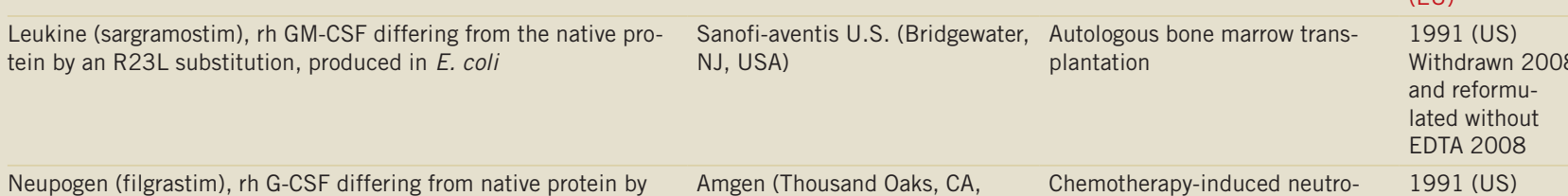

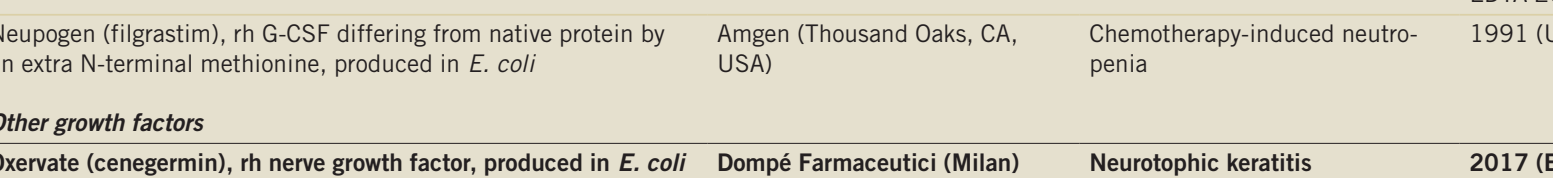

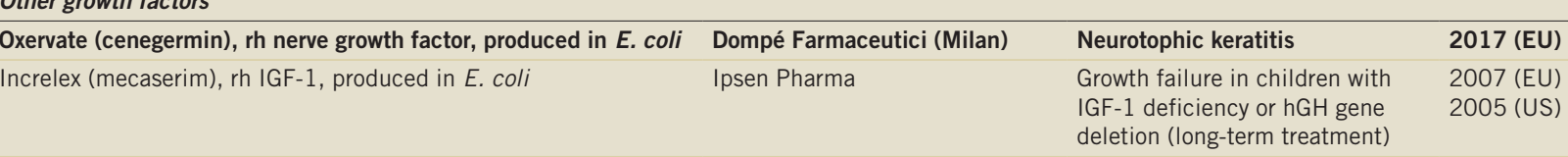

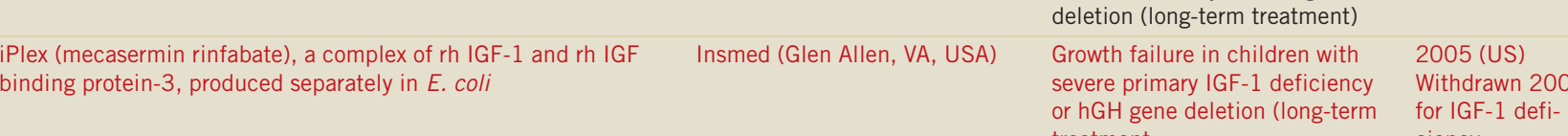

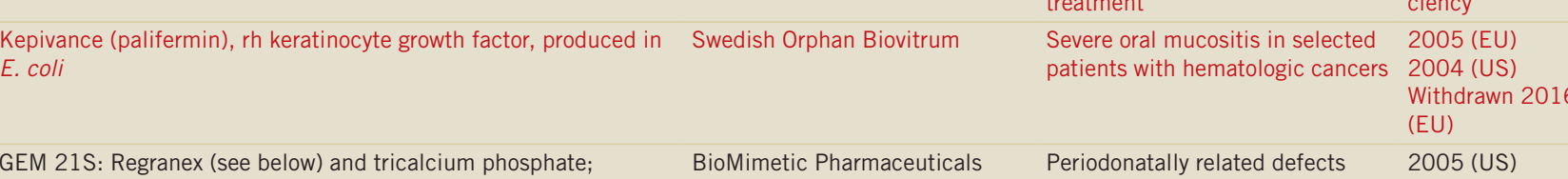

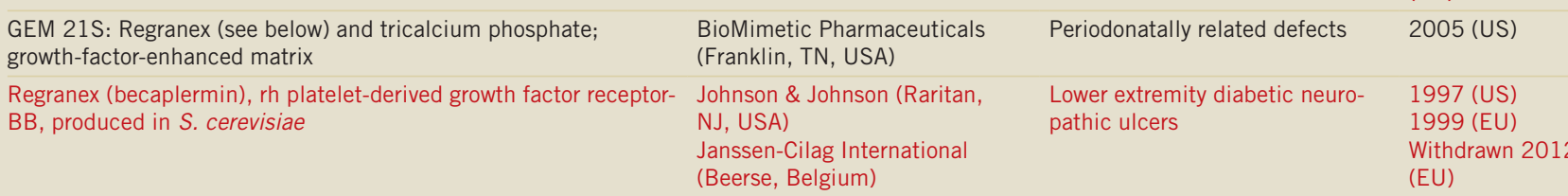

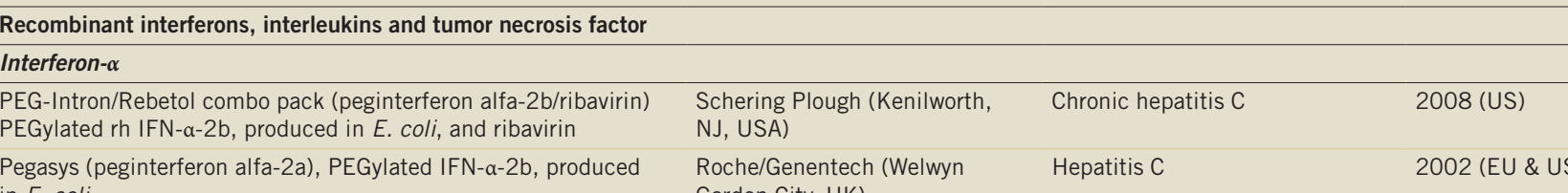

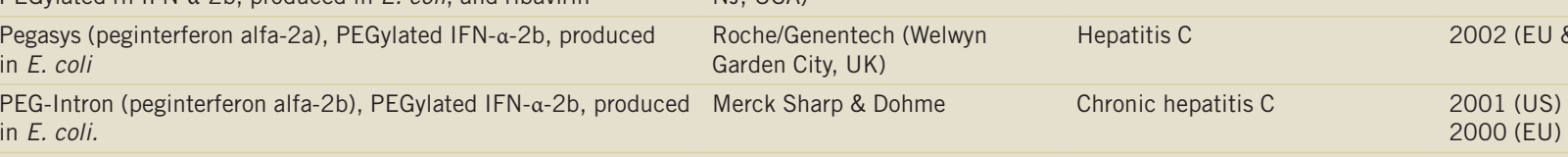

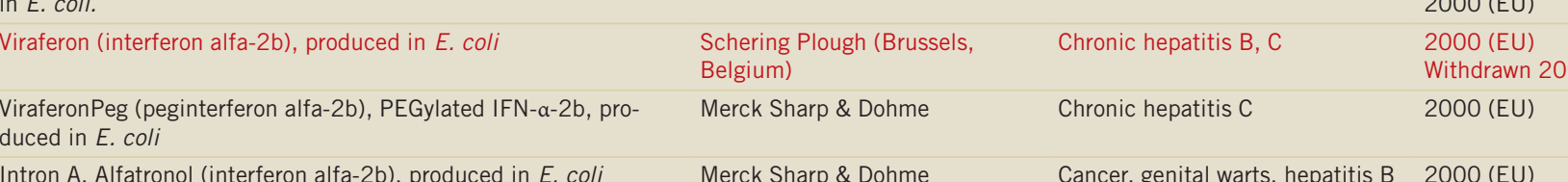

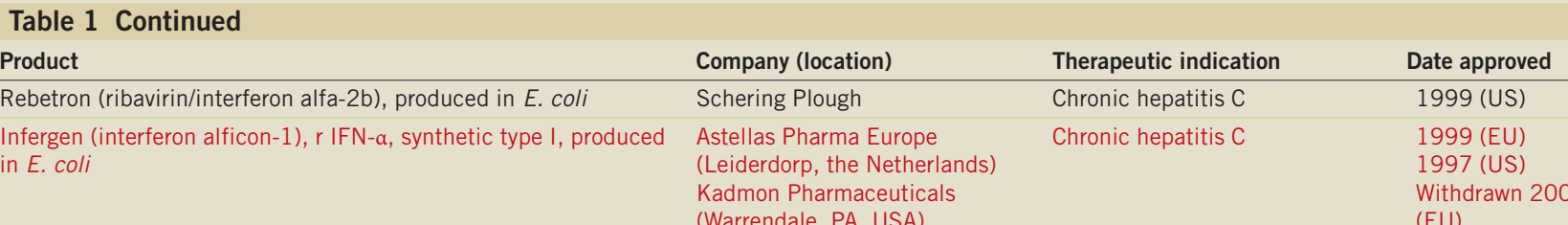

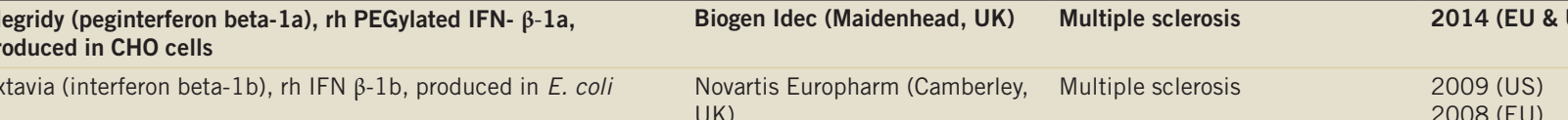

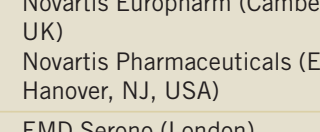

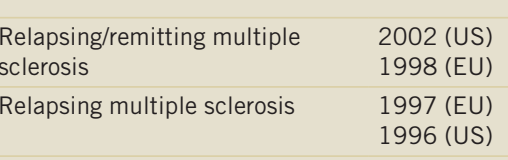

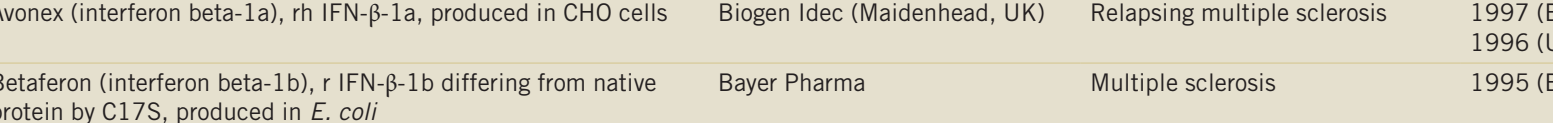

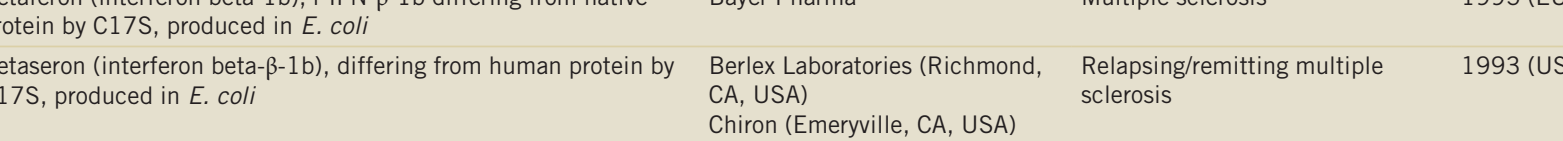

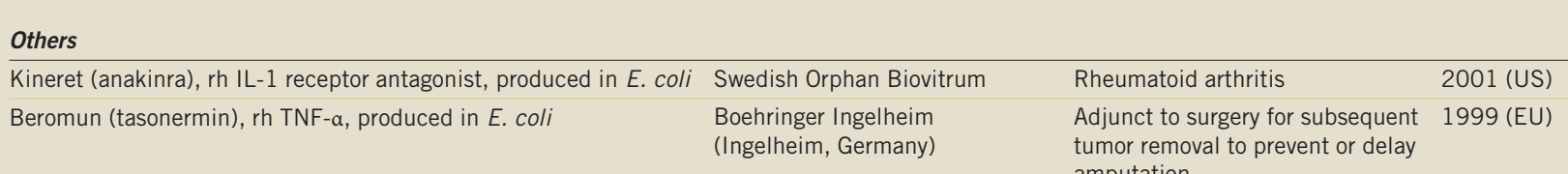

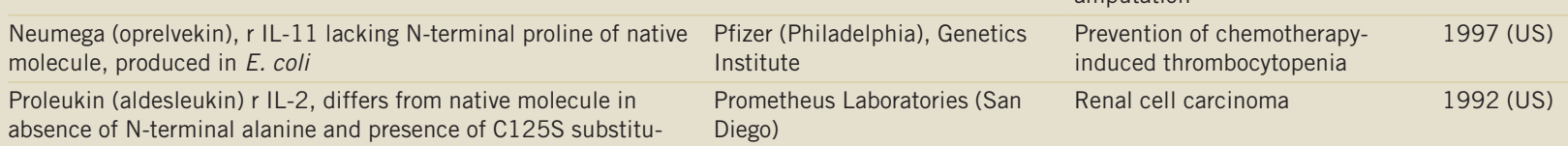

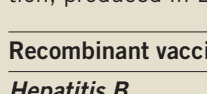

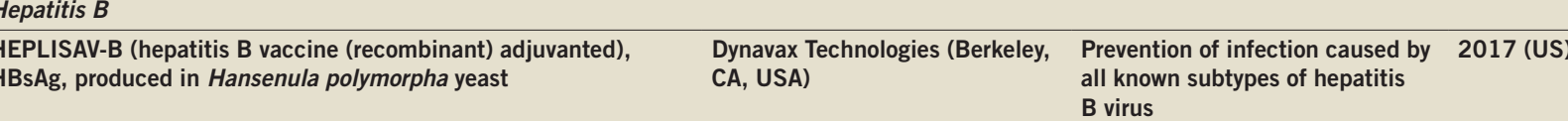

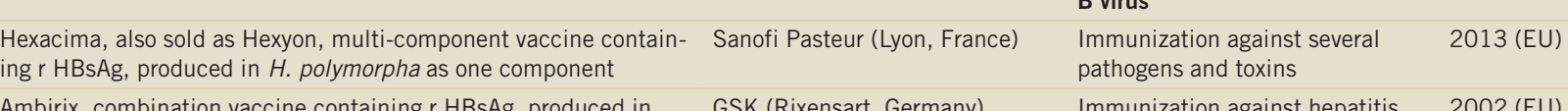

(a)

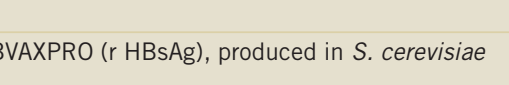

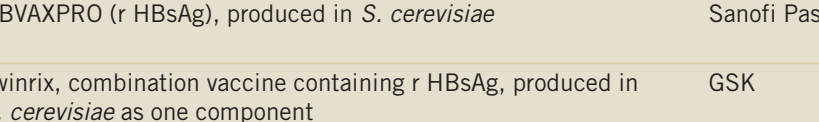

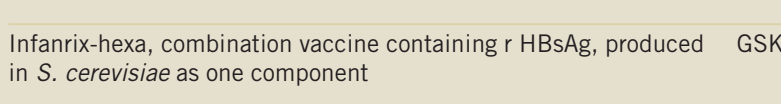

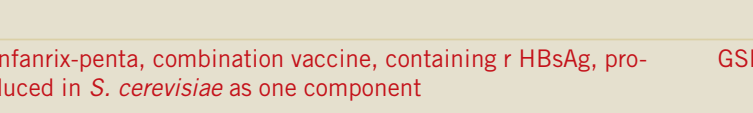

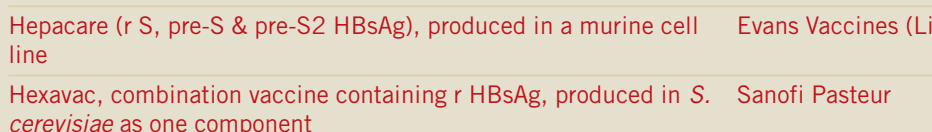

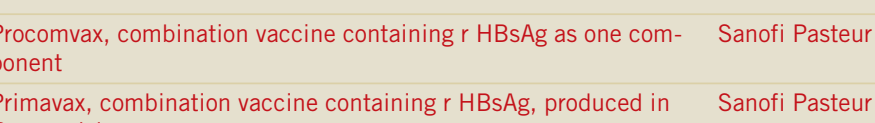

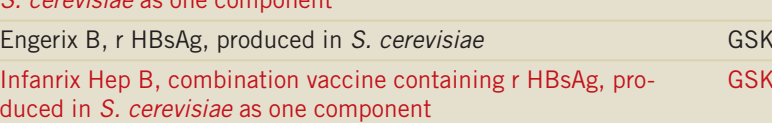

and

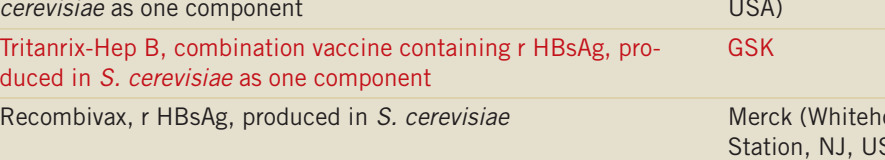

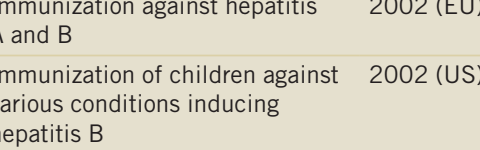

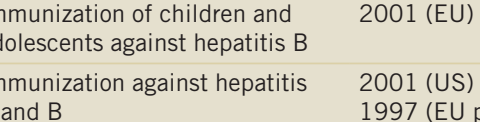

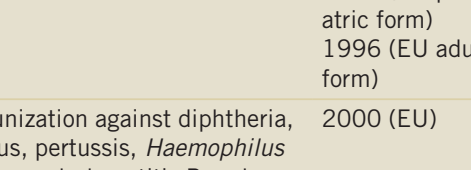

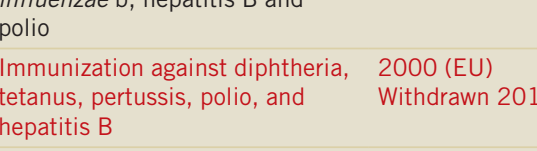

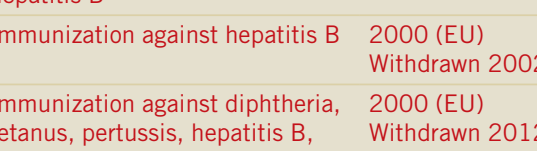

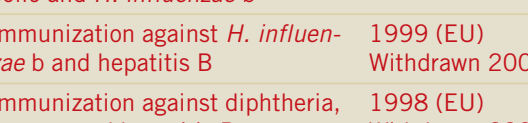

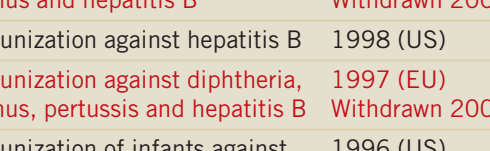

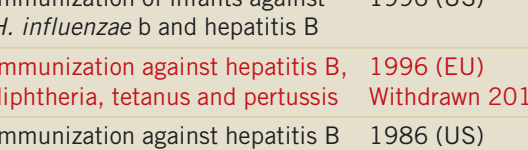

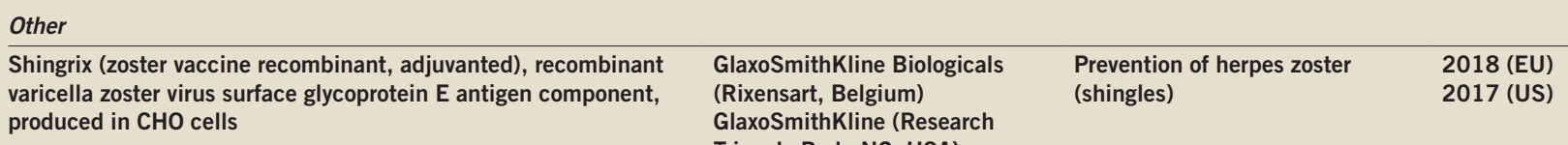

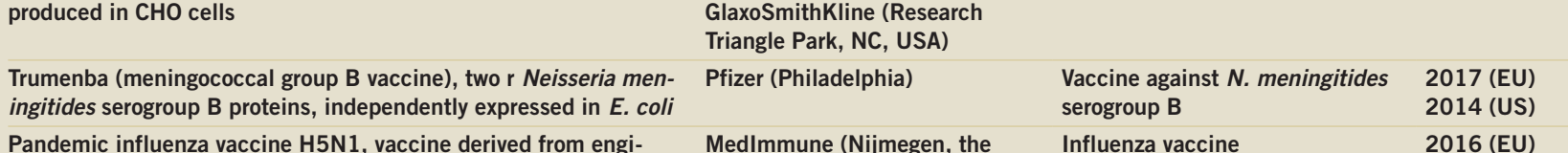

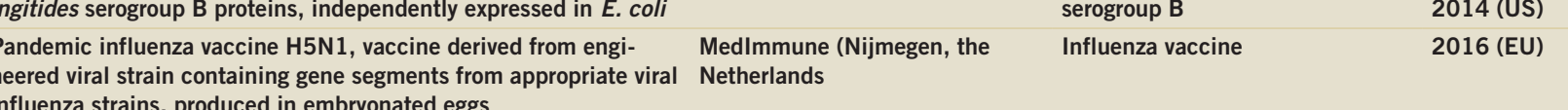

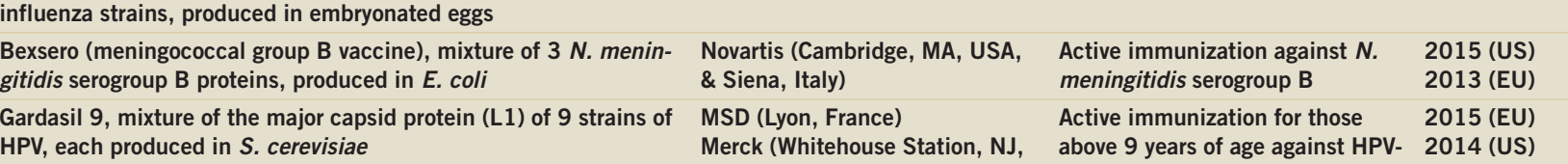

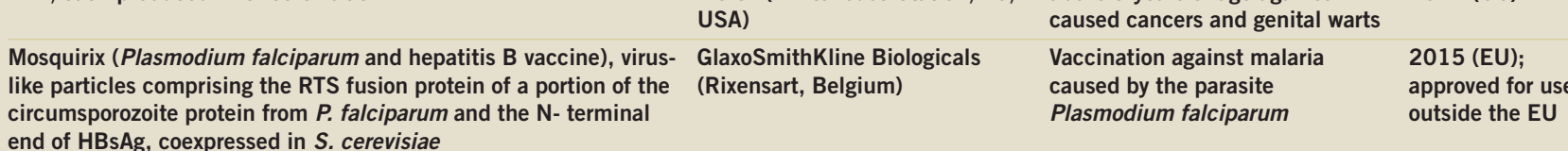

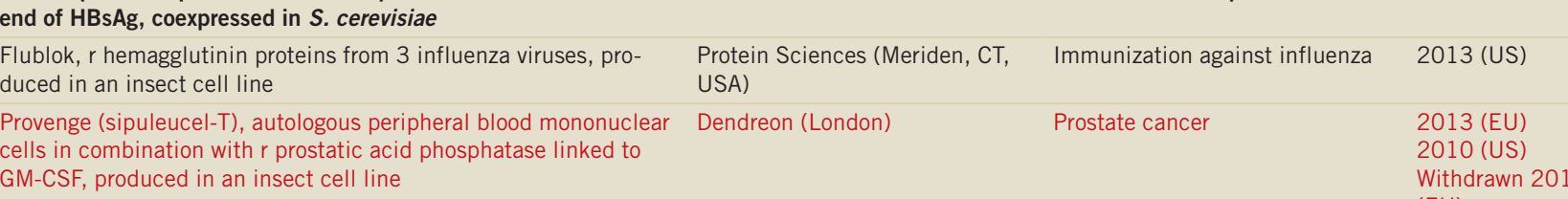

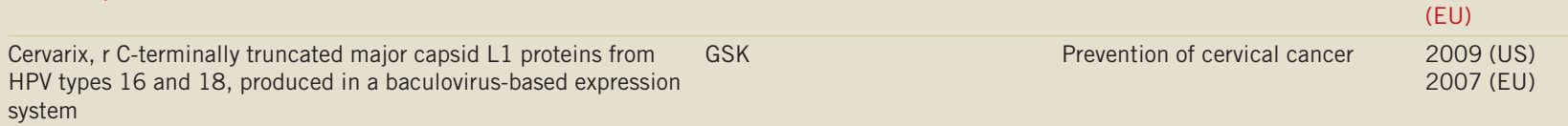

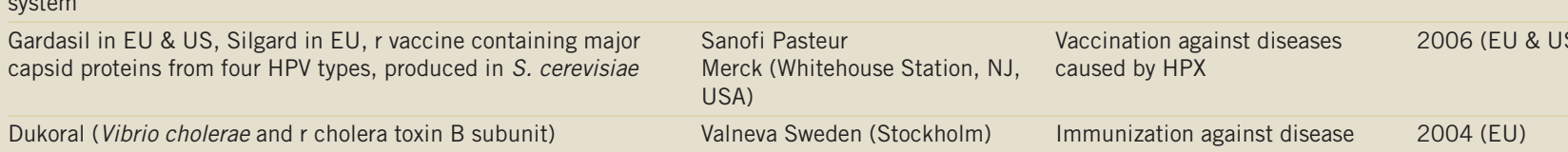

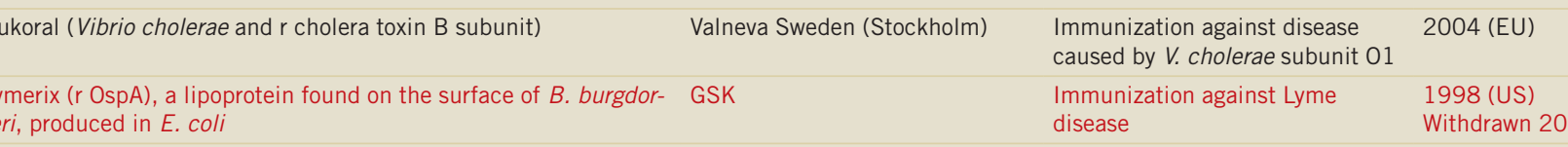

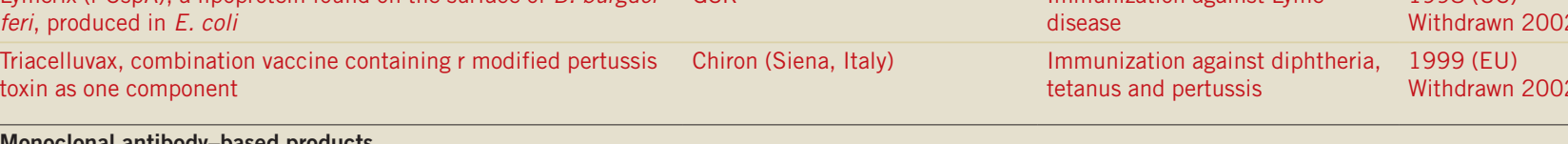

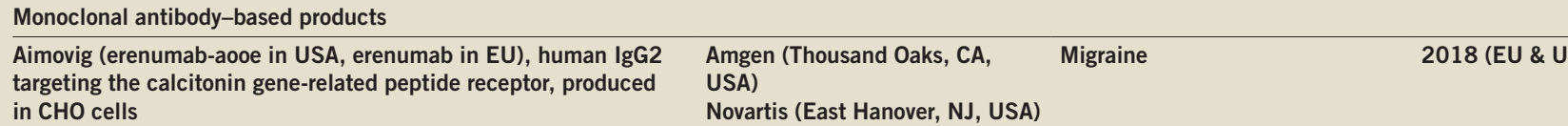

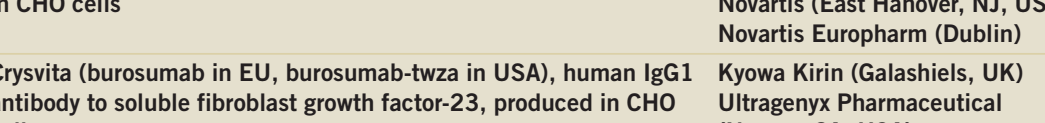

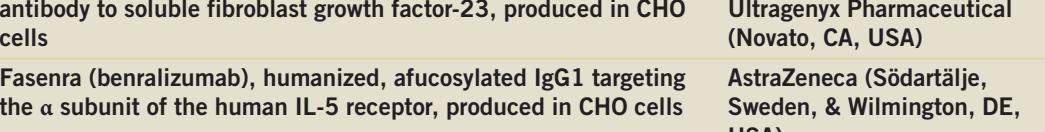

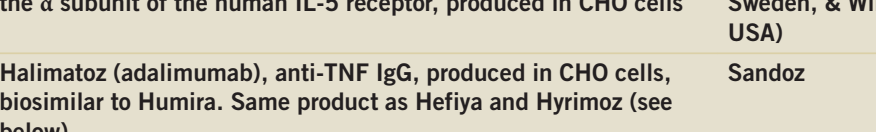

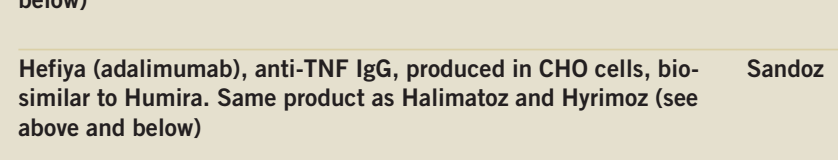

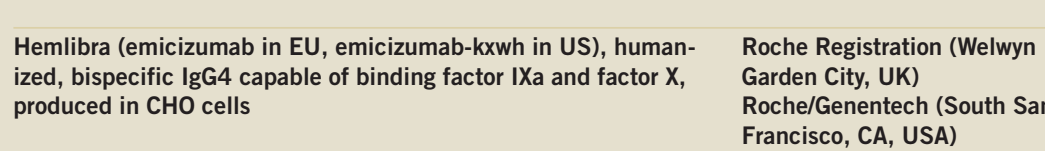




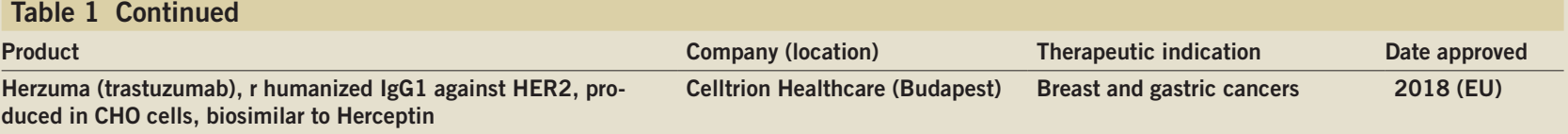

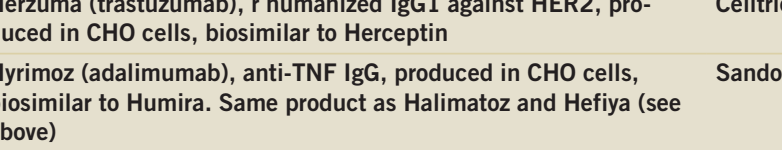

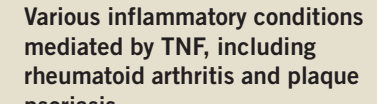

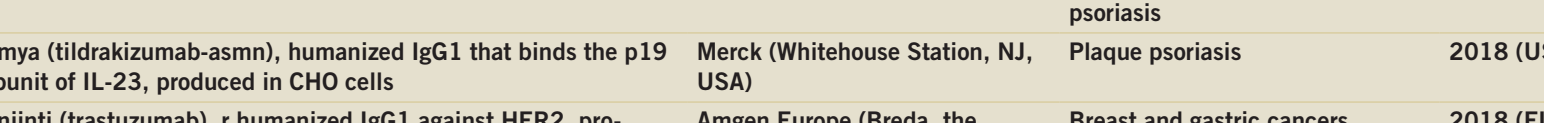

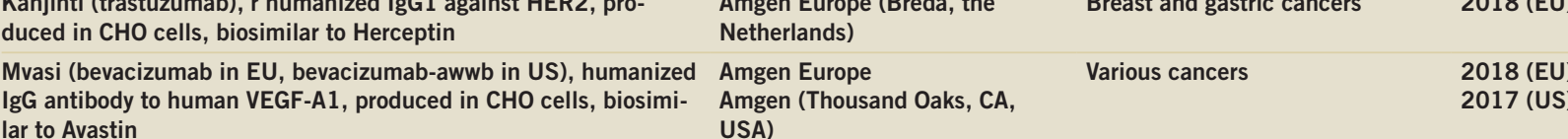

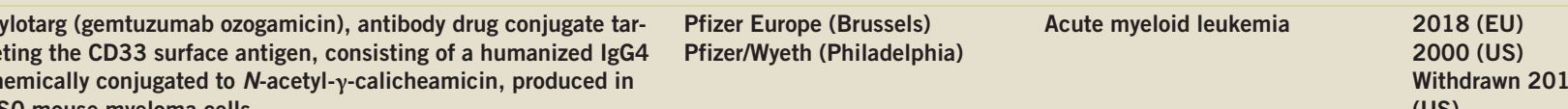

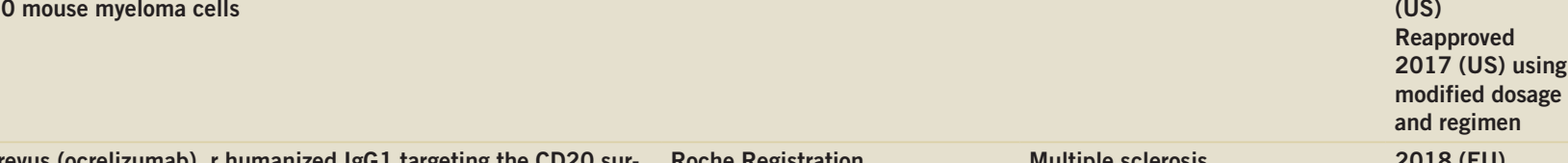

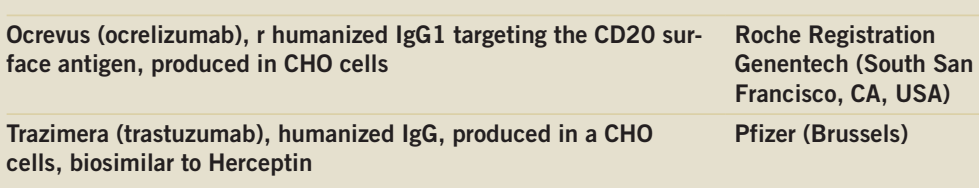

(1)

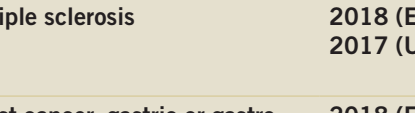

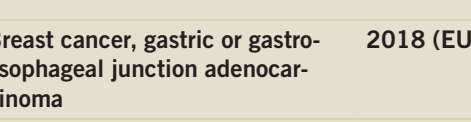

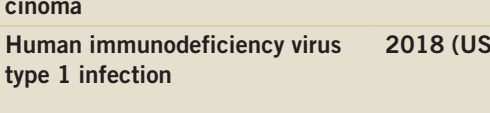

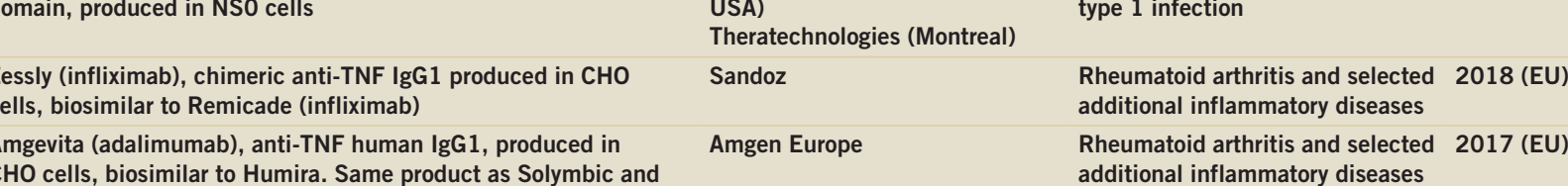

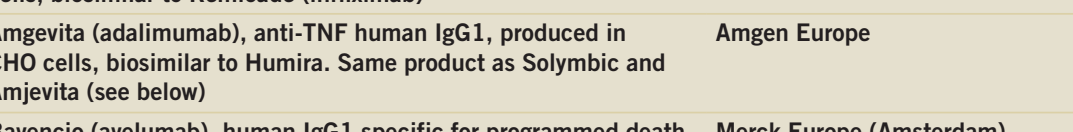

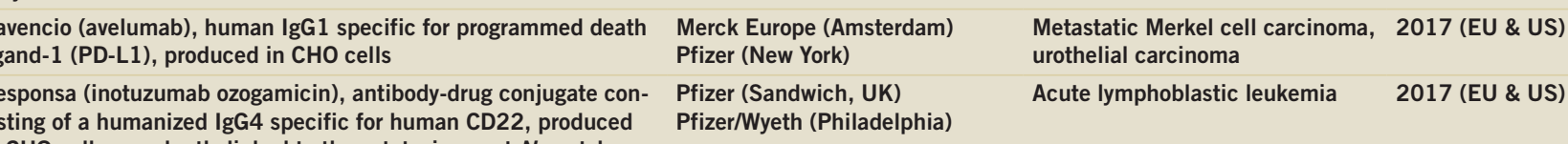

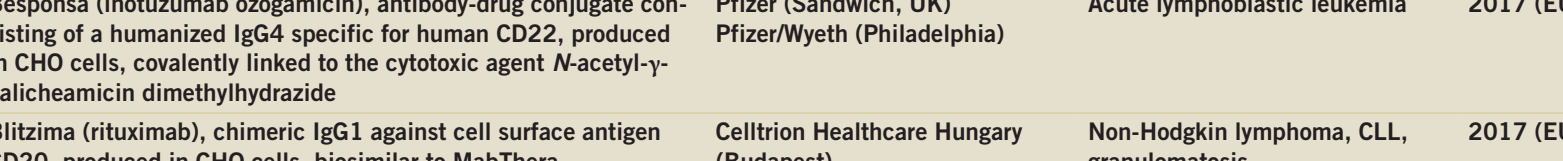

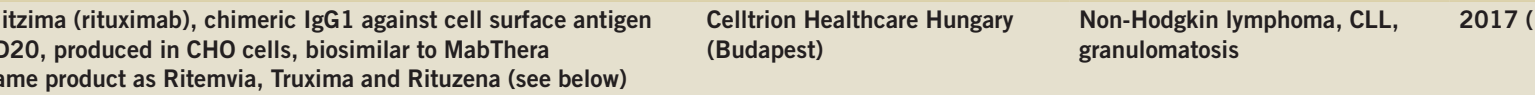

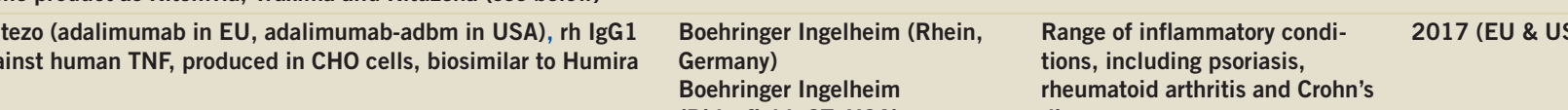

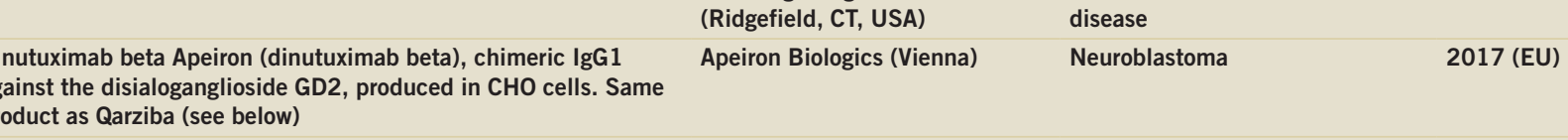

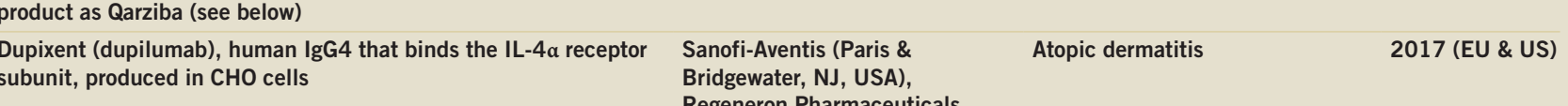

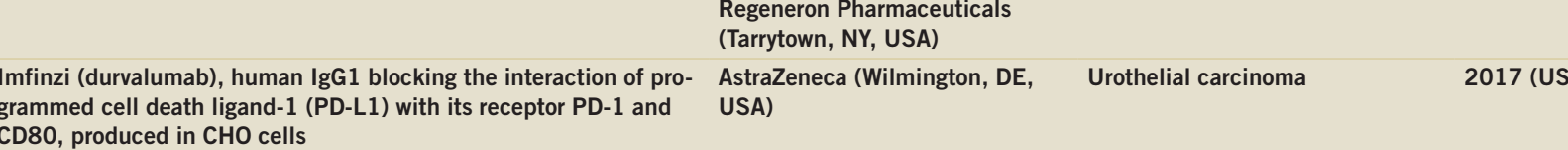

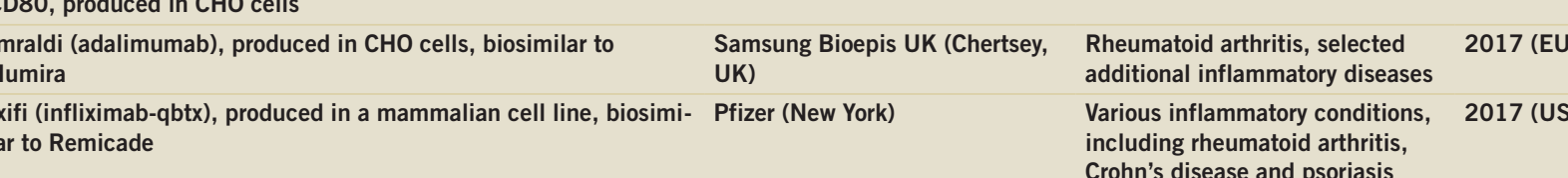

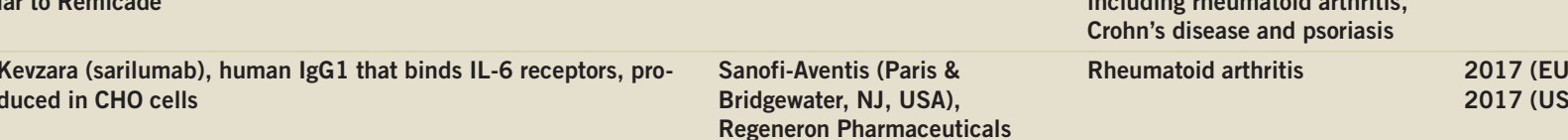

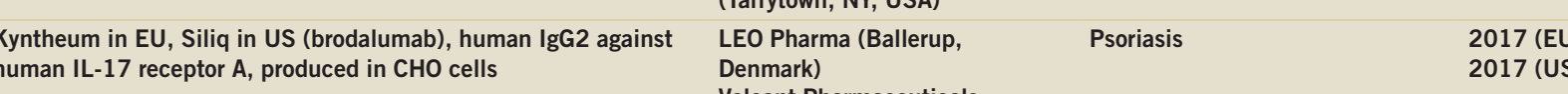

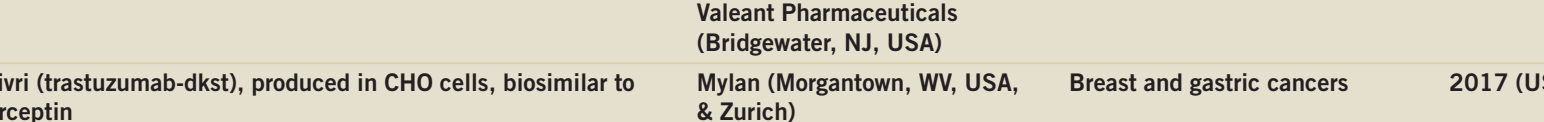

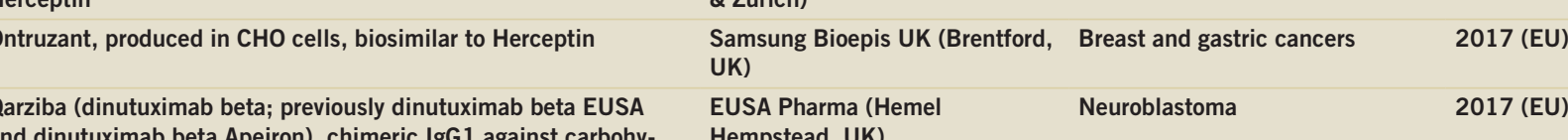

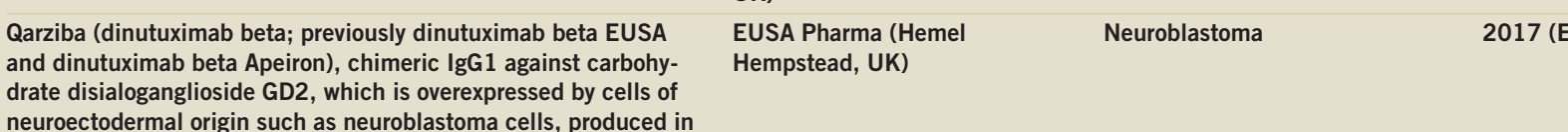

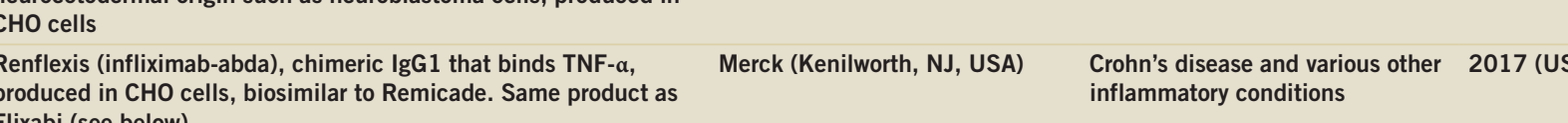

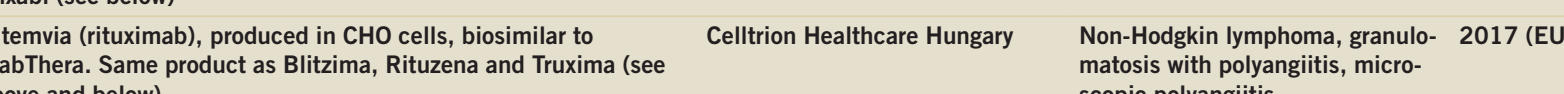

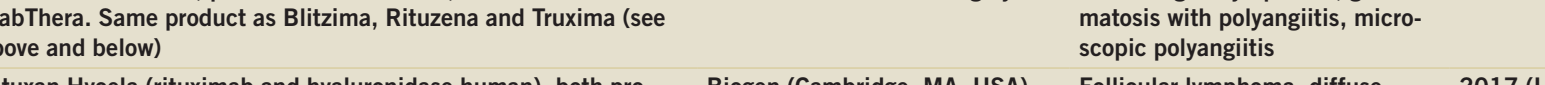

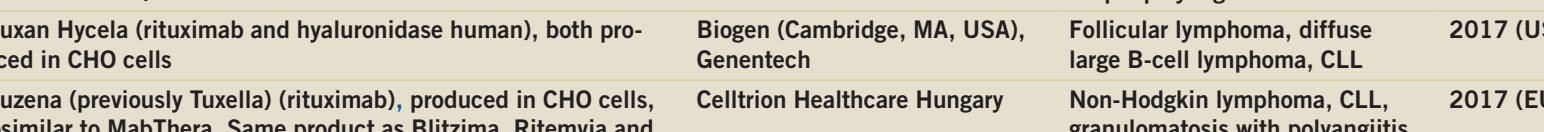

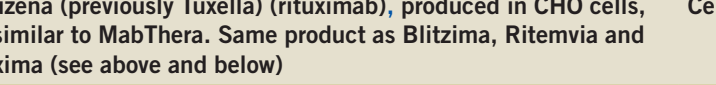

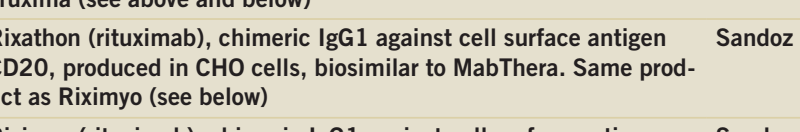

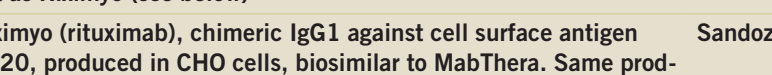

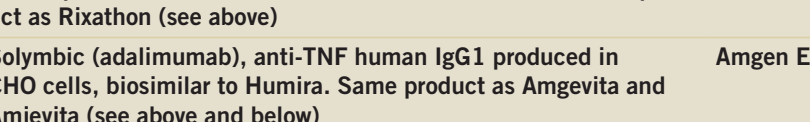

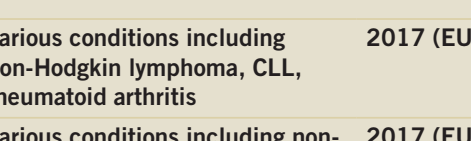

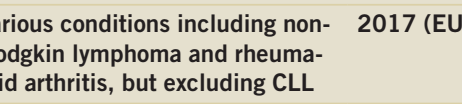

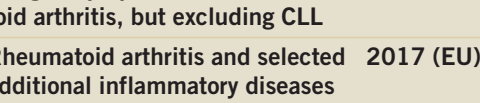

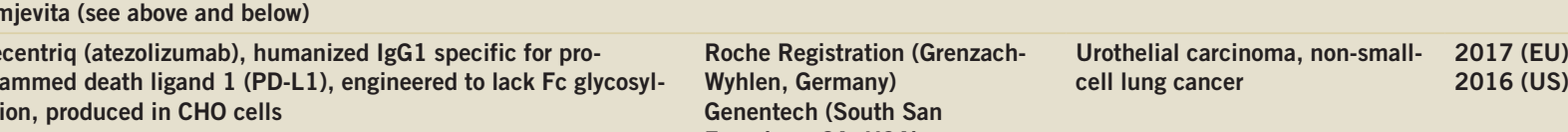

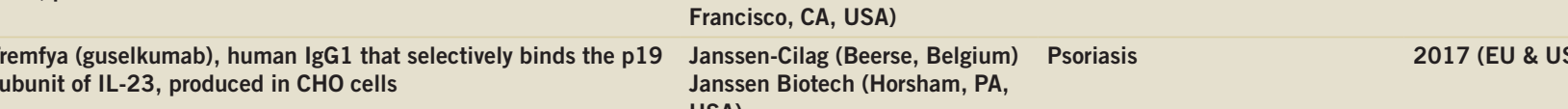

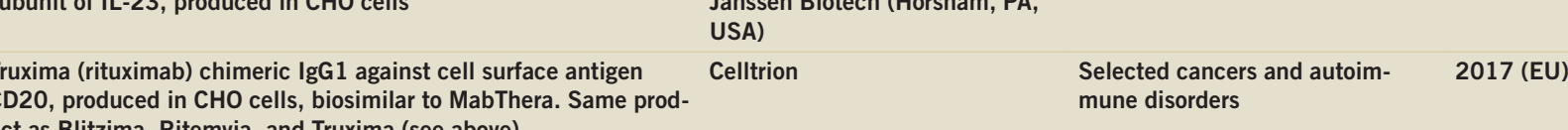

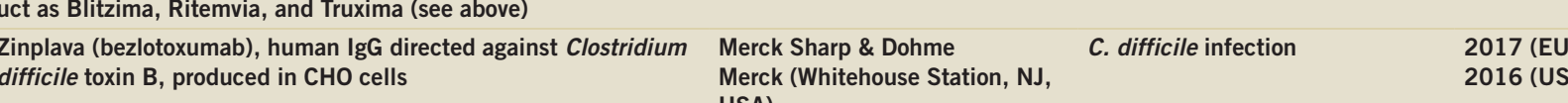

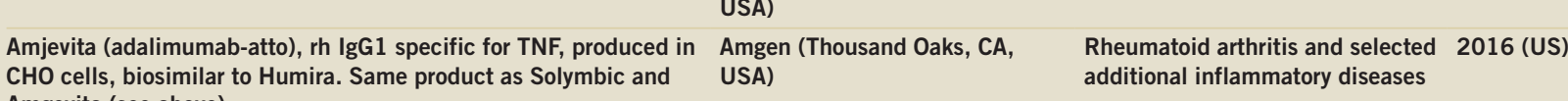

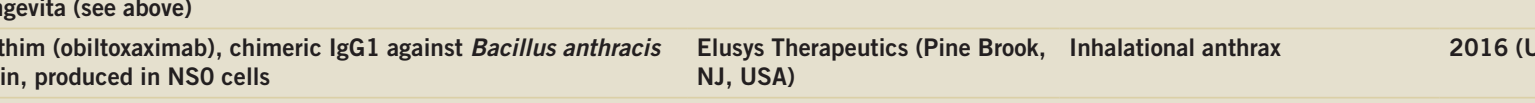

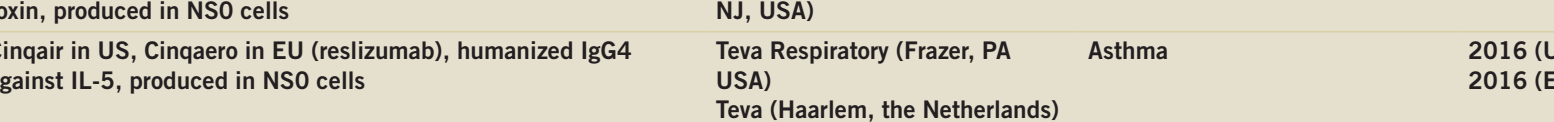

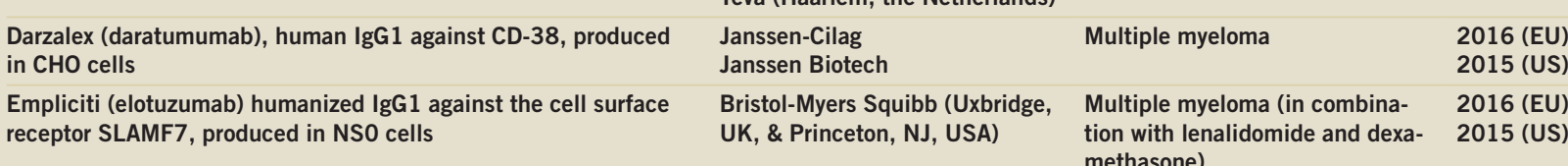

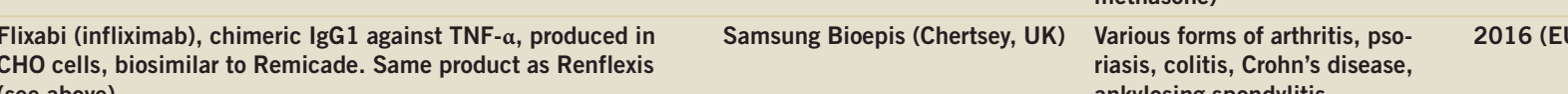

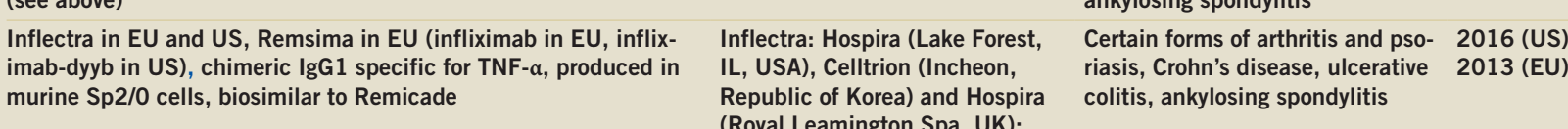

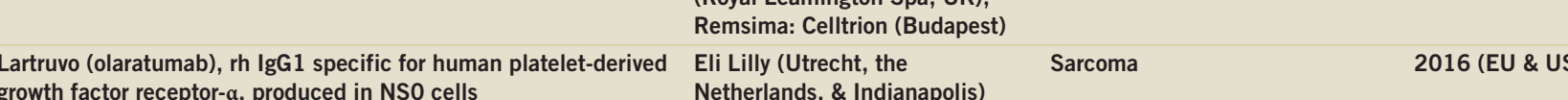

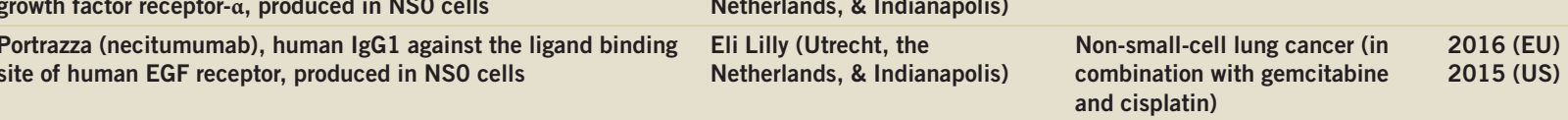

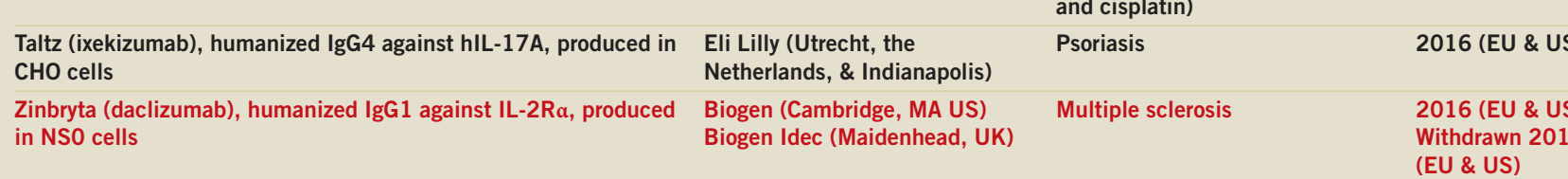

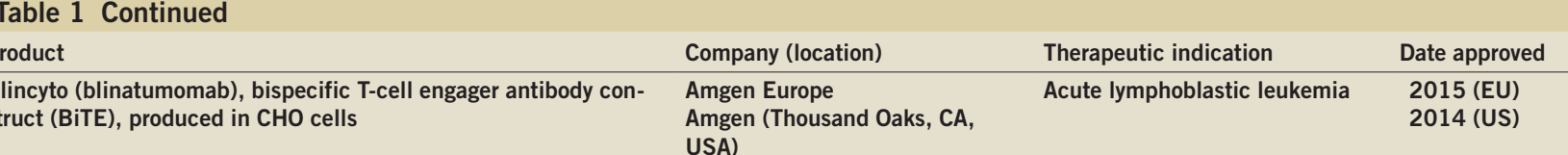

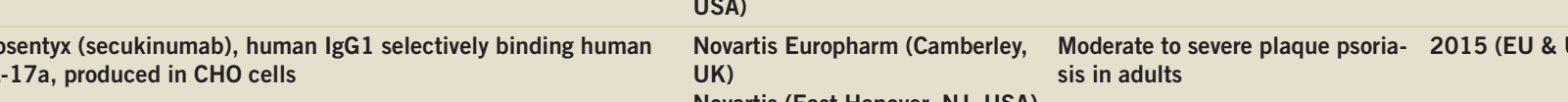

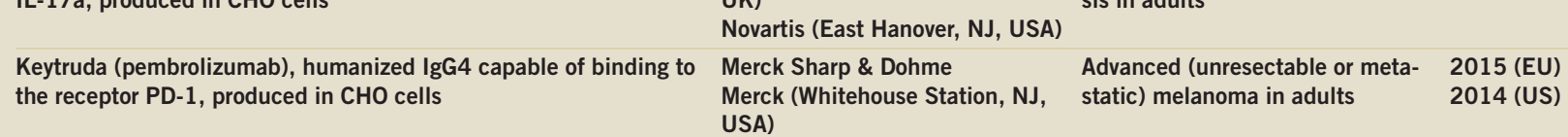

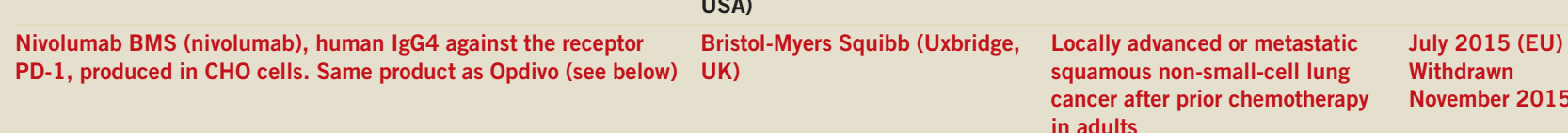

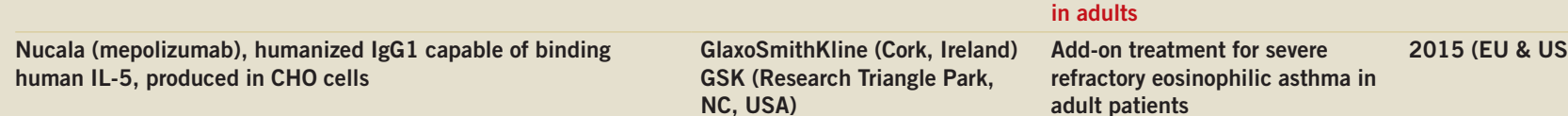

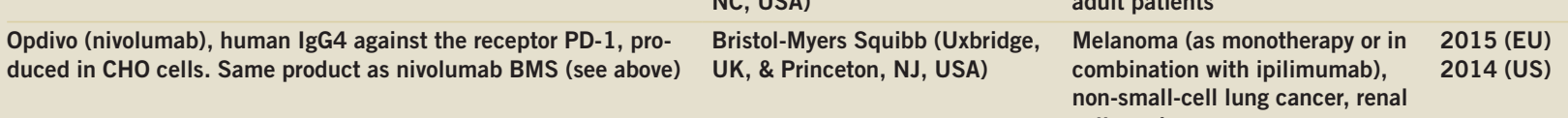

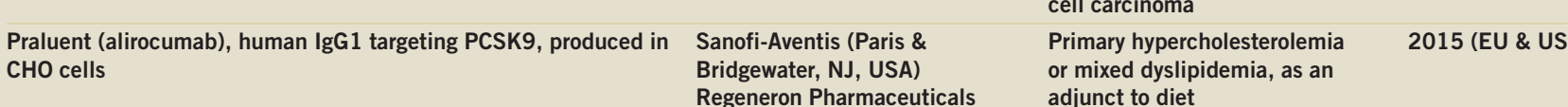

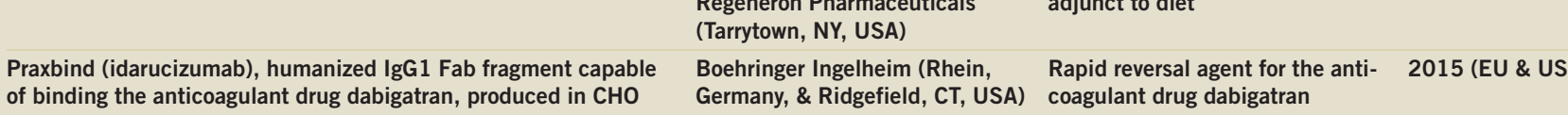

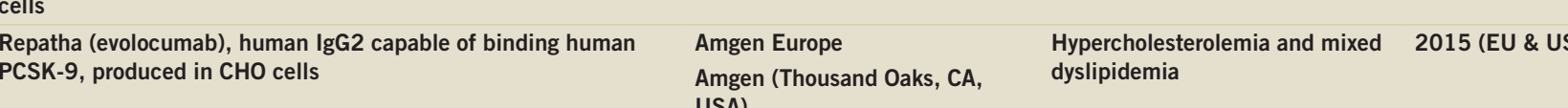

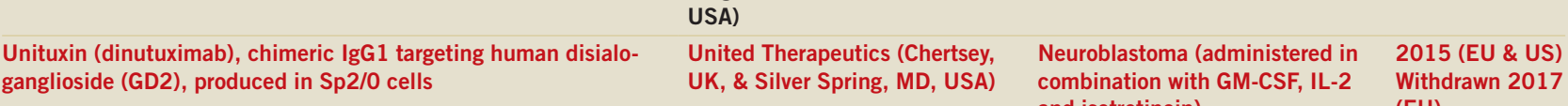

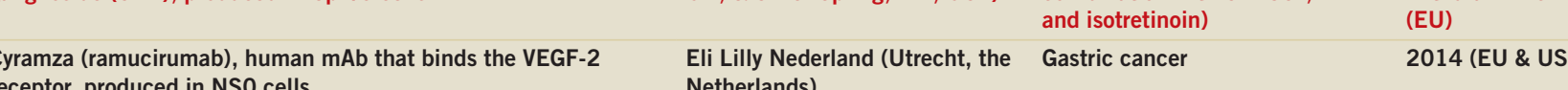

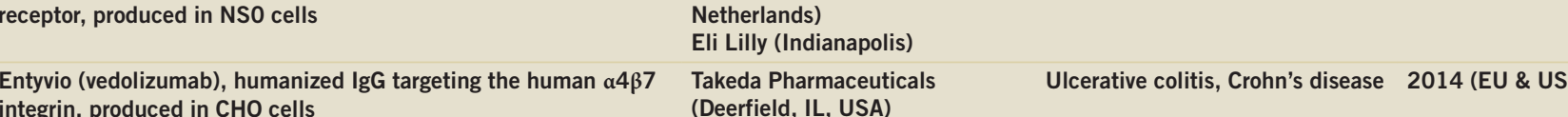

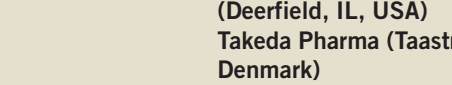

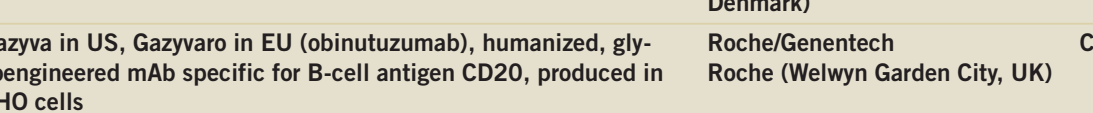

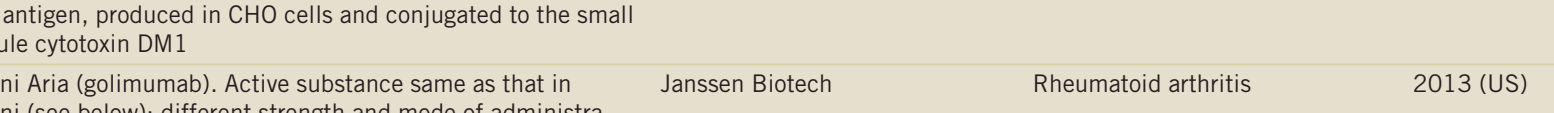

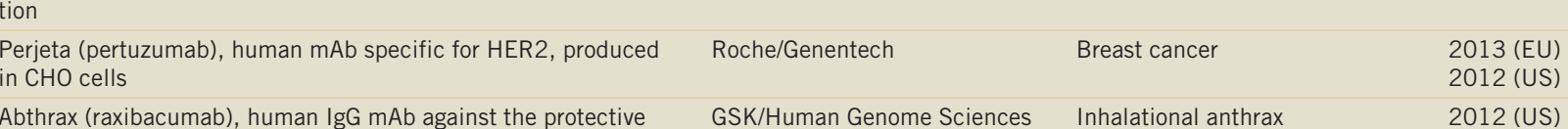

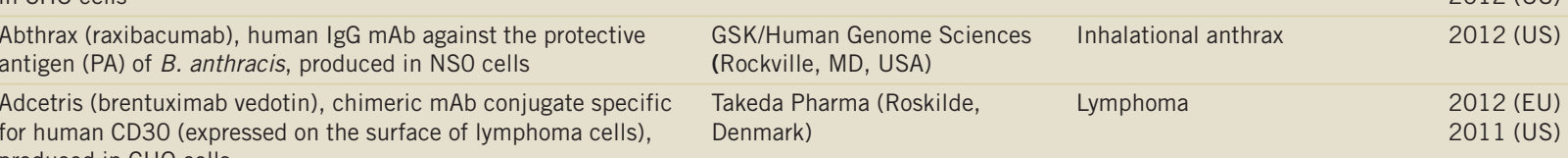

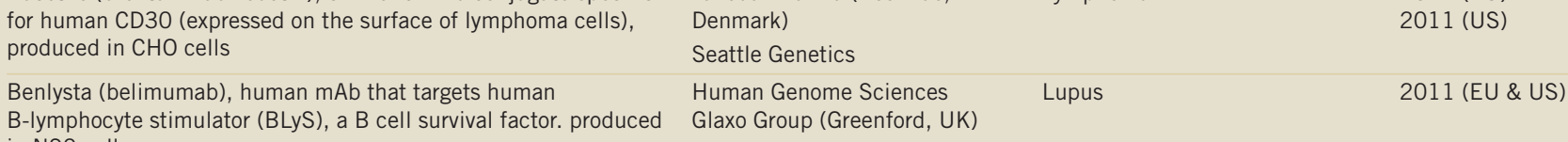

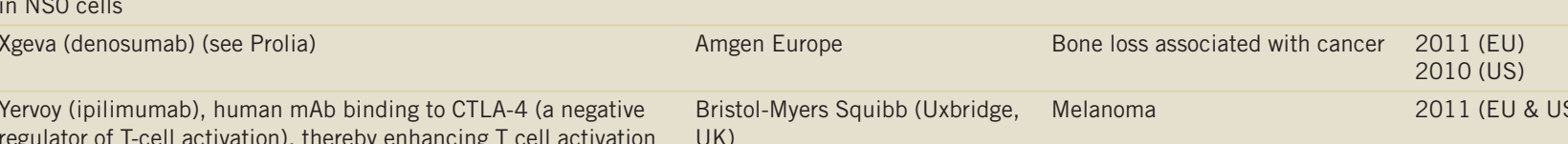

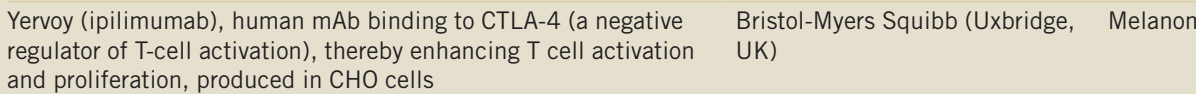

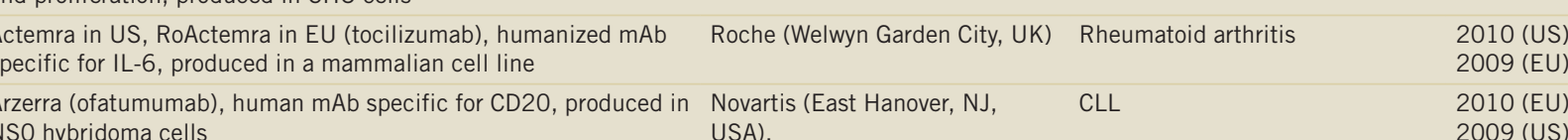

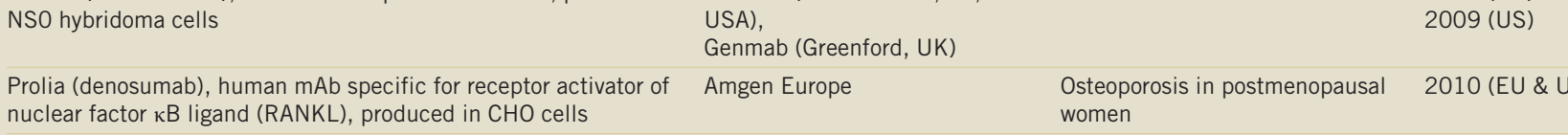

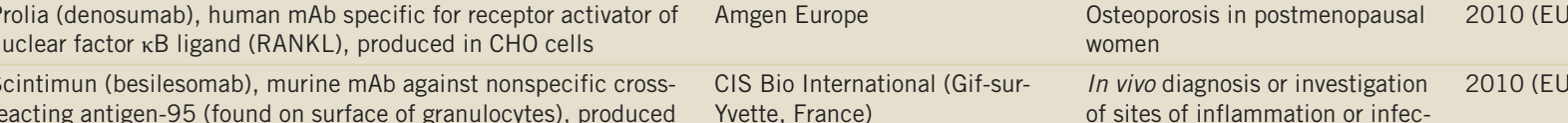

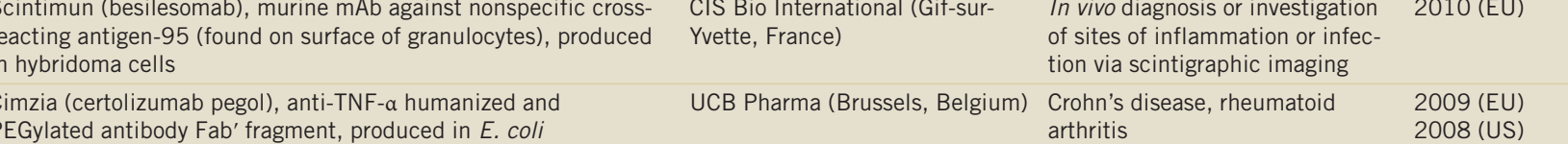

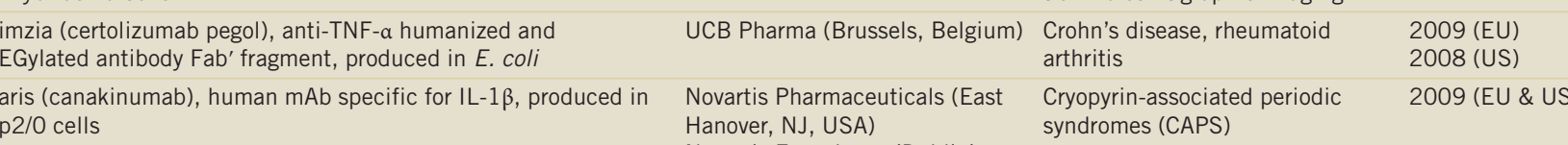

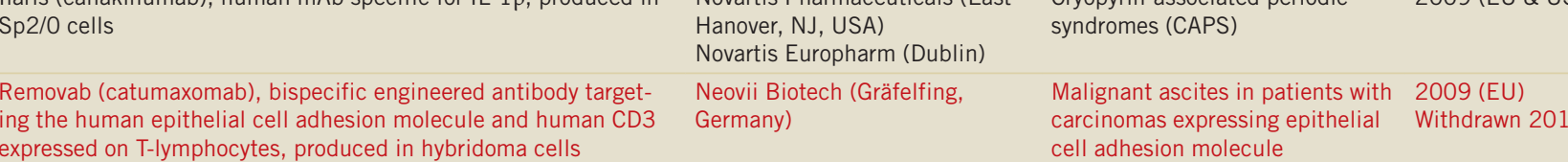

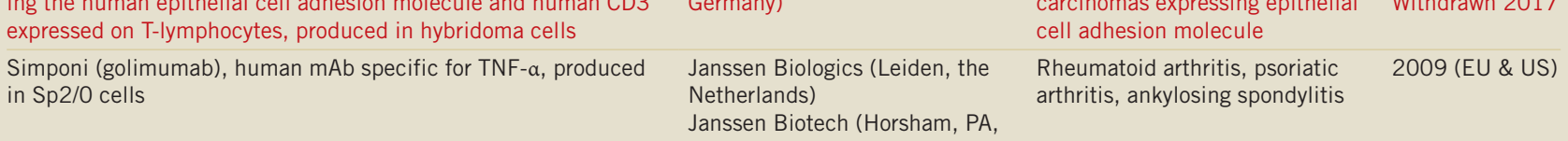

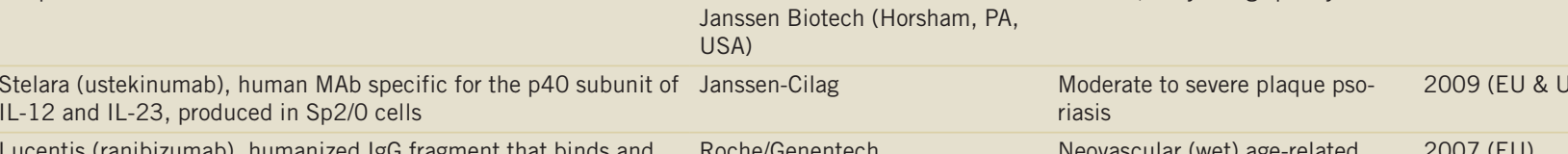

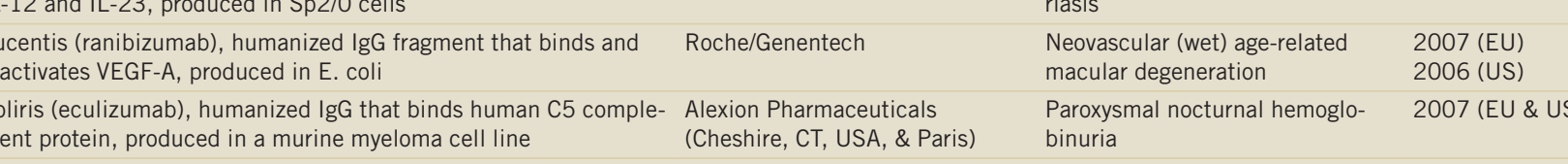

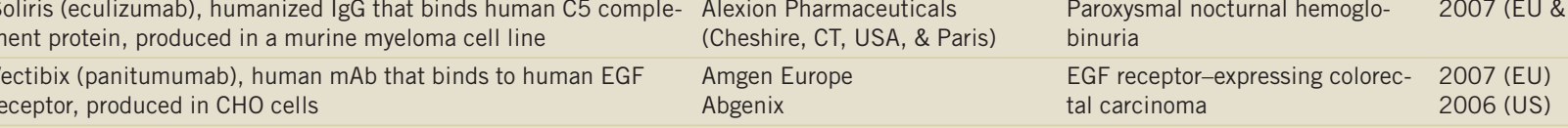

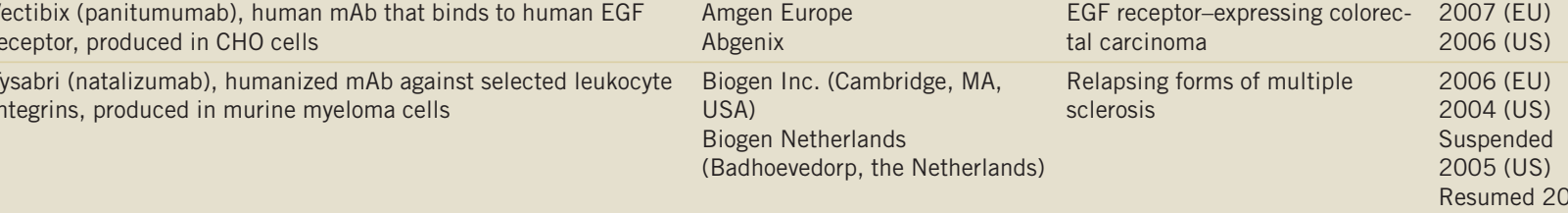

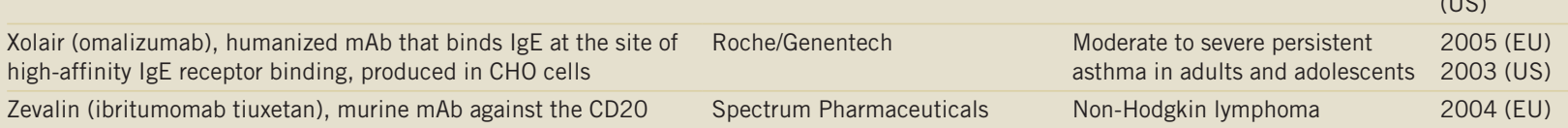

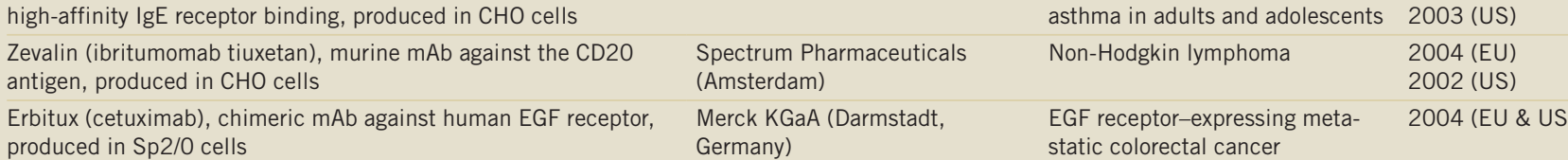

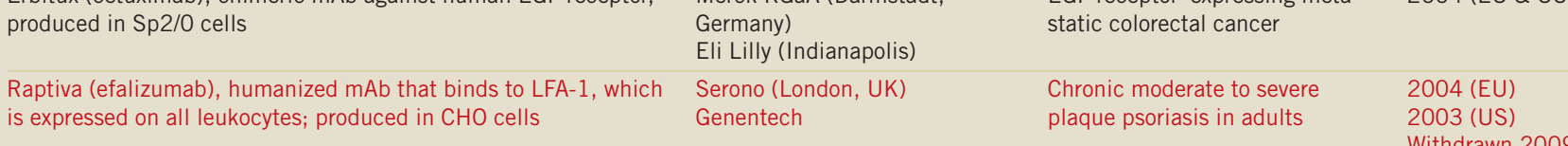

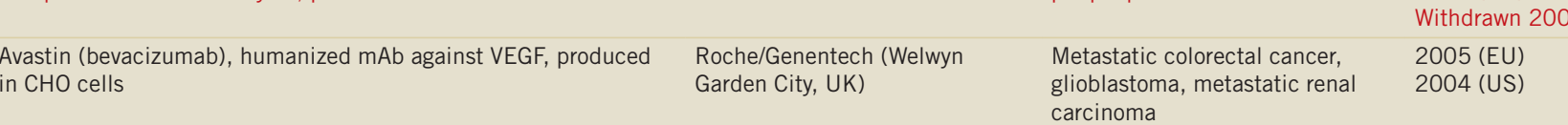

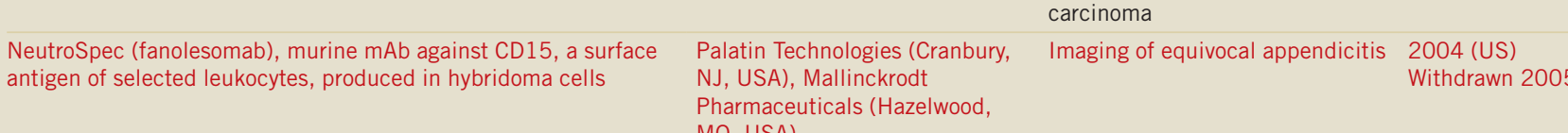

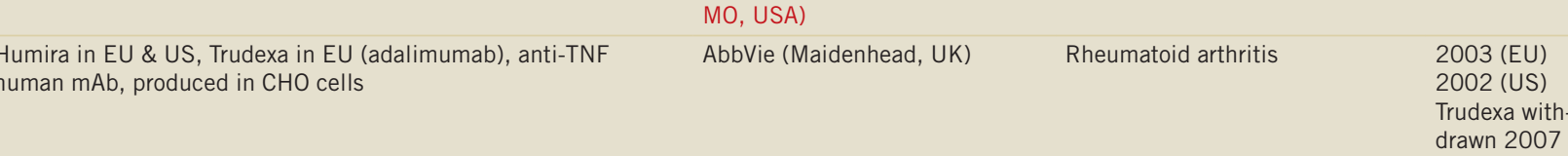

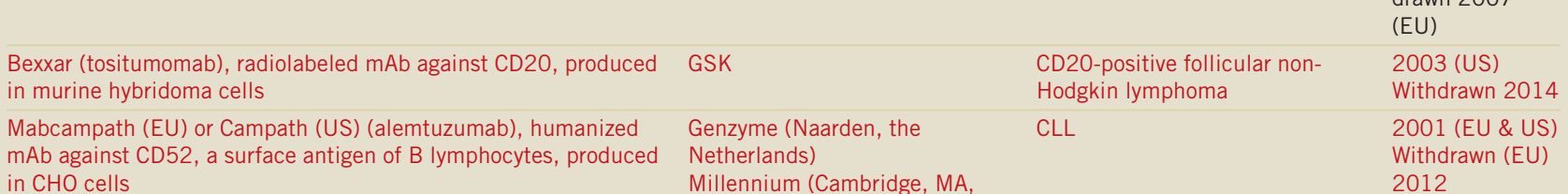

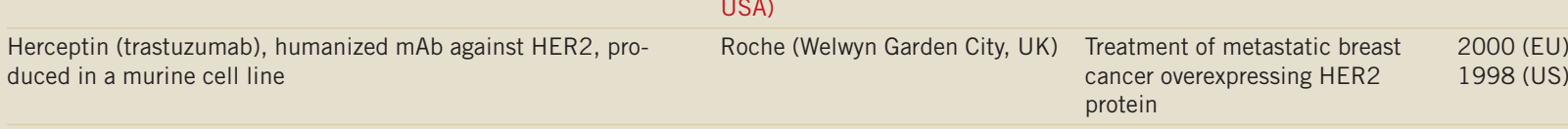

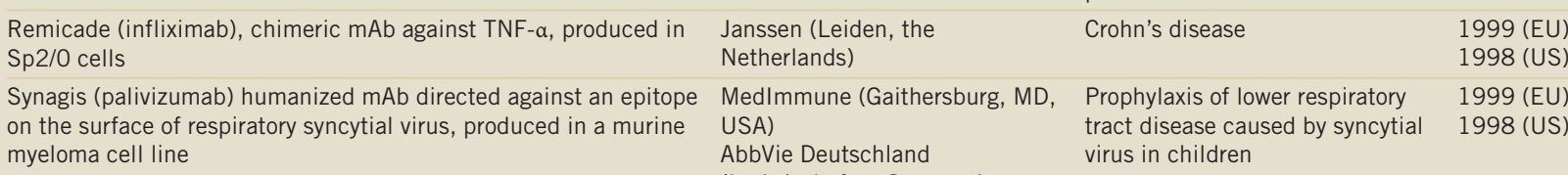

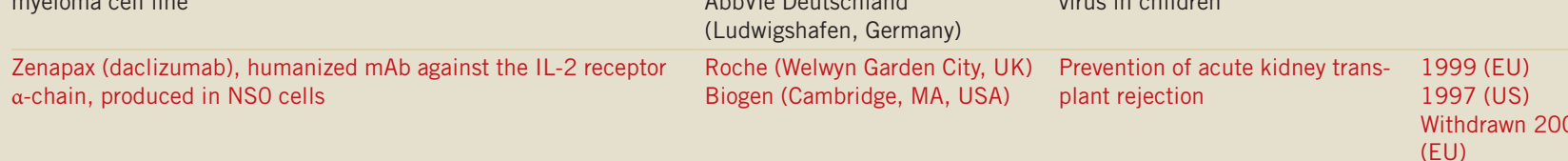

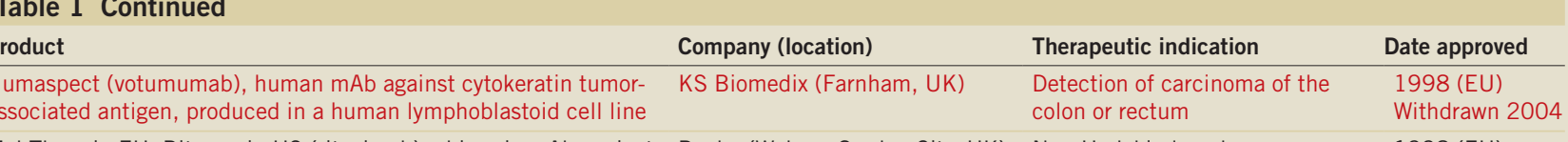

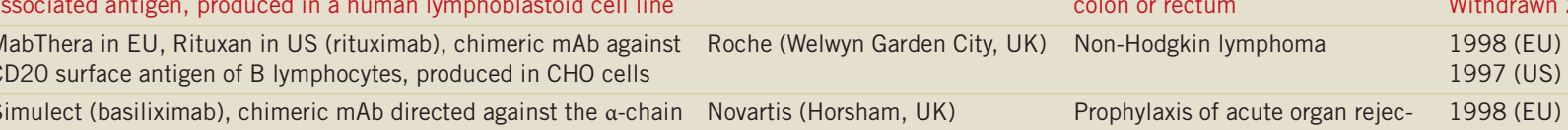

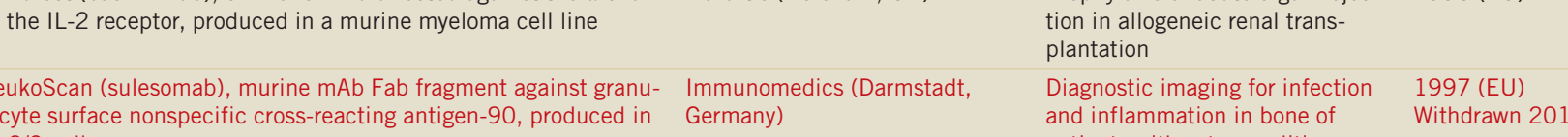

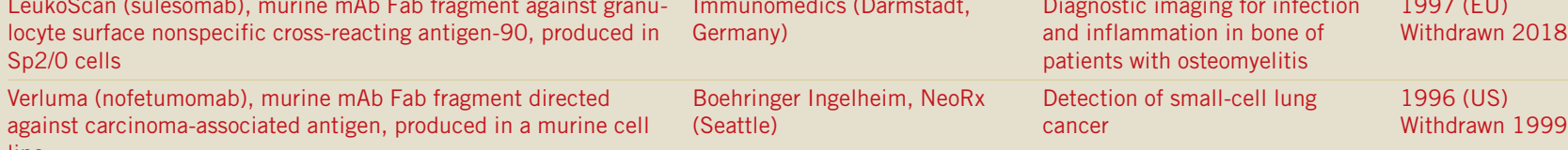

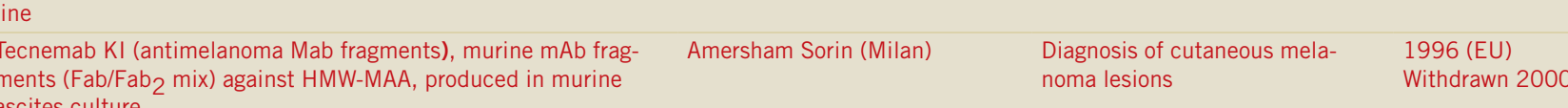

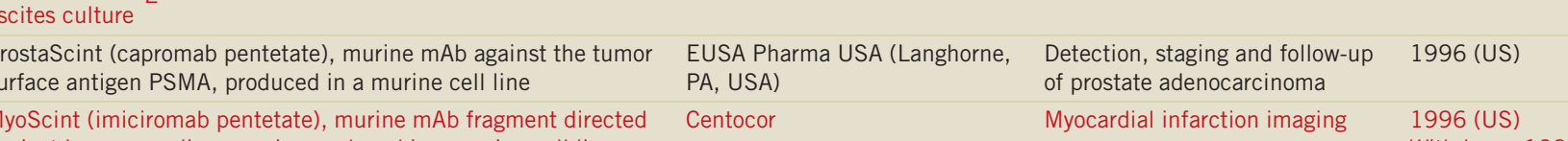

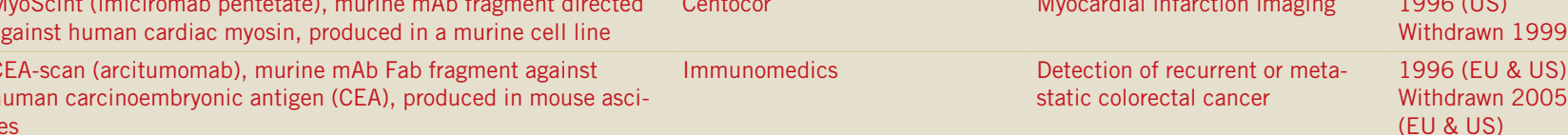

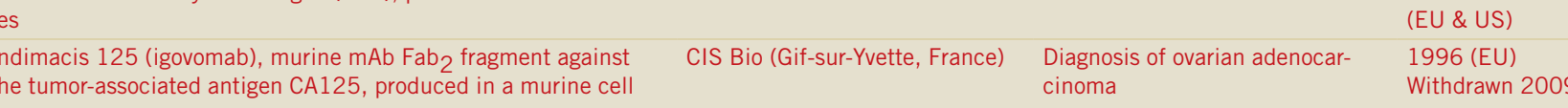

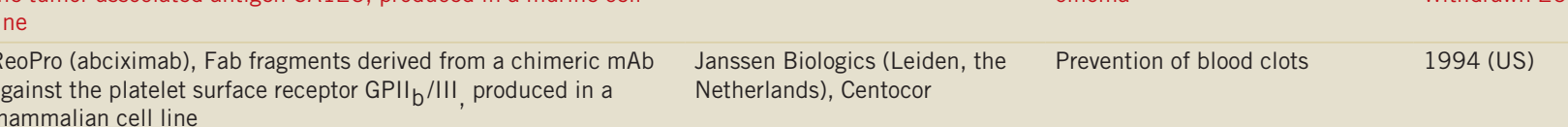

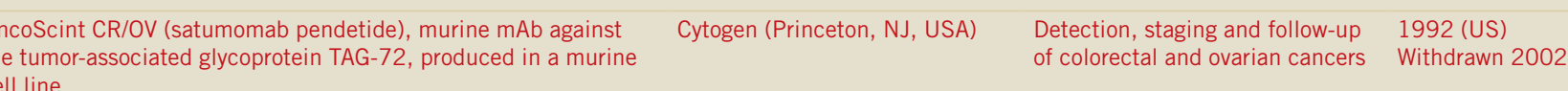

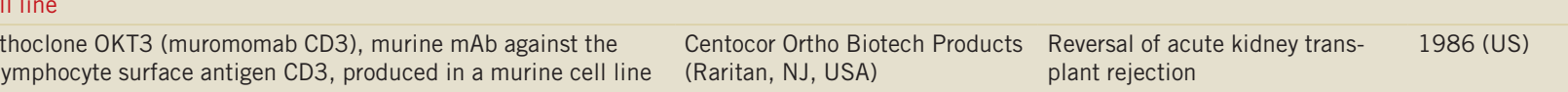

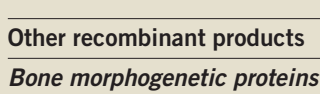

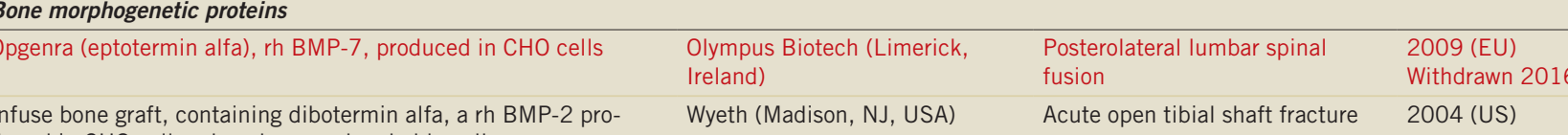

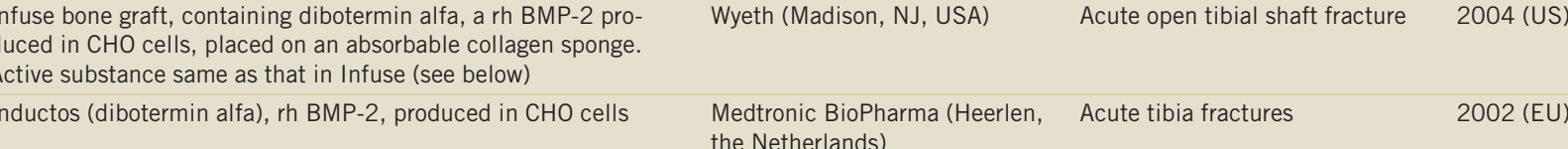

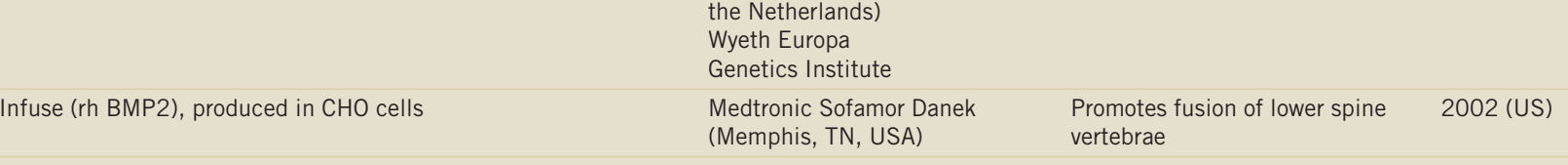

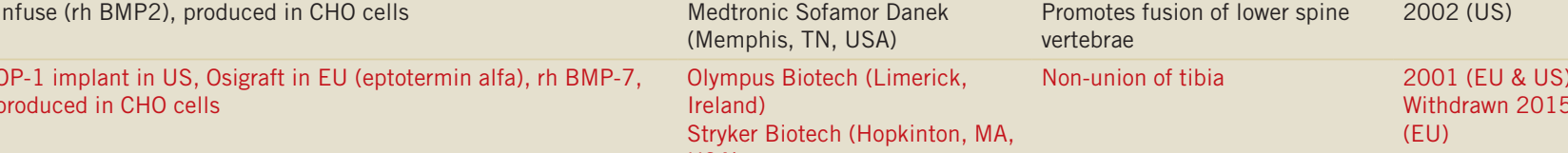

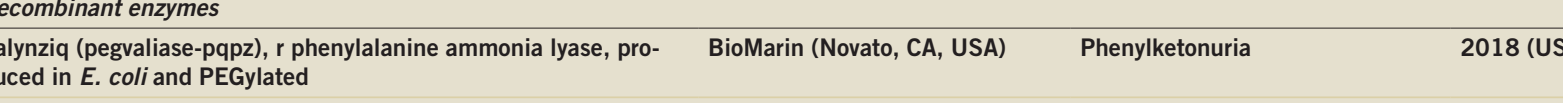

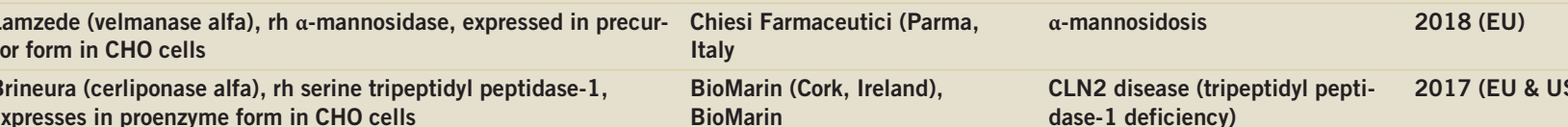

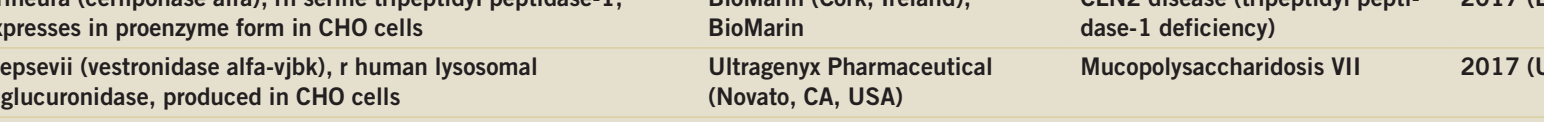

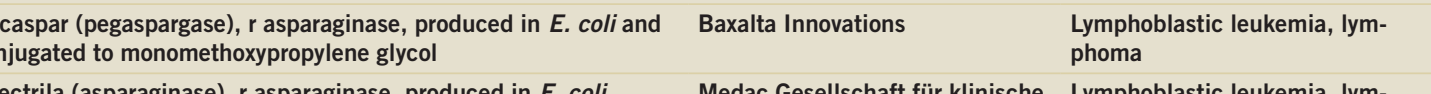

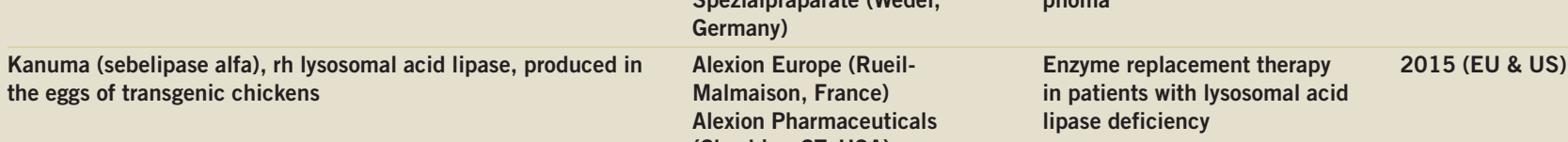

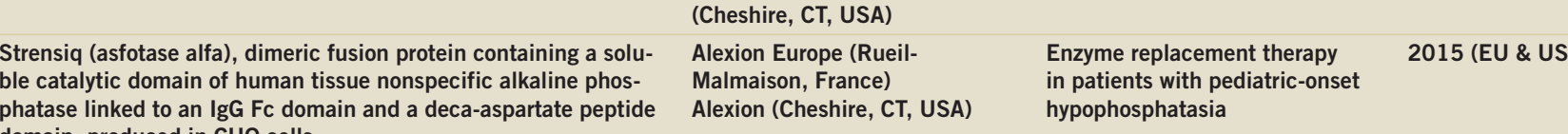

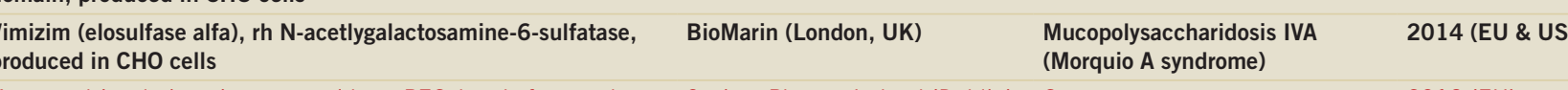

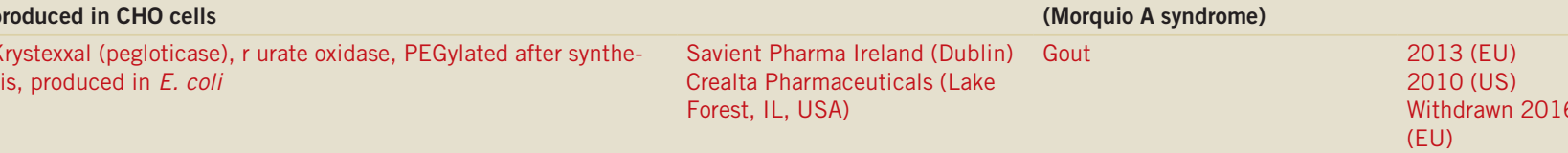

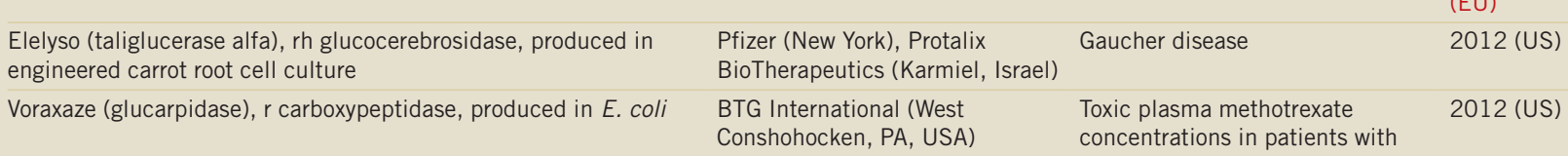

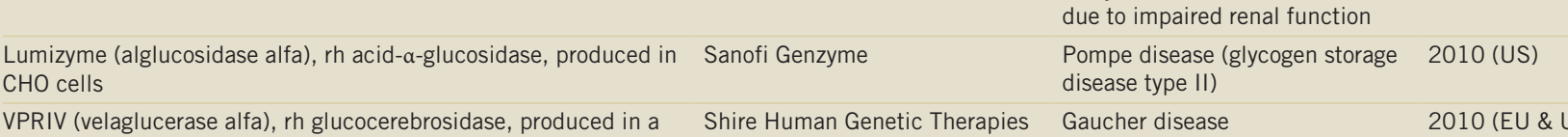

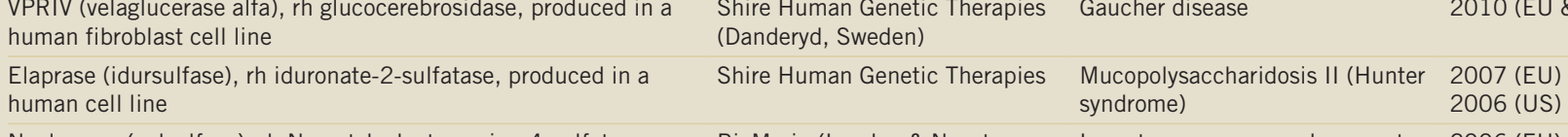

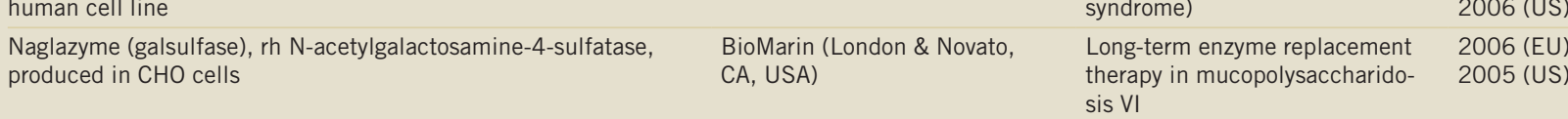

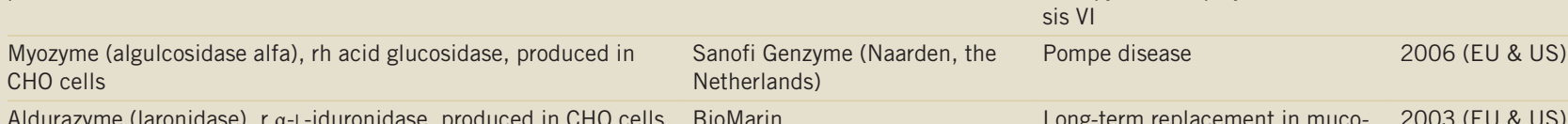

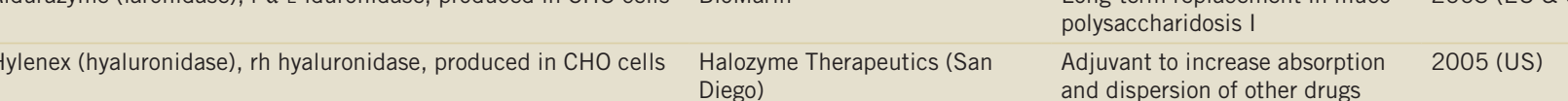

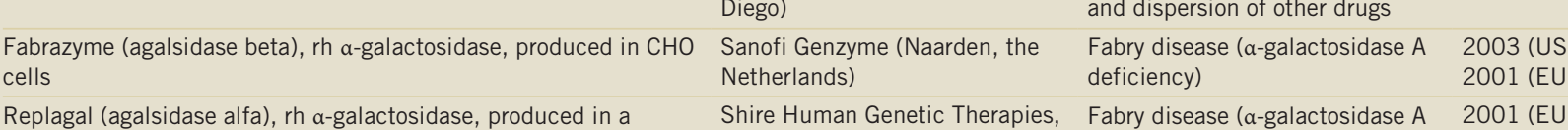

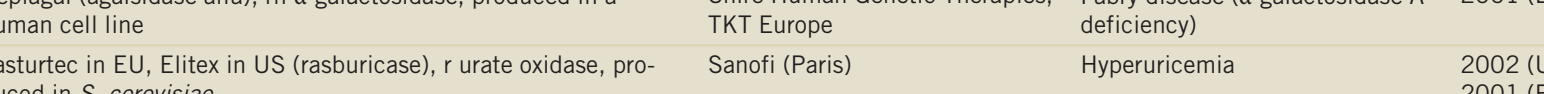

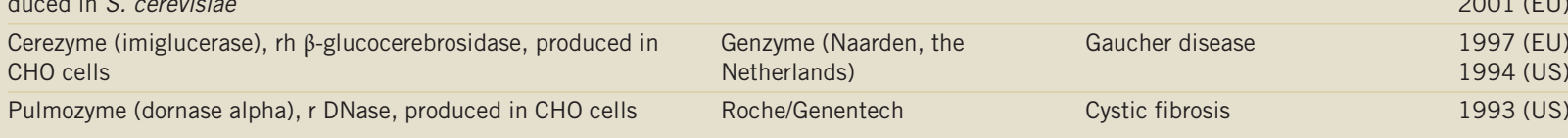

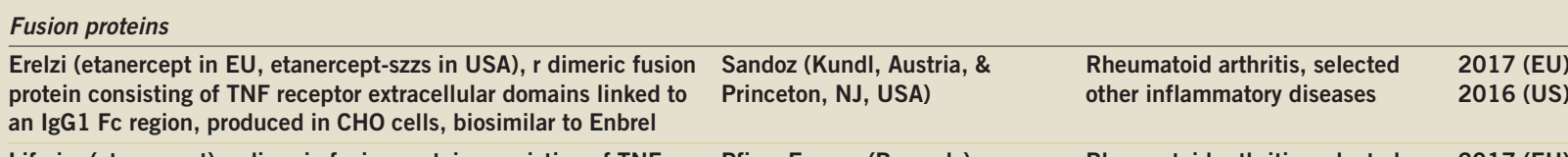

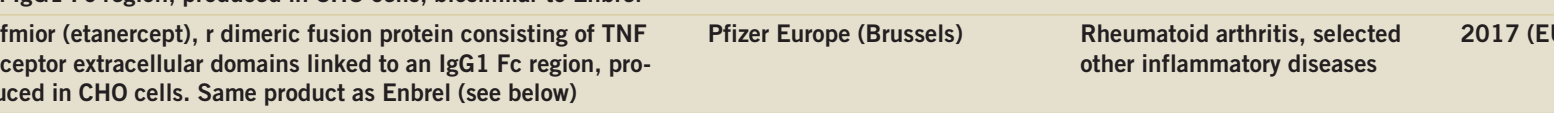

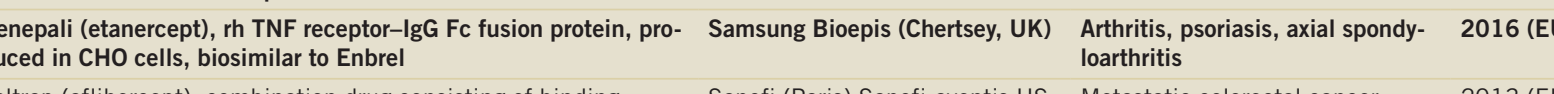

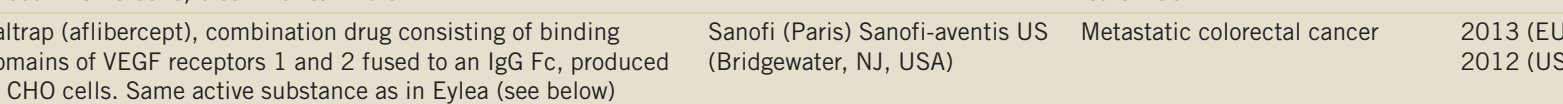

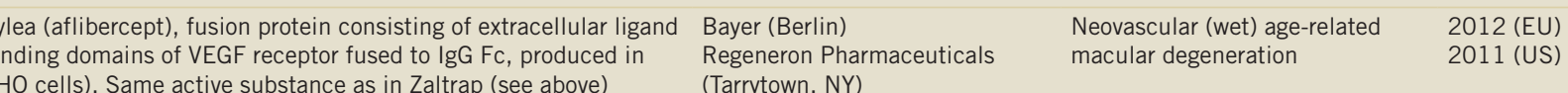

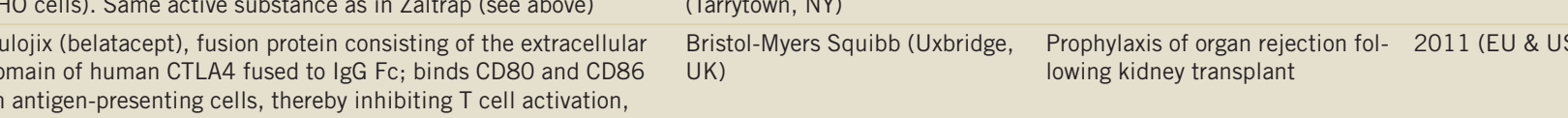

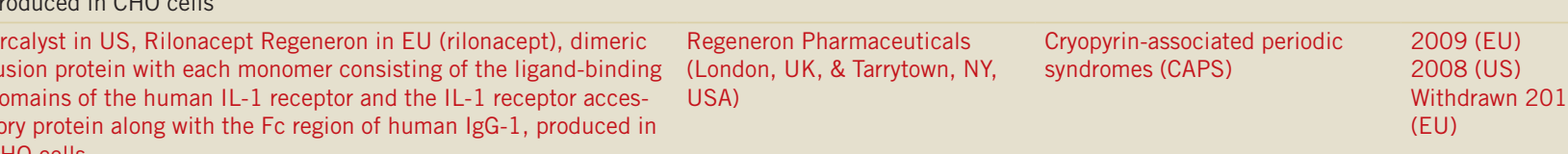

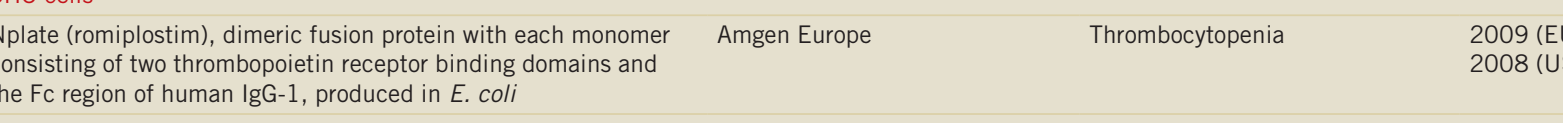

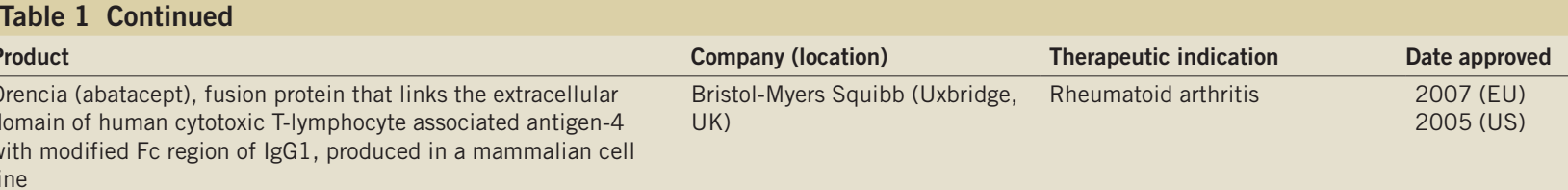

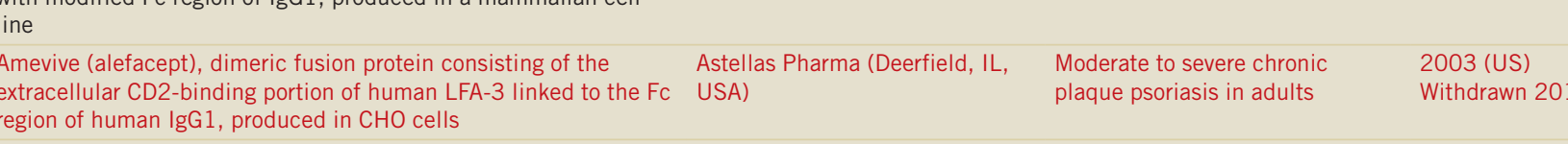

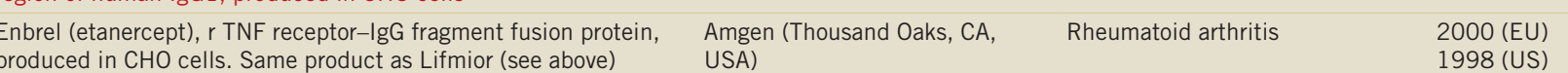

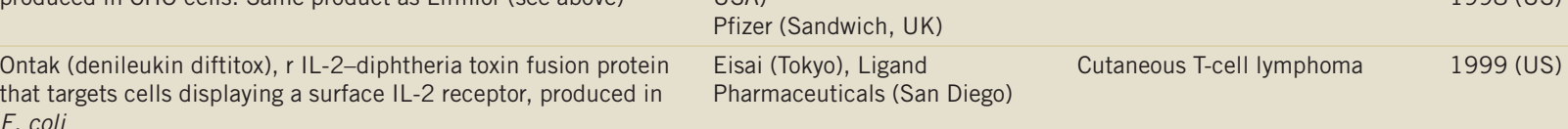

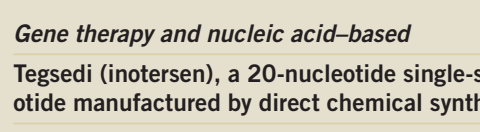

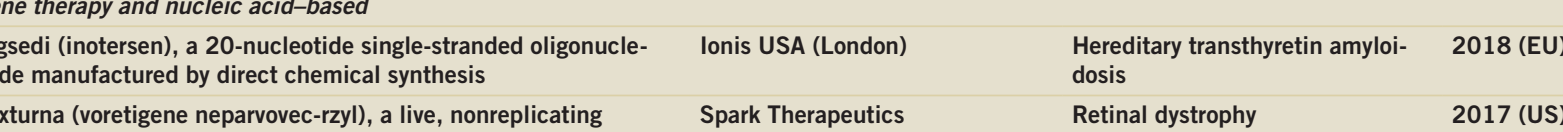

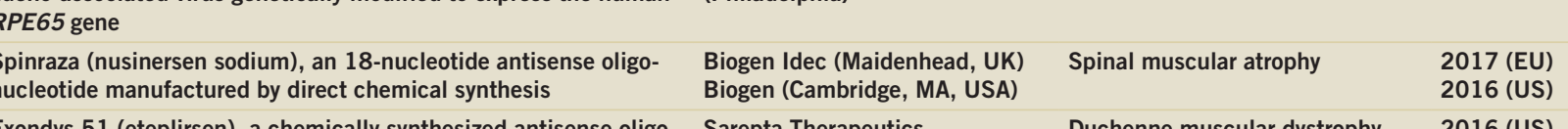

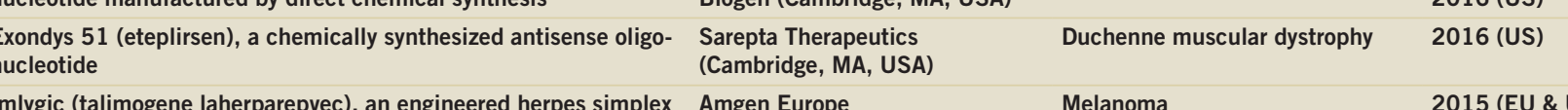

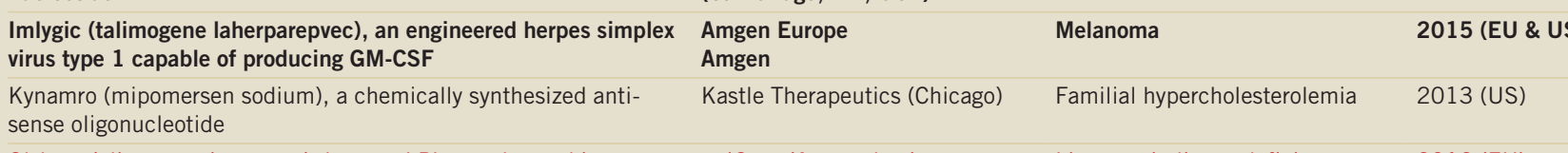

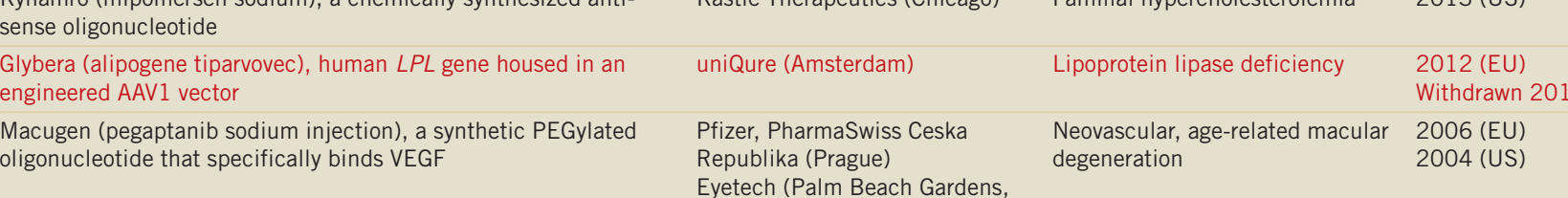

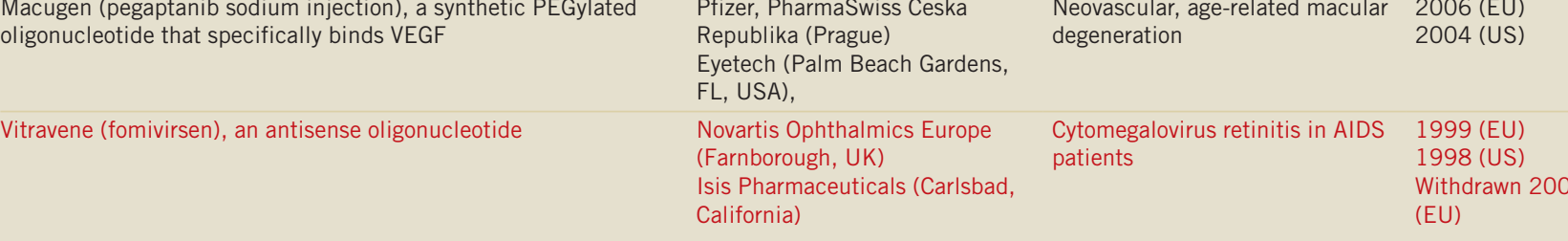

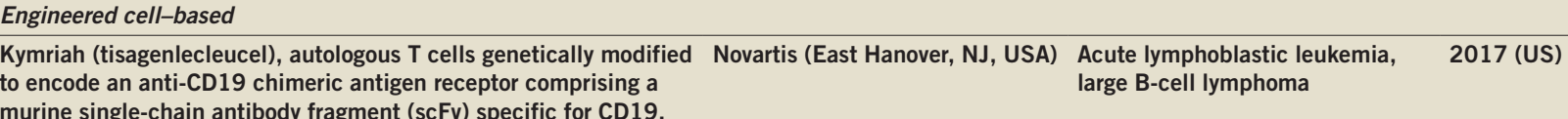

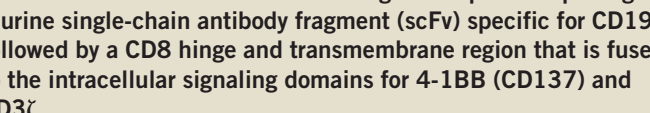

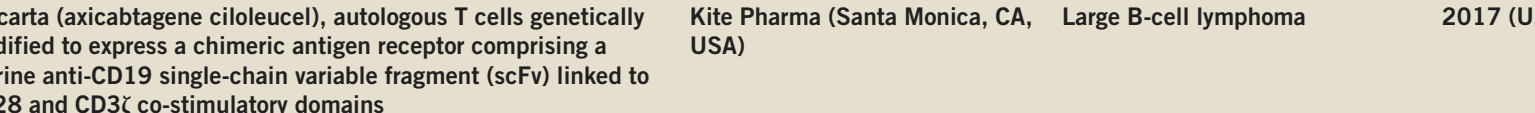

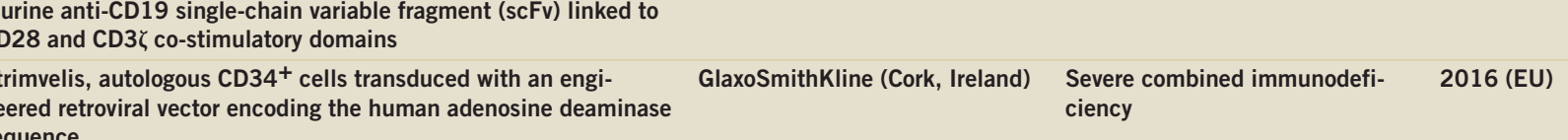

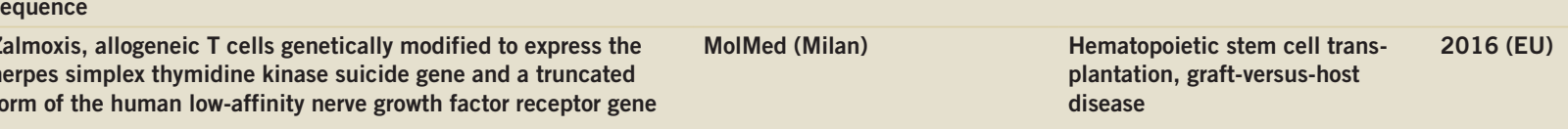

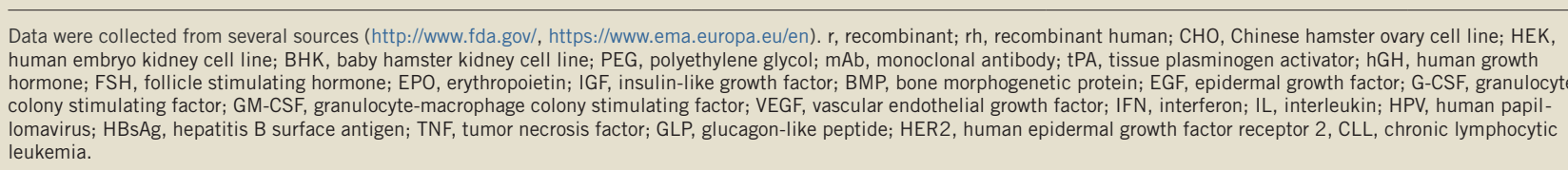

